\title{
5 Empirischer Teil
}

In unserem Projekt ging es primär darum, die soziale Wirklichkeit interethnischer Wohnnachbarschaft im Spiegel des konkreten nachbarschaftlichen Kontakt- und Konfliktgeschehens zu analysieren. Das Ziel der Untersuchung lag vor allem darin, detaillierte empirische Befunde zur ethnisch gemischten Wohnnachbarschaft in Wien vorzulegen. Die Resultate basieren auf keiner Repräsentativerhebung und können nicht den Anspruch erfüllen, eine vollständige Analyse des Nachbarschaftsverhaltens von Inländern und Migranten in Wien zu sein. Es ist aber der Versuch unternommen worden, das Spezifische der ethnisch „gemischten“ Nachbarschaft in den drei untersuchten Wohnbautypen herauszuarbeiten, wobei manches im deskriptiven Bereich verbleiben musste. Die Analyse fokussierte auf das Nachbarschaftsverhalten, auf seine Formen, seine Frequenz und Intensität. Von Interesse waren weiters die Bewertung seiner Qualität sowie interaktionshemmende und -fördernde Faktoren.

\subsection{Datengrundlage und methodische Probleme}

Der dieser Studie zugrunde liegende Datensatz resultiert aus einer in den Monaten Juli bis September 2005 in Wien von einem dreiköpfigen Erhebungsteam ${ }^{19}$ durchgeführten Befragung. Diese erfolgte auf Basis eines umfangreichen Fragebogens. Das Sample umfasste 111 Personen, die zumeist von den Interviewern in den Höfen von Wohnhausanlagen angesprochen und um ein Interview gebeten wurden. In einigen Fällen ergaben sich auch „Schneeballeffekte“. Die Respondenten wurden also zufällig ausgewählt, es handelt sich um kein repräsentatives Sample.

Zunächst stellte sich die Schwierigkeit, den qualitativen Aspekt des Sozialkontaktes umfassend zu erheben. Dazu wurde ein pragmatischer Ansatz gewählt. Unter „Kontakt“ wurde die konkrete Realisierung eines Face-to-face-Kontaktes, das faktische Zusammentreffen mit Nachbarn, verstanden. Der nachbarschaftliche Kontakt wurde also als reale zwischenmenschliche Interaktion definiert. Die diesen Kontakten inhärente soziale Nähe oder Distanz wurde über unterschiedliche Kontakttypen (Gespräche, Hilfeleistungen, Besuche etc.) operationalisiert.

Eine grundlegende Frage stellte sich in der Unterscheidung zwischen dem als Nachbarschaft erlebten Raum, den innerhalb der Grenzen dieses Raumes lebenden „potentiellen“ Nachbarn und den in sozial interaktiver (meist kommunikativer) Beziehung zum Befragten stehenden „tatsächlichen“ Nachbarn. Die soziale Kategorie des Nachbarn unterliegt also unterschiedlichen Eigendefinitionen. So können nur die

19 Das Befragungsteam bestand aus zwei Studentinnen und einem Studenten der Geographie im 2. Studienabschnitt bzw. Dissertationsstadium, und zwar aus Frau Ulrike Knaus, Frau Wibke Strahl und Herrn Mag. Marco Helbich. 
unmittelbar Tür-an-Tür-Wohnenden als Nachbarn bezeichnet werden. Andererseits existieren auch extensive Klassifikationen, welche alle Bewohner einer Wohnstiege bzw. sogar des gesamten Hauses, sofern sich dieses durch eine noch halbwegs überschaubare Bewohnerstruktur und eine nicht zu große Zahl an Stiegen und Hausparteien auszeichnet, dazuzählen. Der Nachbarschaftsbereich im Sinne eines „primär kommunikativen Umweltbezuges" (Vierecke 1972: 25) besitzt eine geringere Ausdehnung als der übergeordnete, begrifflich zum Wohnen gehörende weitere Bereich der Nachbarschaft, der unter primär funktionalen Gesichtspunkten zu sehen ist.

Um hier Klarheit zu schaffen, wurde als Nachbarschaftsbereich im engeren Sinn in den Items des Fragebogens normativ das eigene Wohnhaus vorgegeben. Dabei zeigten sich konfligierende raumbezogene Definitionen hinsichtlich des Nachbarschaftsbereiches „Wohnhaus“. Die Wiener Befragten definierten in einem hohen Ausmaß nur die eigene Wohnstiege als ihr „Wohnhaus“ und somit als ihren Nachbarschaftsbereich. Diese Wahrnehmung des „eigenen“ Treppenhauses als der eigentlichen „Nachbarschaft“ deckte sich auch mit den Resultaten ausländischer Studien (vgl. Barre et al. 1977: 150 ff.).

\subsection{Empirische Befunde}

\subsubsection{Eindrücke zur Fragebogenerhebung im Rahmen des Projektes „Gespanntes Nachbarschaftsverhältnis?“ aus der Perspektive einer Interviewerin (Wibke Strahl)}

Auffallend bei der Interviewerhebung war, dass großteils eine Unsicherheit der Befragten zu bemerken war, so als ob man sie aushorchen oder ihnen etwas Böses wollte. Im Laufe des Interviews fassten die meisten Probanden jedoch Vertrauen und beantworteten den Großteil der Fragen bereitwillig. Schwierigkeiten gab es bei der Beantwortung der Fragen 3 und 5 im Teil II des Fragebogens. Viele Probanden haben sich hierbei überfordert gefühlt, da die heutige Zeit großteils von einer gewissen Schnelllebigkeit (häufiger Wohnungswechsel) sowie einer damit zusammenhängenden Anonymität gekennzeichnet ist. Oftmals fehlt der Kontakt zu den Nachbarn völlig, man erkennt einander und bemerkt vielleicht auch noch, dass Leute über einem wohnen, aufgrund zufallender Türen, Streitigkeiten und des Geräusches von Schritten, was sich sonst im Haus jedoch abspielt, bekommt man vor allem als berufstätige Person kaum mit. Man begegnet einander im Stiegenhaus, grüßt und geht weiter, auf Gespräche lassen sich v. a. junge Menschen kaum ein. Man nimmt wahr, dass sich die Bewohnerstruktur aus jungen und alten Menschen, Familien und Singles sowie Zuwanderern und Österreichern zusammensetzt. Einigen Zuwanderern kann man eine Herkunftsnationalität zuordnen, bei anderen fällt dies schwer. Anhand der Klingelschilder kann man ebenfalls auf unterschiedliche Nationalitäten schließen, doch die wenigsten der Befragten achten darauf. Weiters kann man an den Klingelschildern 
zum Teil auch das Bildungsniveau ablesen, doch lassen sich ein niedriges und ein mittleres Bildungsniveau kaum voneinander unterscheiden.

Aufgrund der vielerorts vorherrschenden Anonymität kommt es auch nur bedingt zu Konflikten. Auseinandersetzungen ergeben sich verstärkt dort, wo viele Menschen auf engem Raum wohnen. So war in der Siedlung „Schöpfwerk“ und in der Großfeldsiedlung ein gewisses Konfliktpotential nachweisbar.

Weiters war bei einigen Probanden zu bemerken, dass eine negative Grundhaltung zum Thema Migration durchaus gegeben war, die Beantwortung der Fragen fiel dann jedoch anders aus, denn wer möchte schon gerne als ausländerfeindlich dastehen?

Von den ausländischen Respondenten erfuhr man im Laufe der Befragung zusätzlich zur Beantwortung der Interviewfragen, dass seitens einiger österreichischer Nachbarn sehr wohl Ausdrücke wie „Kanaken“, „Tschuschen“ oder Ähnliches verwendet werden. Man erfuhr auch, dass Wände oder Aufzüge mitunter mit Hakenkreuzen und ausländerfeindlichen Sprüchen ,verziert“ sind.

Auffallend war auch die Tatsache, dass mit einer zunehmenden Zahl von Migranten im jeweiligen Wohnhaus auch die fremdenfeindliche Stimmung der österreichischen Mitbewohner zunimmt. Ein relativ geringer Prozentsatz von im Haus wohnhaften Zuwanderern wird hingegen ohne weiteres geduldet, weil kaum bemerkt. Sie fallen nicht ins Gewicht und werden zum Teil sogar auch gern gesehen.

Viele Befragte - sowohl Österreicher als auch Angehörige diverser anderer Nationalitäten - haben die Meinung vertreten, dass das Zusammenwohnen mit türkischen Hausbewohnern besonders schwierig sei und sie sich jede andere Nationalität als Nachbarn eher vorstellen könnten als Türken. Dies könnte jedoch auch darauf zurückzuführen sein, dass diese Gruppe in Wien sehr zahlreich anzutreffen ist und wie es ein Respondent ausdrückte - ,es so viele von denen gibt“.

Probleme im Zusammenhang mit dem Fragebogen selbst bestanden zum einen in seiner Länge, wodurch viele Probanden, die zuvor zusagten, einen Fragebogen auszufüllen, dann doch abgeschreckt waren. Pensionisten und Arbeitslose waren jene Personengruppen, die sich vom Umfang am wenigsten irritiert zeigten. Auch war zu bemerken, dass Pensionisten, also Leute, die am ehesten Zeit haben, die intensivsten Nachbarschaftsbeziehungen pflegen.

Besonders den ausländischen Respondenten fiel es mitunter schwer, den Kontext sowie auch einige Fragestellungen zu verstehen, da sie ihrer Meinung nach zu verkompliziert ausgedrückt waren. Mit einigen Umschreibungen konnte der Großteil der Fragen dann jedoch doch noch beantwortet werden. Bei Teil V: „Zur Person“ verweigerten anfangs viele Probanden die Auskunft und fragten ,Wieso?" „,Warum?“ oder „Wofür müssen Sie das wissen?“ Auch der Hinweis auf die stets zugesicherte Anonymität konnte da nur bedingt helfen. Ausländische Befragte waren dabei noch um einiges misstrauischer als die Österreicher. Sie waren es auch, die häufig keine Auskunft geben wollten und sich mit den Worten ,Ich spreche nicht Deutsch!“ umdrehten und weitergingen. Vor allem viele ausländische Frauen, darunter größtenteils Musliminnen, verweigerten die Beantwortung der Fragen. Resümierend kann man 
jedoch festhalten, dass der Großteil der Respondenten kooperativ und hilfsbereit war, Rede und Antwort im Rahmen unserer Befragung zu stehen.

\subsubsection{Die Grundstruktur des Samples}

Im Rahmen der Erhebungsphase konnten von unseren Interviewern insgesamt 111 Personen befragt werden, davon waren 53,2\% (59 Personen) Frauen und 46,8\% (52) Männer. Ist unter den Befragten mit Migrationshintergrund das Geschlechterverhältnis fast ausgeglichen (49,2\% Frauen, 50,8\% Männer), so dominieren in der Subgruppe ohne Migrationshintergrund eindeutig die Frauen (58\%).

Die Altersverteilung ist trotz unermüdlicher Bemühungen unserer Interviewer etwas „schief" geblieben. Leider wurden überproportional viele junge Menschen interviewt, was primär mit der hohen Befragungsverweigerungsrate potentieller älterer Respondenten zusammenhing. Nur 7 Befragte $(6,4 \%)$ waren älter als 60 Jahre und 13 Personen $(22,7 \%)$ waren zwischen 50 und 60 Jahre alt. Besonders viele Respondenten befanden sich im Alter von 21 bis 30 (36 Personen oder 32,4\%) oder von 31 bis 40 Jahren (29 Personen oder 26,1\%). Die Altersstruktur variiert auch je nach vorhandener/nicht vorhandener Migrationsbiographie. Während mit 44,9\% unter den Österreichern vor allem die jüngste Altersklasse bis 30 Jahre quantitativ am stärksten besetzt war, sind unter den Migranten besonders viele 31- bis 44-Jährige (41\%) befragt worden. In der Subgruppe mit Migrationshintergrund ist die Alterskategorie über 45 Jahre mit $27,9 \%$ die am schwächsten besetzte, bei den Österreichern ist mit $26,5 \%$ die Altersklasse der 31- bis 44-Jährigen am wenigsten präsent.

An Staatsbürgerschaften ist eine breite Palette vertreten: Zahlenmäßig dominieren die österreichischen Staatsangehörigen (72 Personen oder 64,9\%), aus Deutschland und Rumänien haben jeweils 5 Personen in das Sample Eingang gefunden, aus Indien 4 und aus dem Iran 3. Mit jeweils 2 Befragten sind etliche jugoslawische Nachfolgerepubliken, aber auch Polen, Spanien und die Türkei vertreten. Zahlreiche Staaten sind mit einzelnen Respondenten enthalten, darunter der Irak, Nepal, Syrien, die Slowakei, Ungarn u.a. Bezüglich der Staatsbürgerschaft zum Befragungszeitpunkt ist also keine Konzentration auf ein bestimmtes Land vorhanden.

Etwas anders sieht es bezüglich der Herkunfts- bzw. Geburtsländer aus, da Neoösterreicher doch eine zahlenmäßig bedeutende Gruppe im Sample repräsentieren. Nach dem Kriterium des Geburtslandes stellt Österreich mit 51 Personen $(45,9 \%)$ das größte Kontingent, gefolgt von der Türkei mit acht $(7,2 \%)$ und Rumänien mit sieben $(6,3 \%)$ Personen. Ebenfalls sieben Befragte stammen aus dem ehemaligen Jugoslawien, haben aber in unterschiedlichen Nachfolgerepubliken das Licht der Welt erblickt. Die Islamische Republik Iran ist mit vier, der Irak mit drei Respondenten vertreten. In zahlreichen weiteren Staaten lagen die Geburtsorte von jeweils einem oder zwei Befragten.

In der Subgruppe der Eingebürgerten dominiert die Türkei mit sechs Personen (23\%) vor dem Iran mit vier $(15,4 \%)$ und Rumänien mit drei $(11,5 \%)$ Befragten. Je- 
weils zwei der Neoösterreicher besaßen ursprünglich die bulgarische oder die chilenische Staatsbürgerschaft. Mit je einer Person sind Argentinien, der Irak, Litauen, die Philippinen, Serbien, Slowenien, Syrien und Ungarn vertreten. Ein Neoösterreicher war vordem staatenlos. Der Erwerb der österreichischen Staatsangehörigkeit liegt bereits unterschiedlich lange zurück. In zwei Fällen 20 und mehr Jahre, in zehn Fällen zehn bis 19 Jahre. Beim Gros der Neoösterreicher (13 Personen) liegt die Einbürgerung noch kürzer als zehn Jahre zurück.

Hinsichtlich der Dauer des Aufenthaltes in Österreich bzw. der Wohndauer in Wien und im Wohnhaus zum Erhebungszeitpunkt manifestiert sich eine beträchtliche Heterogenität, sodass aus den Relationen zwischen Dauer des Aufenthaltes in Wien und der Wohndauer in der aktuellen Wohnung keine interpretativ relevanten Resultate abgeleitet werden konnten. Nur so viel sei gesagt: 18 Respondenten lebten, seit sie sich in Österreich bzw. in Wien aufhalten, immer in derselben Wohnung, 10 Personen hielten sich bereits länger in Österreich auf, bewohnen aber seit ihrem Zuzug nach Wien immer dieselbe Wohnung. Bei 51 Befragten ist der Aufenthalt in Österreich und in Wien gleich lang, sie haben aber irgendwann einen oder mehrere Umzüge in Wien durchgeführt. In 28 Fällen erfolgte irgendwann in ihrer Biographie die Übersiedlung nach Wien, die aber in der Folgezeit mit einem oder mehreren Wohnungswechseln innerhalb der Bundesmetropole einherging.

Überdurchschnittlich hoch und damit nicht wirklich repräsentativ für die Wiener Verhältnisse ist das Bildungsniveau unserer Befragten. 20,7\% besitzen einen Universitätsabschluss und 23,4\% haben die Reifeprüfung einer höheren Schule absolviert. Eine Fachschule oder eine Lehre können 18 bzw. 19,8\% vorweisen. Nur 14,4\% sind Pflichtschulabsolventen oder haben die Pflichtschule nicht abgeschlossen.

Bezüglich der Verteilung der Bildungsgruppen auf die drei Baubestandskategorien ist bei den Pflichtschulabsolventen mit Lehrabschluss eine starke Konzentration auf den kommunalen Wohnbau festzustellen (13 der 22 Angehörigen dieser Bildungsklasse bewohnen Gemeindewohnungen, fünf logieren in einem Gründerzeithaus und vier in einer Eigentums- oder Genossenschaftswohnung), bei den Akademikern hingegen ein Schwergewicht im Baubestandssegment „Gründerzeit“ (13 von 23 Hochschulabsolventen). In den anderen Bildungskategorien liegt eine gleichmäßigere Distribution über die drei Baubestandskategorien vor.

Die Bandbreite der beruflichen Positionierung unserer Befragten reicht vom Hilfsarbeiter bis zum öffentlichen Bediensteten in leitender Position mit Schwerpunkten bei niedrigen/mittleren (20\%) sowie höheren Angestellten (10\%). Relativ hoch ist der Anteil jener, die zum Erhebungszeitpunkt nicht im Erwerbsleben standen. Dies hatte unterschiedlichste Gründe: 13,6\% waren arbeitslos (oder erhielten Notstands- bzw. Sozialhilfe), 11,8\% befanden sich noch in Ausbildung und jede(r) Zehnte war als Hausfrau/-mann tätig.

Da die Interviews mit Rücksicht auf eine Geringhaltung der Befragungskosten generell in deutscher Sprache durchgeführt wurden, spielte bei den Befragten mit Migrationshintergrund auch das Niveau der Deutschkenntnisse eine nicht unerhebli- 
che Rolle. Bezogen auf das gesamte Sample wurden die Deutschkenntnisse der Befragten von den Interviewern folgendermaßen klassifiziert: 61,3\% (Inländer sowie Respondenten mit Migrationshintergrund) sprachen und verstanden Deutsch sehr gut, $20,7 \%$ verfügten über gute deutsche Sprachkenntnisse, bei $16,2 \%$ waren die Deutschkenntnisse als mittelmäßig einzustufen und bei nur $1,8 \%$ als wirklich schlecht.

Hinsichtlich der Haushaltsstrukturen bildet sich im Sample eine verhältnismäßig breite Streuung, mit einem sich aber doch deutlich manifestierenden Schwergewicht bei den Kleinhaushalten, ab. $25,7 \%$ der befragten Personen leben in Einpersonenhaushalten, mehr als ein Drittel (36,7\%) in einem Zweipersonenhaushalt, 14,7\% wohnen mit zwei weiteren Personen im selben Haushalt zusammen und insgesamt nahezu ein Viertel in einem größeren Familienhaushalt (11\% in Vier-, 9,2\% in Fünf- und $2,8 \%$ in Sechs- oder Mehrpersonenhaushalten).

Nachbarschaftliche Interaktionen finden in erster Linie in Form von sozialen Kontakten oder Konflikten statt. Naheliegenderweise spielt hierbei für das Individuum ein bestehender bzw. nicht bestehender Migrationshintergrund eine wesentliche Rolle, wobei für die Einstellungen der Respondenten selbst, jedoch weniger für die Reaktionen des nachbarschaftlichen sozialen Umfeldes auf diese auch die aktuelle Staatsangehörigkeit von Relevanz ist. Die darauf basierende basale Untergliederung des Samples spiegelt sich in Form von zwei Variablen wider:

1) Das Kriterium ist ein vorhandener bzw. nicht vorhandener Migrationshintergrund: $45 \%$ der Respondenten weisen keinen Migrationshintergrund auf, $55 \%$ verfügen über einen Migrationshintergrund, wurden also im Ausland geboren und sind irgendwann in ihrem Leben - eigeninitiativ oder im Kontext des Familiennachzuges nach Österreich zugewandert.

2) Ein zweites wesentliches Kriterium manifestiert sich in der Staatsbürgerschaft zum Befragungszeitpunkt: In dieser Hinsicht gliedert sich unser Primärdatenpool folgendermaßen auf: $45 \%$ waren (immer) und sind österreichische Staatsbürger, 23,4\% der Befragten gehören der Kategorie der „Neoösterreicher“ an, haben also eine Einbürgerung angestrebt und wurden irgendwann in ihrem Leben eingebürgert. 31,5\% der Respondenten waren zum Befragungszeitpunkt aus staatsbürgerschaftsrechtlicher Perspektive noch „echte“ Ausländer mit einer nichtösterreichischen Staatsbürgerschaft.

Dass die Diversifikation des Samples nach den Variablen „Migrationshintergrund“ und „Staatsbürgerschaft" eine nicht unerhebliche Rolle spielt, manifestiert sich bereits in den noch einer sehr deskriptiven Ebene verhafteten empirischen Auswertungen zu den Haushaltsgrößen und -typen unserer Repondenten. Der urbane Singularisierungsprozess ist in der Subgruppe der Österreicher offensichtlich bereits am weitesten fortgeschritten. Von diesen lebt mehr als ein Drittel alleine, 42,9\% teilen sich (zumeist) mit einem/-r Partner/-in einen Zweipersonenhaushalt. 18,4\% - und damit ein deutlich geringerer Prozentsatz als bei den Neoösterreichern oder den ausländischen Staatsbürgern - entfallen auf kleinere Familienhaushalte mit drei oder vier Haushaltsmitgliedern. Bloß 4,1\% der österreichischen Respondenten sind in einen größeren Fami- 
lienhaushalt mit mehr als vier Haushaltsmitgliedern eingebunden. Im Gegensatz dazu leben in der Subgruppe der „Eingebürgerten“ 23\% in einem größeren Familienhaushalt mit fünf oder mehr Haushaltsmitgliedern. Jeweils 15,4\% sind in kleinere Familienhaushalte mit drei oder vier Personen eingebunden, ungefähr ein Fünftel $(19,2 \%)$ teilt sich einen Zweipersonenhaushalt mit einem/-r Partner/-in und 26,9\% der befragten Neoösterreicher führen einen Singlehaushalt. Unter den Respondenten mit ausländischer Staatsangehörigkeit ist die Präsenz der Großhaushalte mit 14,7\% zwar deutlich höher als bei den Österreichern, aber im Vergleich auch erheblich niedriger als bei den Eingebürgerten. Mit 17,6\% bzw. 14,7\% entsprechen die Anteile der Dreiund Vierpersonenhaushalte unter den Ausländern in etwa jenen in der Kategorie der Neoösterreicher. Die in unserem Sample befragten Ausländer leben vor allem in Zweipersonenhaushalten (41,2\%). Das Singledasein ist mit 11,8\% in dieser Gruppe eine ungleich seltenere Lebensform als bei den Eingebürgerten und vor allem unter den Österreichern und Österreicherinnen.

\subsubsection{Baubestandsstrukturen im Spiegel der Befragungsresultate}

Da diesbezüglich eine gewisse terminologische Uneinheitlichkeit und Unsicherheit im Alltagssprachgebrauch der Bevölkerung besteht und dieses Problem empirisch auch in anderen Erhebungen bereits nachgewiesen wurde, haben wir unsere Respondenten auch gefragt, welche räumliche Einheit sie eigentlich als ,ihr (Wohn)haus“ interpretieren. ${ }^{20}$ Hierbei stellte sich heraus, dass sich 56,8\% der Befragten in ihren Aussagen tatsächlich auf das gesamte Haus - auch mit mehreren Stiegen - beziehen, während immerhin 43,2\% bloß die eigene Wohnstiege als Bezugseinheit heranziehen.

Die Stichprobe teilt sich folgendermaßen auf die drei zu untersuchenden Wohnungsbestandstypen auf: 39 (35,1\%) Respondenten bewohnten gründerzeitliche Mietshäuser, 40 (36\%) lebten im Gemeindewohnungssektor und 32 (28,8\%) verfügten über eine Genossenschafts- oder Eigentumswohnung.

In unseren Auswertungen haben wir auch den gemeinsam genutzten Bereichen im Haus in ihrer Eigenschaft als „Kontakt- bzw. Konfliktarena“ Augenmerk gewidmet. Ein Aufzug ist in 66 der 111 im Sample enthaltenen Wiener Wohnhäuser vorhanden, eine Waschküche in 61 sowie diverse Abstellräume in 74 Fällen. 28 Häuser verfügen über einen Wäschetrockenraum und 19 über eine Art von Gemeinschaftsraum. Mit Garagen und Grünflächen sind 44 bzw. 45 Wohngebäude ausgestattet, einen Hof besitzen 81 und einen Kinderspielplatz 42. Die „klassische“ Gemeinschaftsinfrastruktur in Gründerzeithäusern ist noch in 22 (Gang-WC) bzw. 17 (Bassena) Fällen vorhanden und wird von 3 (Bassena) bzw. 9 (Gang-WC) Personen auch selbst noch genutzt.

20 Die Frage lautete: „,Wenn Sie von „Ihrem Wohnhaus“ sprechen, meinen Sie damit tatsächlich das ganze Haus oder nur den Stiegenaufgang, auf welchem Sie wohnen? " 


\subsubsection{Die Bewohnerstrukturen der im Sample vertretenen Wiener Wohnhäuser}

Um sicherzugehen, dass ins Sample nur Personen Eingang finden, die auch tatsächlich mit Nachbarn mit Migrationshintergrund im selben Haus zusammenleben, aber vor allem auch, um Aufschluss über die Bewohnerstrukturen der in unserer Stichprobe enthaltenen Wiener Wohnhäuser zu erhalten, haben wir auch einige Fragen zur Zusammensetzung der Hausbewohner gestellt. Die diesbezüglichen Resultate basieren selbstverständlich auf persönlichen Einschätzungen und individuellen Annahmen der Befragten. Es erwies sich in der Praxis angesichts des damit verbundenen extremen Erhebungsaufwands als unmöglich und finanziell auch nicht leistbar, die Bewohnerstrukturen statistisch exakt zu erheben.

Als eine Determinante des interethnischen Kontakt- und Konfliktgeschehens stellt die Bewohnerstruktur des jeweiligen Hauses eine wichtige Variable dar. Bezüglich der Formulierungen im Fragebogen und in Anlehnung an den in Wien üblichen Alltagssprachgebrauch hatten wir uns darauf geeinigt, von ,,ausländischen Hausparteien“ als Synonym für Menschen mit Migrationshintergrund zu sprechen. Terminologisch beziehen sich das Adjektiv „ausländisch“" sowie das Substantiv „Ausländer“ also nicht auf den staatsbürgerschaftsrechtlichen Status (welcher im wohnnachbarschaftlichen Kontext ja zumeist weitgehend irrelevant ist und auch sehr schwer zu erheben wäre), sondern auf den Status als Migrant bzw. Person mit migratorischem Background.

Tabelle 1: Bewohnerstrukturen nach Wohnungsbestandskategorien

\begin{tabular}{lrrrrrrrr}
\hline Gebäudetyp & \multicolumn{2}{c}{ Österreich } & \multicolumn{2}{c}{ Eingebürgerte } & \multicolumn{2}{c}{ Ausländer } & \multicolumn{2}{c}{ insgesamt } \\
& abs. & in \% & abs. & in \% & abs. & in \% & abs. & in \% \\
\hline gründerzeitliches Mietshaus & 20 & 40,0 & 7 & 26,9 & 12 & 34,3 & 39 & 35,1 \\
Gemeindebau & 16 & 32,0 & 12 & 46,2 & 12 & 34,3 & 40 & 36,0 \\
Genossenschaft, Eigentum & 14 & 28,0 & 7 & 26,9 & 11 & 31,4 & 32 & 28,8 \\
insgesamt & 50 & 100,0 & 26 & 100,0 & 35 & 100,0 & 111 & 100,0 \\
\hline
\end{tabular}

Quelle: Befragung 2005.

Von den befragten Österreichern leben $40 \%$ und damit die Mehrheit in gründerzeitlichen Mietshäusern, $32 \%$ besitzen eine Gemeindewohnung und $28 \%$ sind Wohnungseigentümer oder bewohnen eine Genossenschaftswohnung. Unter den Neoösterreichern ist der Anteil der Gemeindewohnungsnutzer am höchsten (46,2\%). Jeweils $26,9 \%$ sind Mieter in Altwiener Zinshäusern oder besitzen den Status eines Wohnungseigentümers bzw. Genossenschaftsmieters. Die ausländischen Respondenten verteilen sich relativ gleichmäßig auf die drei untersuchten Wohnbaukategorien. Jeweils 34,3\% bewohnen kommunale oder gründerzeitliche Mietwohnungen und $31,4 \%$ verfügen über eine Genossenschafts- oder Eigentumswohnung (vgl. Tab. 1). 
Da die Respondenten weitgehend nach dem Zufallsprinzip rekrutiert wurden, weisen die Bewohnerstrukturen in den von ihnen bewohnten Häusern eine erhebliche Variationsbreite auf. Zum Zwecke der Vereinfachung wurden bezüglich der Spezifikation der Bewohnerstruktur drei Kategorien gebildet: 1) Häuser mit mehrheitlich österreichischer Bewohnerschaft, 2) „Mischhäuser“" mit in etwa gleich vielen Österreichern und Zuwanderern in der Bewohnerschaft sowie 3) „Ausländerhäuser“, d.h. Häuser, die mehrheitlich von Personen mit Migrationshintergrund bewohnt werden.

Inländer leben zu rund 70\%, Eingebürgerte zu $63 \%$ in Häusern, die mehrheitlich von Österreichern bewohnt werden, während dies nur auf $48,6 \%$ der ausländischen Befragten zutrifft. $40 \%$ der Letztgenannten geben bezüglich der Bewohnerstruktur „ihres“ Wohnhauses an, dass Österreicher und Bewohner mit Migrationshintergrund einander anteilsmäßig einigermaßen die Waage halten. Exakt ein Fünftel der befragten Österreicher und 19,2\% der Eingebürgerten sind in „Mischhäusern“ zu Hause. Jeder zehnte Inländer und 11,5\% der Neoösterreicher bewohnen „Ausländerhäuser“, in welchen die Bewohnermehrheit durch Zuwanderer repräsentiert wird. Bezogen auf das gesamte Sample leben also fast zwei Drittel $(63,1 \%)$ in mehrheitlich von Inländern bewohnten Wohnbauten, etwa jeder Vierte $(26,1 \%)$ in Häusern mit einer gemischten Bewohnerstruktur aus ungefähr gleich vielen In- und Ausländern und etwa jeder Zehnte (10,8\%) verfügt über eine Wohnung in einem Haus mit Zuwanderermajorität (vgl. Tab. 2).

Tabelle 2: Migrationshintergrund und Bewohnerstruktur des Wohnhauses

\begin{tabular}{lrrrrrrrr}
\hline \multirow{2}{*}{ Bewohnerstruktur } & \multicolumn{2}{c}{ Österreich } & \multicolumn{2}{c}{ Eingebürgerte } & \multicolumn{3}{c}{ Ausländer } & \multicolumn{2}{c}{ insgesamt } \\
& abs. & in \% & abs. & in \% & abs. & in \% & abs. & in \% \\
\hline Mehrheit Österreicher & 35 & 70,0 & 18 & 62,9 & 17 & 48,6 & 70 & 63,1 \\
Österr. = Zuwanderer & 10 & 20,0 & 5 & 19,2 & 14 & 40,0 & 29 & 26,1 \\
Mehrheit Zuwander & 5 & 10,0 & 3 & 11,5 & 4 & 11,4 & 12 & 10,8 \\
insgesamt & 50 & 100,0 & 26 & 100,0 & 35 & 100,0 & 111 & 100,0 \\
\hline
\end{tabular}

Quelle: Befragung 2005.

Bezüglich des Bildungsniveaus zeigen sich erhebliche Divergenzen zwischen den Baubestandskategorien, welche wahrscheinlich auch für viele Unterschiede in den nachbarschaftlichen Kontakt- und Konfliktszenarien mit verantwortlich zeichnen. So ragen die in Gründerzeitmietshäusern wohnenden Befragten durch ein überdurchschnittlich hohes Bildungsniveau heraus. 56,4\% besitzen die Reifeprüfung einer höheren Schule oder haben ein Hochschulstudium absolviert. Fachschulen wurden von $15,4 \%$ der Mieter in gründerzeitlichen Häusern abgeschlossen, Pflichtschulabschluss mit Lehre können 12,8\% vorweisen. Auf eine absolvierte oder in seltenen Fällen auch unabgeschlossene Pflichtschule beschränkt sich die Qualifikation von 15,4\%.

Im Vergleich dazu ist für die Mieter von Gemeindewohnungen ein deutlich niedrigeres schulisches Ausbildungsniveau festzustellen. Nur $30 \%$ verfügen über eine 
Matura und/oder haben ein Hochschulstudium abgeschlossen, 17,5\% haben eine Fachschule durchlaufen. Fast ein Drittel (32,5\%) sind Pflichtschulabsolventen, die auch eine anschließende Lehre absolvierten, also Facharbeiter. Exakt ein Fünftel der Gemeindewohnungsmieter besitzt nur Pflichtschulbildung bzw. haben diese nicht einmal die Grundschule erfolgreich hinter sich gebracht.

Das Bildungsniveau der Wohnungseigentümer bzw. Genossenschaftsmieter ist deutlich höher als jenes der Mieter von Kommunalwohnungen, aber etwas niedriger als im gründerzeitlichen Baubestand. Mit 31,3\% ist der Maturantenanteil hier der höchste unter den drei analysierten Baubestandskategorien. Der Akademikeranteil von $15,6 \%$ ist zwar etwas höher als im Gemeindebau, aber doch deutlich niedriger als in den gründerzeitlichen Mietshäusern. Mit 21,9\% ist die Präsenz von Fachschulabsolventen hier die höchste im Vergleich der drei Baubestandssegmente. 12,5\% der Genossenschaftsmieter/Wohnungseigentümer besitzen eine Facharbeiterausbildung. Dies entspricht nahezu exakt deren prozentueller Präsenz im Gründerzeitwohnsegment, ist aber deutlich geringer als in den Gemeindebauten. 18,7\% können nur Pflichtschulbildung vorweisen, was in etwa dem Anteil dieser Bildungsgruppe in den kommunalen Wohnbauten in unserem Sample entspricht.

Die Bewohnerstrukturen sind äußerst unterschiedlich. Bezogen auf das gesamte Sample leben $70(63,1 \%)$ in mehrheitlich von inländischen Parteien bewohnten Gebäuden, $12(26,1 \%)$ haben eine Wohnung in Mischhäusern mit einer quantitativen Balance österreichischer und nichtösterreichischer Bewohner und $12(10,8 \%)$ sind in mehrheitlich von Migranten bewohnten Häusern wohnhaft. Von den österreichischen Respondenten im Sample bewohnen 70\% Wohnhäuser, in denen sich die Bewohnerschaft in der Mehrheit aus Inländern konstituiert, 20\% leben in Gebäuden, in denen in etwa gleich viele österreichische und nichtösterreichische Hausparteien vorhanden sind und 10\% in Häusern, die in der Mehrheit von Zuwanderern bewohnt werden. In der Subgruppe der Neoösterreicher geben $69,2 \%$ an, in einer Wohnung in einem Haus mit österreichischer Bewohnermehrheit zu logieren, 19,2\% bewohnen Mischhäuser, in welchen einander österreichische Mieter und solche mit Migrationshintergrund weitgehend die Waage halten, und 11,5\% entfallen auf Gebäude mit Zuwanderermehrheit. Von den nicht eingebürgerten Respondenten sind 48,6\% in Gebäuden, in denen österreichische Bewohner die Mehrheit darstellen, wohnhaft, $40 \%$ haben eine Wohnung in Mischhäusern und bei 11,4\% wird das Haus mehrheitlich von Migranten besiedelt.

Wir haben unsere Befragten auch nach ihrer ganz persönlichen Einschätzung des Anteils der „Hausbewohner ausländischer Herkunft““21 in „,ihrem“ Wohnhaus ge-

21 Der Entscheidung für diesen Terminus sind detaillierte Überlegungen und umfangreiche Diskussionen vorangegangen. Im gängigen Wiener Alltagssprachgebrauch wird ganz grob zwischen „Österreichern“ und Ausländern“ unterschieden, wobei bei letzteren irrelevant ist, ob sie bereits eingebürgert sind oder vielleicht bereits - wie häufig der Fall - in Österreich geboren und/oder aufgewachsen sind. Der der ,political correctness“ entsprechende 
fragt. $^{22}$ Dabei zeigte sich, dass kein einziger in einem „rein österreichischen“ Haus wohnte. Die Ausländeranteile variieren allerdings in einem sehr starken Ausmaß. Rund ein Fünftel $(21,1 \%)$ bewohnt eine Wohnung in einem Haus mit bis zu $10 \%$ an ausländischen Hausparteien. Zwischen 10 und 20\% beläuft sich der Ausländeranteil in einem weiteren Fünftel der durch Respondenten im Sample enthaltenen Wohnhäuser. Fast 60\% aller Befragten schätzen den Anteil der Hausbewohner mit Migrationshintergrund auf einen Wert von bis zu 30\%. Prozentsätze von 21 bis 35\% erreicht der Anteil ausländischer Hausbewohner in 19,3\% der Gebäude, und in einem Viertel (25,7\%) der Fälle wird der Ausländeranteil auf 36 bis 50\% geschätzt. 86,3\% aller Respondenten bewohnen also Wohnhäuser mit einer prozentuellen Präsenz von Nachbarn mit Migrationshintergrund von bis zu 50\%. 13,5\% der Befragten leben in ausgesprochenen „Ausländerhäusern“, in denen Zuwanderer mehr als die Hälfte der Mieter/Eigentümer ausmachen. Es liegt in der Natur der Sache solcher Schätzungen und am dem Dezimalsystem weitgehend verhafteten Denken der Menschen, dass das Gros der Befragten den Ausländeranteil auf volle Zehnerprozentwerte (also 10, 20, $30 \%$ etc.) hin geschätzt hat. In welchem Ausmaß diese Schätzungen die faktischen Ausländeranteile im Haus tatsächlich wiedergeben, muss leider dahingestellt bleiben. Eine exakte Erhebung derselben hätte einen nicht finanzierbaren Aufwand erfordert und musste aus diesem Grund unterbleiben.

Die Analyse der drei Baubestandskategorien nach dem Kriterium des Ausländeranteils zeigt, dass den Schätzungen unserer Befragten gemäß besonders hohe Anteile ausländischer Bewohner vor allem im gründerzeitlichen Mietshaussegment erreicht werden (vgl. Tab. 3). 52,6\% der Respondenten geben hierbei Anteile ausländischer Hausparteien über $36 \%$ an. In 18,4\% der Fälle beläuft sich die Ausländerpräsenz sogar auf mehr als die Hälfte, 34,2\% der Befragten bewohnen Häuser mit 36 bis 50\% an ausländischen Wohnparteien. Im kommunalen Wohnbau betragen in einem Viertel der Fälle die „Ausländeranteile“ 11 bis 20\%. Ein Fünftel der Befragten bewohnt ein Gemeindewohnhaus mit 21 bis 35\% Mietern mit Migrationshintergrund und 25,6\% geben Anteile von Migranten im Haus von 26 bis 50\% an. Höhere Wohnkonzentrationen von Zuwanderern sind mit 12,8\% deutlich seltener als im gründerzeitlichen Bausegment, am seltensten treten diese aber mit 9,4\% in der Wohnbestandskategorie „Genossenschaft/Eigentum“ auf. Hier beläuft sich in mehr als einem Drittel der Gebäude der Ausländeranteil auf höchstens ein Zehntel und in rund 22\% der Fälle auf 11 bis höchstens 20\%. Nicht ganz 19\% der befragten Genossenschaftsmieter bzw.

Terminus „Menschen/Personen mit Migrationshintergrund“ hat sich im Alltagssprachgebrauch noch recht wenig durchsetzen können, obwohl er in den Medien bereits häufiger zu vernehmen ist. In der nachbarschaftlichen Alltagsrealität ist davon auszugehen, dass vor allem die „Sichtbarkeit“ (äußeres Erscheinungsbild) und die „Hörbarkeit“ (sprachlicher Akzent) für die Klassifikation eines Nachbarn als „Ausländer“ die entscheidende Rolle spielen.

22 Die Frage lautete: „Schätzen Sie bitte die Anteile österreichischer Bewohner und der Bewohner ausländischer Herkunft in Ihrem Wohnhaus insgesamt in Prozent? “ 
Wohnungseigentümer schätzen den Migrantenanteil im Haus auf 21 bis 35\%, rund $16 \%$ auf 36 bis $50 \%$.

Tabelle 3: Ausländeranteile nach Wohnungsbestandskategorien

\begin{tabular}{lrrrrrrrr}
\hline $\begin{array}{l}\text { Ausländer- } \\
\text { anteil }\end{array}$ & \multicolumn{2}{c}{ Gründerzeit } & \multicolumn{2}{c}{ Gemeindebau } & \multicolumn{2}{c}{$\begin{array}{r}\text { Genossenschaft, } \\
\text { Eigentum }\end{array}$} & insgesamt \\
& abs. & in \% & abs. & in \% & abs. & in \% & abs. & in \% \\
\hline bis 10\% & 6 & 15,8 & 6 & 15,4 & 11 & 34,4 & 23 & 21,1 \\
11 bis $20 \%$ & 5 & 13,2 & 10 & 25,6 & 7 & 21,9 & 22 & 22,2 \\
21 bis 35\% & 7 & 18,4 & 8 & 20,5 & 6 & 18,8 & 21 & 19,6 \\
36 bis 50\% & 13 & 34,2 & 10 & 25,6 & 5 & 15,6 & 28 & 25,7 \\
über 50\% & 7 & 18,4 & 5 & 12,8 & 3 & 9,4 & 15 & 13,8 \\
insgesamt & 38 & 100,0 & 39 & 100,0 & 32 & 100,0 & 109 & 100,0 \\
\hline
\end{tabular}

Quelle: Befragung 2005.

Neben der Spezifikation des Zuwandereranteils unter den im Haus wohnhaften Parteien hat uns auch die persönliche Einstellung unserer Respondenten dazu interessiert. Aus diesem Grund wurde nachgefragt, ob sie diesen Anteil als zu niedrig, zu hoch oder als gerade richtig bewerten würden. Nahezu drei Viertel $(73,6 \%)$ gaben hierbei eine persönliche Bewertung als ,gerade richtig“ ab, bloß 11,8\% der Respondenten klassifizierten den Ausländeranteil als zu hoch und 14,5\% fanden ihn sogar zu niedrig.

Tabelle 4: Persönliche Bewertung des Ausländeranteils im Wohnhaus nach Wohnungsbestandskategorien

\begin{tabular}{lrrrrrrrr}
\hline & \multicolumn{2}{c}{ Gründerzeit } & \multicolumn{2}{c}{ Gemeindebau } & \multicolumn{2}{c}{$\begin{array}{c}\text { Genossenschaft, } \\
\text { Eigentum }\end{array}$} \\
& & & & \multicolumn{2}{c}{ insgesamt } \\
Bewertung & abs. & in \% & abs. & in \% & abs. & in \% & abs. & in \% \\
\hline zu niedrig & 3 & 7,7 & 8 & 20,0 & 5 & 16,1 & 16 & 14,5 \\
gerade richtig & 30 & 76,9 & 27 & 67,5 & 24 & 77,4 & 81 & 73,6 \\
zu hoch & 6 & 15,4 & 5 & 12,5 & 2 & 6,5 & 13 & 11,8 \\
insgesamt & 39 & 100,0 & 40 & 100,0 & 31 & 100,0 & 110 & 100,0 \\
\hline
\end{tabular}

Quelle: Befragung 2005.

Die persönlichen Bewertungen der Ausländeranteile variieren auch in Abhängigkeit von demographischen Variablen. Dass der Migrantenanteil im Haus zu hoch sei, ist eine nicht sehr häufig geäußerte Meinung. Mit 15,4\% ist diese unter Mietern von Gründerzeitwohnungen am öftesten anzutreffen, etwas seltener $(12,5 \%)$ wird derlei von Mietern der Gemeinde Wien artikuliert und am wenigsten sind Genossenschafts- 
mieter bzw. Wohnungseigentümer (6,5\%) dieser Überzeugung. Ein interessantes Detail am Rande: Unter den Gemeindewohnungsmietern ist immerhin genau ein Fünftel der Meinung, der Ausländeranteil im Haus sei zu gering! Dass die anteilsmäßige Präsenz ausländischer Mieter ,gerade richtig“ sei, bekunden jeweils mehr als drei Viertel der in Gründerzeithäusern sowie in Genossenschafts-/Eigentumswohnungen lebenden Respondenten.

Tabelle 5: Persönliche Bewertung des Ausländeranteils im Wohnhaus nach vorhandenem/nicht vorhandenem Migrationshintergrund

\begin{tabular}{lrrrrrrrr}
\hline & \multicolumn{2}{c}{ Österreich } & \multicolumn{2}{c}{ Eingebürgerte } & \multicolumn{2}{c}{ Ausländer } & \multicolumn{2}{c}{ insgesamt } \\
Bewertung & abs. & in \% & abs. & in \% & abs. & in \% & abs. & in \% \\
\hline zu niedrig & 6 & 12,2 & 5 & 19,2 & 5 & 14,3 & 16 & 14,5 \\
gerade richtig & 36 & 73,5 & 18 & 69,2 & 27 & 77,1 & 81 & 73,6 \\
zu hoch & 7 & 14,3 & 3 & 11,5 & 3 & 8,6 & 13 & 11,8 \\
insgesamt & 49 & 100,0 & 26 & 100,0 & 35 & 100,0 & 110 & 100,0 \\
\hline
\end{tabular}

Quelle: Befragung 2005.

Unterschiede nach dem Geschlecht sind hier ebenfalls nachweisbar, müssen aber vorsichtig interpretiert werden. So sind die Einstellungen von Frauen in dieser Frage ungleich pointierter als jene der befragten Männer. Während 80,4\% der Männer meinen, der Ausländeranteil im Haus sei gerade richtig und sie diesen nur zu jeweils 9,8\% als zu niedrig oder zu hoch bewerten, sprechen sich nur wenig mehr als zwei Drittel der Frauen ebenfalls für die Kategorie ,gerade richtig“ aus. Während 13,6\% der Respondentinnen den Ausländeranteil als zu hoch empfinden, sind immerhin 18,6\% davon überzeugt, er sei eigentlich zu niedrig. Auch eine vorhandene eigene Migrationsbiographie spielt im Kontext dieser Bewertung eine nicht unerhebliche Rolle (vgl. Tab. 5). Mit 14,3\% ist unter den Österreichern der Standpunkt, der Migrantenanteil im Haus sei zu hoch, am weitesten verbreitet. Unter den ausländischen Staatsbürgern in der Stichprobe sind etwa bloß 8,6\% dieser Meinung. Dass der Migrantenanteil zu gering sei, meinen vor allem die Neoösterreicher (19,2\%) und die Ausländer (14,3\%) und am seltensten die Befragten ohne Migrationshintergrund (12,2\%). In Bezug auf das Alter manifestiert sich in der vorliegenden Stichprobe ein unerwarteter Effekt. Während empirisch in zahlreichen Studien nachgewiesen werden konnte, dass ablehnende Einstellungen gegenüber Migranten sehr stark altersabhängig sind (je jünger, desto toleranter) ist in unserem Wiener Sample der Anteil jener, die den Ausländeranteil im Haus als zu hoch klassifizieren, mit 15\% in der Altersgruppe bis 30 Jahre am höchsten und beträgt unter den über 45-Jährigen beispielsweise bloß 9,7\%.

Zusätzlich zur rein quantitativen Schätzung der Ausländeranteile wurden die Befragten auch nach einer darüber hinausgehenden Spezifikation der ethnonationalen Herkunft der im Haus lebenden Immigranten gefragt. Diese Auswertungen haben keine krassen Konzentrationen bestimmter Herkunftsgruppen in den in unserer Stichpro- 
be enthaltenen Wohnhäusern ergeben. Naturgemäß und in Korrelation zu ihrer quantitativen Dominanz in der Wiener Zuwandererpopulation wurde besonders häufig angegeben, dass die ausländischen Hausbewohner aus Exjugoslawien und/oder der Türkei stammen. Bezüglich Exjugoslawiens war es den meisten Respondenten nicht möglich, eine exaktere Herkunftsspezifikation, bezogen auf eine konkrete Nachfolgerepublik, abzugeben. Nur sechs Personen bekundeten, in einem Haus mit Migranten zusammenzuwohnen, die ausschließlich aus dem ehemaligen Jugoslawien kommen. In vier Fällen stammen sämtliche im Haus ansässigen Immigranten aus der Türkei. In all diesen zehn Fällen handelt es sich allerdings um Häuser mit mehrheitlich österreichischen Bewohnern! In der Subkategorie der Häuser mit gleich vielen österreichischen wie nichtösterreichischen Bewohnern gab jeweils ein Befragter an, sämtliche Immigranten stammten aus der Türkei bzw. aus dem ehemaligen Jugoslawien. In den anderen Fällen ist die Bewohnerstruktur ihrer Herkunft nach stark gemischt. Gleiches gilt für die wenigen Häuser mit Migrantenmehrheit. Naheliegenderweise werden hier zwar wiederum Exjugoslawen und Türken am häufigsten angeführt, abgesehen von einer Ausnahme aber stets in Kombination mit Migranten verschiedenster anderer Herkunft.

\subsubsection{Interethnische Nachbarschaftskontakte im Spiegel der Wiener Befragung}

\subsubsection{Wohnzufriedenheit und Zufriedenheit mit dem nachbarschaftlichen Verhältnis}

Um die Unterschiede hinsichtlich der Wohnzufriedenheitslevels zwischen den unterschiedlichen Wohnbestandskategorien herauszuarbeiten, haben wir in der Erhebung zunächst ganz allgemein nach der Zufriedenheit mit Wohnhaus und Nachbarn gefragt.

Tendenziell zeigt sich, dass die Zufriedenheit mit dem Wohnhaus etwas stärker ausgeprägt ist als jene mit den Nachbarn, wobei das höchste Wohnzufriedenheitslevel in Genossenschafts-/Eigentumswohnbauten erreicht wird (vgl. Tab. 6). 40,6\% der hier wohnhaften Respondenten sind sehr zufrieden, weitere 34,4\% eher zufrieden. Dies ergibt zusammen einen Anteil von exakt drei Vierteln der in diesem Segment wohnhaften Respondenten, die Zufriedenheit mit „ihrem“ Wohnhaus artikulieren. Im Gemeindebau sind nur 27,5\% zufrieden, aber immerhin noch 30\% eher zufrieden, was in summa einen Anteil der Zufriedenen von 57,5\% ergibt. Im Gründerzeithaus fällt die diesbezügliche Bewertung am schlechtesten aus: 30,8\% der Mieter sind sehr und 15,4\% eher zufrieden - zusammen bedeutet dies also 46,2\% Zufriedene. Explizite Unzufriedenheit ist aber auch nicht allzu stark ausgeprägt, wenngleich hierbei der bekannte Faktor der Resignation und der Adaption der Menschen an die unvermeidliche Wohnrealität ins Kalkül gezogen werden muss (d.h. selbst bei manifester Unzufriedenheit fügt man sich angesichts mangelnder Möglichkeiten zur Veränderung in die Situation und artikuliert auch faktische Unzufriedenheit nur sehr abgeschwächt). 
Explizit unzufrieden sind 3,1\% der Befragten in der Wohnbaukategorie von Genossenschaft/Eigentum, 2,5\% im Gemeindebau und kein einziger Mieter im gründerzeitlichen Bestandssegment.

Tabelle 6: Zufriedenheit mit Wohnhaus und Nachbarn nach Wohnungsbestandskategorien

\begin{tabular}{lrrrr}
\hline & Gründerzeit & Gemeindebau & $\begin{array}{r}\text { Genossenschaft, } \\
\text { Eigentum }\end{array}$ & insgesamt \\
\hline Wohnhaus & & & & \\
sehr zufrieden & 30,8 & 27,5 & 40,6 & 32,4 \\
eher Zufrieden & 15,4 & 30,0 & 34,4 & 26,1 \\
zufrieden & 35,9 & 35,0 & 21,9 & 31,5 \\
eher unzufrieden & 17,9 & 5,0 & 0,0 & 8,1 \\
unzufrieden & 0,0 & 2,5 & 3,1 & 1,8 \\
insgesamt & 100,0 & 100,0 & 100,0 & 100,0 \\
Nachbarn & & & & \\
sehr zufrieden & 30,8 & 30,0 & 25,0 & 28,9 \\
eher zufrieden & 28,2 & 15,0 & 37,5 & 26,3 \\
zufrieden & 28,2 & 42,5 & 34,4 & 35,1 \\
eher unzufrieden & 7,7 & 10,0 & 0,0 & 6,3 \\
unzufrieden & 5,1 & 2,5 & 3,1 & 3,6 \\
insgesamt & 100,0 & 100,0 & 100,0 & 100,0 \\
\hline
\end{tabular}

Quelle: Befragung 2005.

Den Nachbarn wird ein etwas schlechteres Zeugnis ausgestellt als dem Wohnhaus an sich. Sehr zufrieden mit ihrem nachbarschaftlichen Umfeld sind jeweils 30\% der Befragten aus Gründerzeithäusern und Kommunalwohnungen sowie nur ein Viertel der Wiener im Segment Genossenschaft/Eigentum. Zählt man die Kategorie „eher zufrieden“ hinzu, so werden die höchsten Zufriedenheitswerte in Genossenschafts/Eigentumswohnhäusern (62,5\%) erreicht, etwas geringere in Gründerzeitbauten (59\%) und das mit Abstand geringste Ausmaß an Zufriedenheit (45\%) im kommunalen Wohnbau. Eher oder überhaupt unzufrieden mit ihren Nachbarn sind denn auch $12,5 \%$ der Gemeindewohnungsmieter, aber auch 12,8\% der Mieter im Gründerzeitsegment und nur 3,1\% der Befragten in Genossenschafts-/Eigentumswohnungen.

Nach Subgruppen (mit/ohne Migrationshintergrund) aufgefächert, manifestiert sich in unserem Sample eine deutliche Differenzierung hinsichtlich der Zufriedenheitslevels. Das geringste Ausmaß an Zufriedenheit mit dem Wohnhaus (82,9\%) wird von ausländischen Staatsbürgern artikuliert, während 92,3\% der Neoösterreicher und 94\% der österreichischen Befragten hierüber Zufriedenheit äußern. Im Hinblick auf die Nachbarn sind es die Neoösterreicher, welche den Spitzenwert an Unzufrieden- 
heit artikulieren: 19,2\% von ihnen sind unzufrieden (gegenüber 8,6\% bei den Ausländern und nur 6\% der Inländer) (vgl. Tab. 7). Auch in diesem Kontext haben wir eine detaillierte Analyse nach den drei Wohnungsbestandskategorien durchgeführt, die aufschlussreiche Unterschiede ergab:

Tabelle 7: Zufriedenheit mit Wohnhaus und Nachbarn nach vorhandenem/nicht vorhandenem Migrationshintergrund

\begin{tabular}{lrrrr}
\hline & Österreicher & Eingebürgerte & Ausländer & insgesamt \\
\hline Wohnhaus & & & & \\
zufrieden & 94,0 & 92,3 & 82,9 & 90,1 \\
unzufrieden & 6,0 & 7,7 & 17,1 & 9,9 \\
insgesamt & 100,0 & 100,0 & 100,0 & 100,0 \\
Nachbarn & & & & \\
zufrieden & 94,0 & 80,8 & 91,4 & 90,1 \\
unzufrieden & 6,0 & 19,2 & 8,6 & 9,9 \\
insgesamt & 100,0 & 100,0 & 100,0 & 100,0 \\
\hline
\end{tabular}

Quelle: Befragung 2005.

Für die Gründerzeithäuser kann ein besonders hohes Unzufriedenheitspotential mit dem Wohnhaus an sich bei ausländischen Mietern konstatiert werden $(41,7 \%)$. Auch die Eingebürgerten sind mit 28,6\% in einem beträchtlichen Ausmaß unzufrieden, während kein einziger Österreicher explizit Unzufriedenheit über sein gründerzeitliches Domizil äußerte. Gegenüber den Nachbarn herrscht in den gründerzeitlichen Mietshäusern in erster Linie seitens der Neoösterreicher ein besonders hohes Ausmaß an Unzufriedenheit vor. 42,9\% der Eingebürgerten sind mit ihren Nachbarn explizit unzufrieden! Bei Ausländern ist dies bloß zu 8,3\%, bei Inländern zu 5\% der Fall.

Wie sieht es diesbezüglich in den Gemeindebauten aus? Hier sind es in erster Linie die österreichischen Mieter, die mit 12,5\% mit dem Wohnhaus besonders unzufrieden sind. An zweiter Stelle folgen die Ausländer. Allerdings artikuliert kein einziger Neoösterreicher in diesem Punkt Unzufriedenheit. Konträr dazu präsentieren sich die Verteilungen, wenn nach der Zufriedenheit mit den Nachbarn gefragt wird: In diesem Punkt sind jeweils 16,7\% der Eingebürgerten und der Ausländer explizit unzufrieden - von den Österreichern nur 6,3\%.

Im Wohnungsbestand der Kategorie „Genossenschaft/Eigentum“ sind die Zufriedenheitslevels besonders hoch. Sowohl unter den Neoösterreichern als auch unter den hier ansässigen Ausländern artikuliert kein einziger Unzufriedenheit mit Wohnhaus und/oder Nachbarn. Unter den Inländern sind es jeweils nur 7,1\%, die mit Haus und Nachbarn unzufrieden sind. 


\subsubsection{Allgemeine Einstellung zu Nachbarschaftskontakten nach Gebäudetypen} und vorhandenem/nicht vorhandenem Migrationshintergrund

Hinsichtlich der Diskussion um die grundsätzliche Relevanz von nachbarschaftlichen Sozialkontakten ist es ganz wichtig hervorzuheben, dass auch in einer Großstadt wie Wien immerhin 63,3\% der Respondenten Nachbarschaftskontakte an sich nach wie vor als sehr wichtig bzw. zumindest als wichtig einstuften. Nur eine Minorität von $7,3 \%$ betrachtete diese als unwichtig, während $29,4 \%$ eine Bewertung als weniger wichtig abgaben.

Diese Werte sind vor allem angesichts der in der sozialwissenschaftlichen Diskussion artikulierten Zweifel an der grundsätzlichen Wichtigkeit von Nachbarschaftskontakten in modernen Großstädten beachtenswert. Der ,Verlust der Nachbarschaft“ wurde zwar von etlichen Autoren mit einer gewissen Larmoyanz festgestellt und in einen ideologiekritischen Kontext gestellt, seine Ursachen dürften aber - zumindest was unser Sample betrifft - nicht in einer grundsätzlichen Geringschätzung von Nachbarschaftskontakten auf Seiten der Großstadtbewohner zu suchen sein. Distanzverhalten und Kontaktbedürfnisse schließen einander nicht aus, eine gewisse Reserviertheit im nachbarschaftlichen Beziehungsfeld ist keineswegs als Wunsch nach Isolation zu interpretieren. Städtische Mobilität hat zwar zu einem Funktionsverlust der Nachbarschaft geführt, aber in geringerem Maß zu einer Geringschätzung. Dabei messen Frauen Nachbarschaftskontakten eine deutlich wichtigere Rolle bei als Männer. ${ }^{23}$

Nachbarschaftliche Interaktionen scheinen vor allem für Neoösterreicher sehr wichtig zu sein. 76,9\% von ihnen geben eine Einschätzung als wichtig/sehr wichtig ab, während deutlich weniger Österreicher $(59,2 \%)$ und Ausländer $(58,9 \%)$ eine analoge Bewertung artikulieren. Kein einziger der befragten Eingebürgerten klassifiziert nachbarschaftliche Interaktionen als unwichtig. Am ehesten sind Inländer (10,2\%) und ausländische Staatsbürger (8,8\%) dieser Ansicht. Weniger wichtig sind Nachbarschaftskontakte für jeden dritten ausländischen Respondenten (32,4\%), für 30,6\% der österreichischen und für nur 23,1\% der eingebürgerten Personen im Sample (Tab. 8).

Tabelle 8: Bewertung der Wichtigkeit von Nachbarschaftskontakten nach vorhandenem/nicht vorhandenem Migrationshintergrund

\begin{tabular}{lrrrr}
\hline & Österreicher & Eingebürgerte & Ausländer & insgesamt \\
\hline sehr wichtig & 18,4 & 34,6 & 11,8 & 20,2 \\
wichtig & 40,8 & 42,3 & 47,1 & 43,1 \\
weniger wichtig & 30,6 & 23,1 & 32,4 & 29,4 \\
unwichtig & 10,2 & 0,0 & 8,8 & 7,3 \\
insgesamt & 100,0 & 100,0 & 100,0 & 100,0 \\
\hline
\end{tabular}

Quelle: Befragung 2005.

23 Vgl. dazu auch Klages (1968: 147) sowie Barre et al. (1977: 159). 
Ein interessantes Faktum bilden auch die teilweise recht krassen Unterschiede zwischen den Wohnungsbestandskategorien (vgl. Tab. 9). Am häufigsten sind es Bewohner von Genossenschafts- oder Eigentumswohnungen, die Nachbarschaftskontakten eine unwichtige Rolle (12,9\%) beimessen, während mit 2,6\% nur ganz wenige Gemeindebaumieter einer so distanzierten Einstellung zu ihren Nachbarn etwas abgewinnen können. Bewohner von Gründerzeithäusern liegen mit 7,7\% in etwa dazwischen. Mit einem Anteil von 79,4\% sprechen sich die Mieter von Gemeindewohnungen ganz besonders deutlich für die Wichtigkeit von Nachbarschaftskontakten aus. An zweiter Stelle liegen hier die Mieter von Gründerzeitwohnungen, die Nachbarschaftskontakte zu $61,5 \%$ als sehr wichtig bzw. wichtig klassifizieren, während diese Bewertung nur von $45,1 \%$ der Befragten in der Kategorie der Eigentums-/Genossenschaftswohnungen abgegeben wird. Die Bewohner letzterer messen nachbarschaftlichen Interaktionen zu fast 42\% geringere Wichtigkeit bei. Eine Einschätzung, welche auch 30,8\% der Mieter von Gründerzeitwohnungen und rund 18\% der Gemeindebaumieter teilen.

Tabelle 9: Bewertung der Wichtigkeit von Nachbarschaftskontakten nach Wohnungsbestandskategorien

\begin{tabular}{lrrrr}
\hline & Gründerzeit & Gemeindebau & $\begin{array}{r}\text { Genossenschaft, } \\
\text { Eigentum }\end{array}$ & insgesamt \\
\hline sehr wichtig & 25,6 & 17,9 & 16,1 & 20,2 \\
wichtig & 35,9 & 61,5 & 29,0 & 43,1 \\
weniger wichtig & 30,8 & 17,9 & 41,9 & 29,4 \\
unwichtig & 7,7 & 2,6 & 12,9 & 7,3 \\
insgesamt & 100,0 & 100,0 & 100,0 & 100,0 \\
\hline
\end{tabular}

Quelle: Befragung 2005.

Bewertungsunterschiede ergeben sich auch in Abhängigkeit vom Alter und Geschlecht. So bewertet mit 9,8\% ein nahezu doppelt so hoher Anteil der Männer als der Frauen $(5,2 \%)$ Nachbarschaftskontakte als unwichtig. Mit steigendem Lebensalter ändert sich auch die individuelle Bewertung von Kontakten im engeren räumlichen Umfeld - diesen wird ein zunehmender Grad an Wichtigkeit beigemessen. Während kein einziger Respondent im Alter über 45 Jahre Nachbarschaftskontakte als unwichtig bewertet, liegt der entsprechende Anteil bei den bis 30-Jährigen bei immerhin $12,5 \%$. Umgekehrt ist es bloß jeder Zehnte in dieser jungen Alterskategorie, der eine Klassifikation als sehr wichtig abgibt, während der entsprechende Prozentanteil bei den über 45 -Jährigen bei $25,8 \%$ angesiedelt ist.

\subsubsection{Die Bewertung der Kontaktqualität}

Neben der Kontakthäufigkeit stellt die Kontaktqualität eine wichtige Größe zur Beurteilung der intra- und interethnischen Nachbarschaftsbeziehungen dar. Bezüglich 
der Kontaktqualität haben wir einmal mehr die persönlichen Einschätzungen unserer Respondenten abgefragt. ${ }^{24}$ Alle Befragten wurden um eine qualitative Beurteilung ihres nachbarschaftlichen Verhältnisses mit ihren österreichischen Nachbarn gebeten. Hierbei zeigt sich ein überaus positives, die nachbarschaftliche Realität vielleicht nicht perfekt widerspiegelndes Bild: Nahezu die Hälfte $(46,8 \%)$ bewertete dieses Kontaktverhältnis als gut oder sogar sehr gut und immerhin 39,6\% zumindest noch als mittelmäßig. Nur ein Zehntel der Personen im Sample gab diesbezüglich eine Bewertung als eher oder sehr schlecht ab. Nach dem Kriterium des Geschlechts schneiden hier die Frauen eindeutig besser ab. 53,6\% der befragten Frauen, aber nur 43,1\% der Männer bewerten die Kontakte zu ihren österreichischen Nachbarn als gut oder sogar sehr gut. Männer neigen hier sehr stark einer mittelmäßigen Bewertung zu, während die Kategorie „eher schlecht/sehr schlecht“ nur geringe geschlechtsspezifische Unterschiede erkennen lässt. Bezüglich des Alters bestätigen die Wiener Daten eine deutliche Verbesserung der nachbarschaftlichen Interaktionen mit zunehmendem Lebensalter. Während unter den Respondenten, die das 45. Lebensjahr bereits überschritten haben, 70\% ihre Kontakte zu österreichischen Nachbarn als sehr gut bzw. gut einschätzen, liegt der entsprechende Anteilswert unter den bis 30-Jährigen nur bei 38,4\%. Dafür geben $15,4 \%$ der Befragten in der letztgenannten Alterskategorie eine Klassifikation der Kontaktqualität als schlecht/sehr schlecht ab (in der Gruppe ab 45 Jahren bloß 6,7\%).

Die Analyse nach dem Kriterium einer vorhandenen Migrationsbiographie dokumentiert, dass der Kontakt zu den österreichischen Nachbarn von den noch nicht eingebürgerten Ausländern am schlechtesten bewertet wird. 15,1\% geben diesbezüglich eine Einschätzung als eher/sehr schlecht ab, und nur 3\% (!) beurteilen ihr Kontaktklima mit Inländern als sehr gut. Im krassen Gegensatz dazu geben 20,8\% der Eingebürgerten eine Bewertung als sehr gut ab, und bloß 4,2\% äußern die persönliche Meinung, dass das Kontaktklima zu ihren inländischen Nachbarn eher/sehr schlecht sei. Die diesbezügliche Bewertung seitens der Neoösterreicher ist damit sogar positiver als jene der österreichischen Respondenten (10\% eher/sehr schlecht, $18 \%$ sehr gut).

Die komparative Analyse der Mittelwerte lässt die Unterschiede hinsichtlich der Kontaktqualität sehr deutlich zu Tage treten. Die Qualität der Kontakte zu österreichischen Nachbarn sollte sowohl von Inländern als auch von Migranten vergleichend bewertet werden. Hierbei belegt der Wert $\bar{x}=1,42$ die bessere Bewertung seitens der Inländer, während die Migranten mit $\bar{x}=1,56$ eine weniger positive Einschätzung abgeben. Die österreichischen Befragten bewerten ihre Kontakte zu ihren ausländischen Nachbarn mit einem Wert $\bar{x}=1,75$ noch wesentlich negativer. Mit einem arithmetischen Mittel von 0,98 fällt die Bewertung der Kontakte zu ihren Landsleuten seitens der befragten Migranten allerdings signifikant besser aus als die Beurteilung der Kontaktqualität zu ihren anderen ausländischen Nachbarn $(\bar{x}=1,66)$.

24 „Wenn Sie vergleichen, wie würden Sie Ihre Kontakte zu Ihren österreichischen und ausländischen Nachbarn beurteilen?" 
Die Respondenten ohne Migrationshintergrund wurden zudem nach der Kontaktqualität zu ihren ausländischen Nachbarn befragt. Auch hierbei zeigte sich, dass ein dramatisch negatives Nachbarschaftsverhältnis auch im interethnischen Kontext die Ausnahme darstellt. Nur eine Minorität von 15,4\% der Österreicher im Sample bewertete das Kontaktverhältnis zu ihren ausländischen Nachbarn als eher oder sogar sehr schlecht. Der Prozentsatz an schlechten Kontakten ist hier offensichtlich etwas höher als im Umgang mit österreichischen Nachbarn und bezogen auf die gesamte Stichprobe - die Differenz beträgt 5,1 Prozentpunkte und ist hiermit zwar vorhanden, aber als eher undramatisch einzustufen. Aus der Perspektive von $42,3 \%$ der befragten Inländer ist das Nachbarschaftsverhältnis zu Migranten als gut bis sehr gut eingeschätzt worden und exakt derselbe Prozentsatz klassifizierte seine diesbezügliche Interaktionsqualität zumindest als mittelmäßig. Inländische Frauen messen ihren Nachbarschaftskontakten eine deutlich bessere Qualität bei, als dies Männer tun. Immerhin mehr als die Hälfte $(53,3 \%)$ der befragten Österreicherinnen gibt eine Beurteilung als sehr gut/gut ab, gegenüber bloß 27,3\% der Männer. Spiegelbildlich dazu bewerten $22,7 \%$ der männlichen Österreicher und exakt ein Zehntel der Frauen ihr Verhältnis zu im Haus wohnenden Ausländern als eher/sehr schlecht. Das Alter scheint in diesem Zusammenhang eine doch gewichtige Rolle zu spielen. So sind es vor allem die jüngeren Altersklassen, die eine besonders positive Bewertung der interethnischen Kontaktqualität abgeben. $45,5 \%$ der Befragten im Alter bis 30 Jahre beurteilen ihre interethnischen Nachbarschaftskontakte als gut bzw. sehr gut, 13,6\% geben eine Einschätzung als eher schlecht ab, die Kategorie „sehr schlecht" ist in diesem Zusammenhang überhaupt nicht besetzt. Bei den über 45-Jährigen sind $40 \%$ der Meinung, ihre Kontaktqualität sei gut/sehr gut und immerhin exakt ein Fünftel gibt eine Bewertung als eher oder sogar sehr schlecht ab.

Deutlich manifestiert sich dennoch die Wirksamkeit eines Intragruppeneffekts. Die Subgruppe der Befragten mit Migrationshintergrund sollte eine komparative Beurteilung ihres nachbarschaftlichen Verhältnisses mit Landsleuten einerseits sowie mit „,anderen“" Migranten andererseits abgeben. Hierbei zeigt sich, dass bei intraethnischen Kontakten das größte Ausmaß an nachbarschaftlicher Harmonie zu konstatieren ist. Nur 5,4\% beurteilen ihre Nachbarschaftskontakte zu Landsleuten als eher oder sehr schlecht und bloß 12,5\% als mittelmäßig. Mit 54,5\% der Befragten, welche eine Bewertung als gut und 27,3\% welche sogar eine sehr gute Einschätzung abgeben, wird hier ein Spitzenwert an positiven Nachbarschaftsbeziehungen erreicht. Auch bei den Nachbarschaftskontakten innerhalb der eigenen ethnischen Community manifestieren sich ein Geschlechts- sowie ein Alterseffekt. 89,3\% der befragten Migrantinnen, aber nur 74\% der Migranten geben eine Beurteilung hinsichtlich ihrer nachbarschaftlichen Interaktionen mit Landsleuten als sehr gut/gut ab. Unter den Männern tritt die Klassifikation als eher/sehr schlecht mit 7,4\% erheblich öfter auf als bei den Frauen (3,6\%). Während kein einziger Immigrant im Alter ab 45 Jahren Kontakte zu aus seinem eigenen Herkunftsland stammenden Nachbarn als schlecht einstuft, tun dies immerhin 12,5\% der befragten Migranten im Alter bis 30 Jahre. 
Nicht ganz friktionsfrei präsentieren sich die nachbarschaftlichen Verhältnisse unterschiedlicher Migrantengruppen miteinander. Immerhin 12,1\% der Neoösterreicher und Ausländer bekunden hierbei, dass diese Beziehungen eher oder sogar sehr schlecht abschneiden. Mit 43,1\%, die eine Einstufung als gut oder sehr gut vornehmen, und weiteren 44,8\%, die ihre Interaktionen mit anderen Migranten im nachbarschaftlichen Kontext zumindest als mittelmäßig klassifizieren, wird aber dokumentiert, dass auch diese Kontakte in einem hohen Ausmaß als wenig spannungsgeladen einzustufen sind. Neuerlich manifestieren sich der Geschlechts- und der Alterseffekt. Exakt die Hälfte der Frauen mit Migrationsbiographie, aber nur 36,7\% der Männer aus dieser Subgruppe beurteilen ihre Kontakte zu anderen ausländischen Nachbarn als sehr gut bzw. gut. Eine Bewertung als schlecht geben bloß 3,6\% der Frauen, aber immerhin jeder fünfte Mann ab.

Auch für die Kontakte ausländischer Hausbewohner untereinander besitzt die simple Formel ,,je älter, desto harmonischer" Gültigkeit. Genau die Hälfte der Altersklasse über 50 Jahre, aber nur 44,4\% der Befragten bis 30 Jahre beurteilen die Interaktionen zu ihren anderen ausländischen Nachbarn als sehr gut/gut. Umgekehrt sind es $22,3 \%$ der jüngeren Altersklasse, aber deutlich weniger (6,3\%) über 45-Jährige, welche von einem schlechten nachbarschaftlichen Verhältnis sprechen.

\subsubsection{Kontaktintensitäten und -häufigkeiten im Bereich der Wohnnachbarschaft}

\section{Grundlegende Reflexionen}

Die Analyse der Spezifika des interethnischen nachbarschaftlichen Kontaktverhaltens bildete neben der Untersuchung der Konflikte einen der zentralen Schwerpunkte unseres Projektes. Die nachbarschaftlichen Interaktionsformen divergieren hinsichtlich der sozialen Nähe bzw. Distanz und bilden auf diese Weise ein Kontinuum von sehr distanzierten Formen des bloßen Kennens (Nachbarn vom Sehen kennen) und Umganges (Grüßen) bis zu sehr engen Sozialbeziehungen (Besuche, gemeinsame Aktivitäten).

Individualpsychologische Determinanten des Kontaktverhaltens sind in der individuellen Persönlichkeitsstruktur (Introversion, Extraversion) und der daraus resultierenden Kontaktbereitschaft zu orten. Weiters spielen zweifelsohne frühere persönlichen Interaktionserfahrungen und zahlreiche weitere Faktoren eine Rolle. Auf eine Erfassung dieser Einflussfaktoren wurde allerdings bewusst verzichtet.

Das Kontaktbedürfnis ist bei Personen unterschiedlichen Alters und Geschlechts sowie divergierenden familiären und bildungsmäßigen Hintergrundes äußerst unterschiedlich ausgeprägt. Sogar der Rechtstitel der Wohnungsinnehabung kann hierbei eine Rolle spielen. Bei Bewohnern von Eigentumswohnungen etablieren sich Nachbarschaftsbeziehungen, empirischen Befunden gemäß (Vierecke 1972; Schulz 1978: 29), häufig rascher als bei Mietern. Unterschiede sind weiters auch zwischen Neuund Altbauvierteln vorhanden (Heil 1971: 64 ff.; Weeber 1971; Vierecke 1972: 55 ff.), und naheliegenderweise repräsentiert auch die Wohndauer einen wichtigen Ein- 
flussfaktor der sozialen Integration und der Etablierung hausinterner Netzwerke der Bewohner (Kasarda \& Janowitz 1974 in Schulz 1978: 31).

\section{Kontakttypen im nachbarschaftlichen Interaktionskontext}

Neben der Kontakthäufigkeit stellt die Kontaktqualität eine wichtige Größe zur Beurteilung der interethnischen Nachbarschaftsbeziehungen dar. Das distanzierteste „Nachbarschaftsverhältnis“ manifestiert sich darin, die Nachbarn nur vom Sehen zu kennen, wobei - abgesehen von Ausnahmesituationen - keine darüber hinausgehenden Kontakte gepflegt werden. Die folgenden Auswertungen beziehen sich auf das gesamte Sample (ohne Differenzierung nach existierendem/nicht existierendem Migrationshintergrund), um zunächst eine Gesamtschau über das nachbarschaftliche Interaktionsgeschehen, wie es sich in unserem Sample widerspiegelt, zu bieten (vgl. Abb. 1).

Immerhin rund 45\% unserer Respondenten gaben an, alle (in- und ausländischen) Nachbarn nur vom Sehen zu kennen, wobei über die Gründe nichts weiter ausgesagt werden kann. Dieses Faktum deutet auf ein doch sehr distanziertes nachbarschaftliches Verhältnis nahezu der Hälfte der befragten Personen hin. Dieses Verhalten entspricht dem Typus ,, anonym “ der Klassifikation des nachbarlichen Distanzverhältnisses nach Heil (1971: 49). Diese relativ hohen Werte eines distanzierten Nachbarschaftsverhaltens sind nicht automatisch negativ zu interpretieren. Das nachbarschaftliche Sozialklima wird von vielen Menschen bei größerer Anonymität und nachbarlicher Distanz in der Regel sogar positiver bewertet (Weeber 1971: 65) - soziale Distanz wird nicht selten bewusst angestrebt (Herlyn 1970: 144).

Bezüglich des „Vom-Sehen-Kennens“ zeigen sich nur schwache wohnungsbestandsbezogene Trends. Im gründerzeitlichen Baubestand geben 92,3\% der Befragten an, alle inländischen Nachbarn vom Sehen zu kennen. 82,1\% der Mieter von Gründerzeitwohnungen artikulieren Analoges für die ausländischen Nachbarn. Im Gemeindebau kennen $90 \%$ der Respondenten ihre österreichischen Nachbarn vom Sehen, für $87,5 \%$ gilt dies gegenüber den ausländischen Mitbewohnern. Im Genossenschaftswohnbau belaufen sich die Prozentwerte auf $87,5 \%$ (inländische Nachbarn) bzw. 90,6\% (ausländische Nachbarn).

Der formelle Grußkontakt mit allen im Haus wohnhaften Personen ist die regelmäßigste nachbarschaftliche Rudimentärkommunikation. Diese wird von $100 \%$ der Gründerzeithausmieter, 96,9\% der Genossenschafts-/Eigentumswohnungen bewohnenden Befragten sowie von 97,5\% der Gemeindewohnungsmieter, die in gemischter Nachbarschaft leben, praktisch allen inländischen Hausbewohnern gegenüber praktiziert. Im Vergleich dazu wird der Grußkontakt gegenüber allen ausländischen Nachbarn im Gründerzeitmilieu (94,9\%) sowie im kommunalen Wohnbau (92,5\%) deutlich seltener gepflegt. Im Segment Genossenschaft/Eigentum besteht eine exakt gleich hohe Bereitschaft $(96,9 \%)$, nicht nur alle inländischen, sondern auch alle ausländischen Nachbarn zu grüßen. Der Grußaustausch stellt den Minimalstandard nachbarlichen Umgangs in der Großstadt dar und ist dem ,,zeremoniellen Nachbarschaftsverhalten " (Klages 1968: 127) zuzuordnen. Der Gruß ist zwar die häufigste, aber 
auch die unverbindlichste Kontaktvariante (Barre et al. 1977: 156). Er ist eine Kontaktform, die zugleich eine „,Frage des Anstandes wie des Abstandes ist“ (Pfeil 1959: 181). Dies entspricht bei einer Beschränkung des individuellen Nachbarschaftsverhaltens auf das Grüßen dem Kontakttypus der „Distanz“ (Heil 1971: 49). Der Gruß macht aus dem „,Nachbarn der faktischen Nähe“ einen „Nachbarn des kommunikativen Bezugs “ (Vierecke 1972: 47). Das Grußverhalten bildet das soziale Äquivalent zum räumlichen Faktor der Nähe (Vierecke 1972: 16) und resultiert aus der Einhaltung einer nachbarschaftlichen Verhaltensnorm. Dem Grußkontakt kommt vor allem die Funktion der Angstreduktion zu (Schulz 1978: 46).

Beim selektiveren Grußverhalten, das nur einen - nicht näher spezifizierten Teil der Wohnnachbarn (,einige Nachbarn“ gemäß dem Wortlaut des Fragebogens) einbezieht, sind Variationen zwischen den Wohnungsbestandskategorien vorhanden, einer Interpretation aber nur schwer zugänglich. Notorische Nichtgrüßer bilden in unserem Sample zwar nur eine kleine Minorität, es zeigt sich aber deutlich, dass die kategorische Grußverweigerung Ausländern gegenüber häufiger praktiziert wird als im Umgang mit inländischen Nachbarn.

Bezogen auf das gesamte Sample ist die Praxis, alle Nachbarn zu grüßen, mit $79,3 \%$ gegenüber Inländern und mit 78,4\% gegenüber Ausländern nahezu gleich häufig. Unterschiede bestehen beim selektiven Grußverhalten.

Grüßen bedeutet eine Form der Anerkennung in diffuser Form und stellt eine Basis dar, auf der Sozialkontakt intensiviert werden kann. Zwischen dem unverbindlichen Grüßen und unverbindlichen Gesprächen, welche die Überwindung einer gewissen sozialen Distanzschwelle erfordern, zeigt sich eine signifikante Reduktion der Häufigkeit. Während Grußbeziehungen lediglich einen Hinweis darstellen, dass man einander als Nachbar „,bestätigt“, repräsentieren Gespräche einen Indikator für einen engeren persönlichen Kontakt. ${ }^{25}$ Nur 55\% der Respondenten lassen sich auf kurze, zufällige Gespräche mit ihren inländischen Nachbarn ein und zeigen so ein Nachbarschaftsverhalten ,,reduzierter Distanz“ (Heil 1971: 49). Diese kurzen Gespräche sind in der Regel stark ritualisiert und beinhalten keine persönlich-emotionalen Themen.

Im Umgang mit Inländern zeigt sich in den drei Baubestandstypen nur eine geringe Variationsbreite bezüglich der Bereitschaft zu unverbindlichen Gesprächen (Gründerzeit: 53,8\%, Gemeindebau: 55\%, Genossenschaft/Eigentum: 56,3\%). Ausländern gegenüber ist die Bereitschaft zu belanglosen Gesprächen etwas geringer (49,5\%). Die Rate der Gesprächsverweigerung ist mit mehr als einem Drittel (34,2\%) im Umgang mit im Haus lebenden Ausländern signifikant höher als im Kontakt mit inländischen Hausbewohnern (25,2\%). Dies betrifft alle drei Baubestandskategorien, wobei der Unterschied im Segment Genossenschaft/Eigentum am deutlichsten ausfällt. Hier

25 Die nachbarschaftliche Interaktion unterliegt im urbanen Bereich einer Transformation von der Nachbarschaftshilfe, der meist nur mehr Marginalfunktion zukommt, zur Kommunikation, die durchaus weiterbesteht (Schulz zur Wiesch 1982: 260). 
verweigern bloß 31,3\% die Kommunikation mit inländischen Hausbewohnern, aber $40,6 \%$ führen niemals kurze Gespräche mit ausländischen Nachbarn. Niedrigere Verweigerungsraten hinsichtlich unverbindlicher Gespräche kennzeichnen das kommunikative Milieu im Gründerzeithaus (21,1\% führen keine Gespräche mit inländischen und exakt ein Drittel keine mit ausländischen Nachbarn) sowie im Gemeindebau (22,5\% gegenüber 30\% Kommunikationsverweigerer). Mit 53,1\% sind die Bewohner von Genossenschafts-/Eigentumswohnungen, aber auch die Gemeindewohnungsmieter $(52,5 \%)$ am ehesten bereit, kurze Gespräche mit ihren ausländischen Nachbarn zu führen. Am wenigsten wird diese Kommunikationsvariante im Gründerzeitmilieu (43,6\%) gepflegt.

Kommunikation privateren Inhalts (,lange, persönliche Gespräche“) wird im wohnnachbarschaftlichen Kontext nur mehr von 19,8\% aller Befragten gegenüber österreichischen Nachbarn und von 16,2\% gegenüber Ausländern gepflegt. In Gründerzeithäusern ist die Bereitschaft dazu gegenüber in- wie auch ausländischen Nachbarn mit $23,1 \%$ exakt gleich stark ausgeprägt. Im Gemeindebau $(22,5 \% \mathrm{zu} 17,5 \%)$ und vor allem in der Kategorie Genossenschaft/Eigentum (12,5\% zu 6,3\%) bleiben persönliche Gespräche viel eher dem Kontakt mit inländischen Nachbarn vorbehalten.

Zieht man unverbindliche und persönliche Gespräche zu einer Kategorie zusammen wie in Abbildung 1, so manifestieren sich folgende Unterschiede: In Gründerzeithäusern und im kommunalen Wohnbau werden Gespräche häufiger mit inländischen Nachbarn geführt. Die Relationen betragen 76,9\% zu 66,6\% im Gründerzeitmilieu sowie $77,5 \%$ zu 70\% in Gemeindebauten. Im Gegensatz dazu führen unsere in Genossenschafts- bzw. Eigentumswohnanlagen wohnhaften Befragten Gespräche viel eher mit ihren ausländischen $(59,4 \%)$ als mit den inländischen $(31,3 \%)$ Nachbarn.

Gefälligkeiten und Hilfeleistungen signalisieren den Übergang zu einem ,qualifizierten " (Vierecke 1972: 47) Nachbarschaftsverhältnis. Basis dafür ist eine Selektion unter den Nachbarn, die zu funktional bedingten Beziehungen führt (Schulz 1978: 16). Potentielle Akteure im Rahmen des Wohnumfelds können auf der Basis eines Selektionsprozesses zu funktional begründeten, primärgruppenhaften Sozialbeziehungen gelangen (Vierecke 1972: 68). Dieser Prozess der Selektion im Bereich des nachbarschaftlichen Solidaritätsverhaltens (Klages 1968: 127) lässt den Nachbarn als ,,typischen Nothelfer" (Weber 1956: 280) in Erscheinung treten. Dem Nachbarn wird die "Zuständigkeit" für unmittelbar auftauchende Probleme (,,immediate emergencies " nach Litwak \& Szeleny 1969 in Schulz 1978: 18) zugewiesen. Während 45,9\% der Befragten das Erbringen jeglicher Gefälligkeiten gegenüber inländischen Hausbewohnern verweigern, steigt der Anteil dieser Verweigerungshaltung auf 53,2\% im Umgang mit ausländischen Nachbarn. In Gemeindebauten (42,5\% zu 50\%) und im Bereich Genossenschaft/Eigentum (50\% zu 65,6\%) sind die diesbezüglichen Unterschiede besonders deutlich ausgeprägt. Auf jeden Fall sind die Befragten in einem ungleich höheren Maße bereit, kleine Gefälligkeiten (wie Ausleihe oder das Erteilen von Auskünften) zu erweisen als größere Hilfeleistungen. Gerade bei größeren Hilfestellungen zeigt sich ein krasses Missverhältnis zwischen der ohnehin nicht sehr hohen Bereit- 
schaft der Respondenten, diese österreichischen Nachbarn (9,9\%) gegenüber zu erweisen, und der noch geringeren Bereitschaft, Migranten Hilfe anzubieten (5,4\%). Die Relationen betragen 12,8\% zu 7,7\% im Gründerzeitmilieu, 10\% zu 7,5\% im kommunalen Wohnbau und 6,3\% zu 0\% im Genossenschafts- und Eigentumswohnbau.

„Enger Kontakt“" (vgl. Heil 1971: 49) in Form gegenseitiger Besuche und kollektiver Aktivitäten, aber auch durch Hinterlegung des Wohnungsschlüssels, was ein hohes Ausmaß an gegenseitigem Vertrauen voraussetzt, wird im nachbarschaftlichen Kontext nur von einer Minorität unserer Respondenten gepflegt. Besuchskontakte zu Nachbarn gelten als prekär; solche engen Kontakte folgen dem Prinzip der freien Wahl der Kontaktpartner und sind nicht automatisch in bloß durch räumliche Nähe vermittelte „Zwangskontakte“ eingebettet (vgl. auch Barre et al. 1977: 153 f.). Vielfach spielen auch eine diffuse Angst vor sozialer Kontrolle (Schulz 1978: 157) sowie das Bedürfnis nach Abgrenzung der Privatsphäre gegenüber den in permanenter räumlicher Nähe wohnenden Nachbarn eine Rolle. Intensive Kontakte mit Nachbarn werden häufig als ein Eindringen in die Privatsphäre und demzufolge als unerwünscht eingestuft (Weichinger et al. 1973: 49).

\section{Abbildung 1: Kontakttypen mit in- und ausländischen Nachbarn nach Baubestandskategorien}

\section{Gründerzeit}

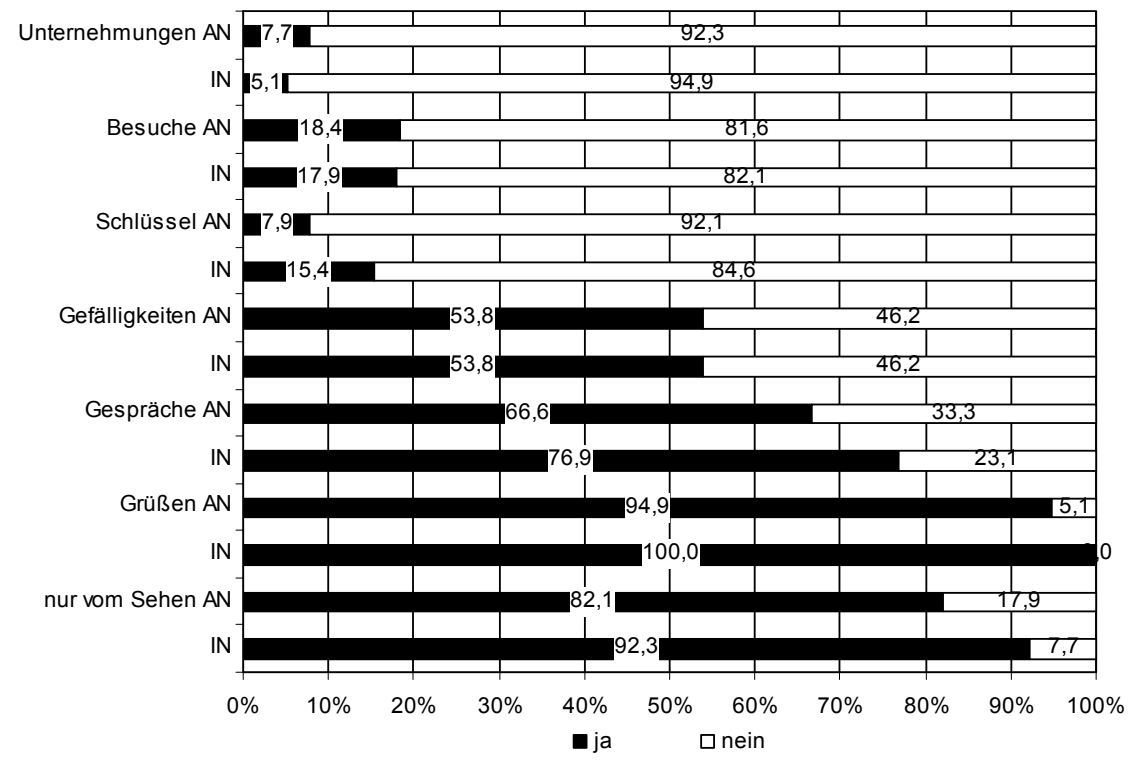




\section{Gemeindebau}

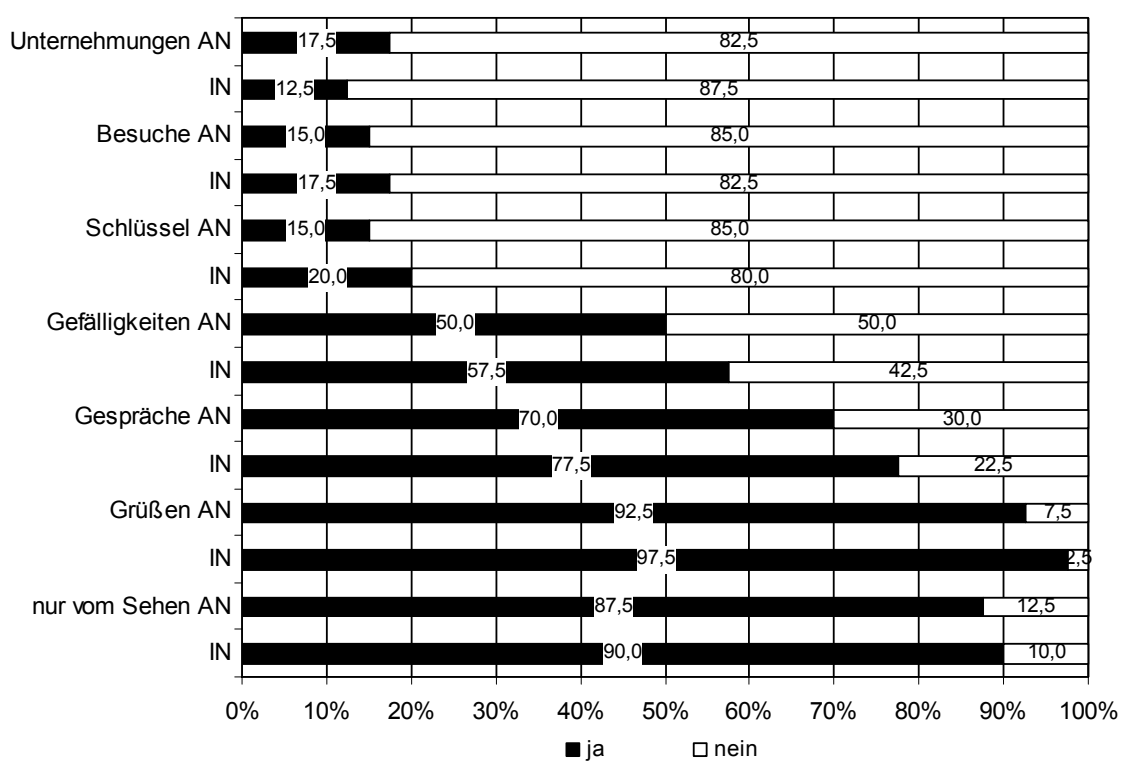

Genossenschaft, Eigentum

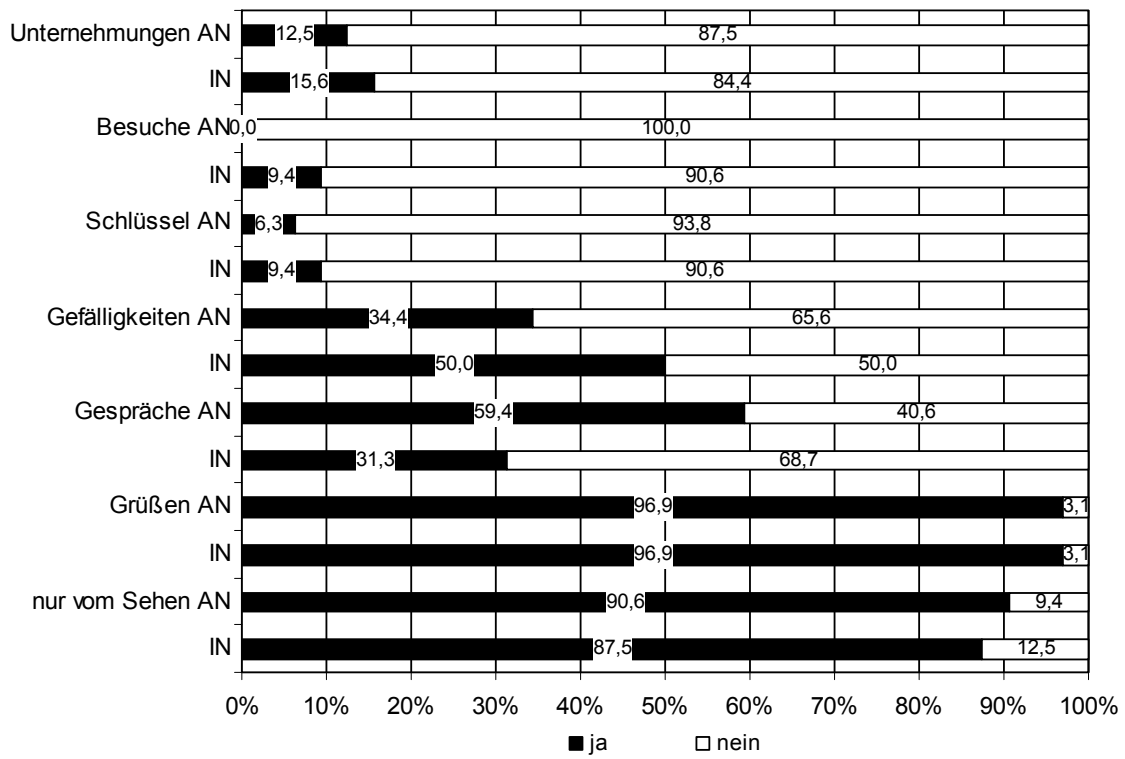

Quelle: Befragung 2005. AN = ausländische Nachbarn, IN = inländische Nachbarn. 
Die Hinterlegung des Wohnungsschlüssels während längerer Absenzen wird von $15,3 \%$ aller Befragten bei inländischen Nachbarn und von $10 \%$ bei Zuwanderern als Nachbarn praktiziert. Es zeigt sich, dass generell die Bereitschaft zur Schlüsselhinterlegung bei einem inländischen Nachbarn in allen drei Wohnungsbestandstypen größer ist (vgl. Abb. 1). In Gründerzeithäusern im Ausmaß von 15,4\% (bei einem Nachbarn mit Migrationshintergrund: 7,9\%); im Gemeindebau zu 20\% (15\%) und im Segment Genossenschaft/Eigentum zu 9,4\% (6,3\%).

Gegenseitige Besuche in der Wohnung werden - bezogen auf das gesamte Sample - von 15,3\% der Befragten gegenüber österreichischen Nachbarn und von 11,8\% gegenüber Migranten praktiziert. Die Divergenzen im Vergleich zwischen in- und ausländischen Nachbarn sind in den Wohnbautypen „Gründerzeit“ und „Gemeindebau“ nur marginal, manifestieren sich aber sehr deutlich im Bestandssegment „Genossenschaft/Eigentum“, wo zwar 9,4\% der Respondenten Besuchskontakte zu Österreichern im Haus pflegen, aber kein einziger (!) solche Kontakte zu einem Nachbarn mit Migrationshintergrund angibt.

Bezüglich gemeinsamer Aktivitäten mit Nachbarn außerhalb des Wohnbereichs im Freizeitkonnex zeigt sich, dass diese Interaktionsvariante wie alle engen Kontaktvarianten relativ selten ist und bloß von etwas mehr als einem Zehntel der Personen in unserem Sample praktiziert wird. In Gründerzeithäusern sowie in Gemeindebauten finden gemeinsame Unternehmungen jedoch häufiger mit Nachbarn mit Migrationshintergrund statt, in Genossenschaftsanlagen eher mit inländischen $(15,6 \%)$ als mit ausländischen Nachbarn (12,5\%).

Eine Analyse der Kontaktvarianten mit inländischen Nachbarn nach dem Kriterium eines vorhandenen bzw. nicht vorhandenen Migrationshintergrunds der jeweiligen Befragten lässt in zahlreichen Kontaktkategorien erhebliche Divergenzen erkennen (vgl. Tab. 10). Bereits bezüglich der distanziertesten Kontaktform, nämlich die meisten Nachbarn bloß vom Sehen zu kennen, sind es bei den Personen ohne Migrationshintergrund 40\%, aber bei jenen mit Migrationserfahrung immerhin 49,2\%, die ein solches Nachbarschaftsverhältnis für sich bekunden. Notorische Nichtgrüßer repräsentieren mit 2\% (Österreicher) bzw. 1,6\% (Migranten) in beiden Subgruppen eine vernachlässigbar kleine Minorität. Alle Nachbarn im Haus zu grüßen ist eine unter Inländern bei weitem häufiger verbreitete Usance als bei den Migranten in unserer Wiener Stichprobe. Letztere geben bloß zu 72,1\% an, allen Hausbewohnern einen Gruß zu entbieten, erstere zu immerhin 88\%. Migranten tendieren mit 26,1\% (gegenüber nur einem Zehntel der Österreicher) in viel höheren Ausmaß zu einem selektiven Grußverhalten, welches nur ,ausgewählte“ Nachbarn einbezieht.

Das Ausmaß der völligen Gesprächsverweigerung im nachbarschaftlichen Interaktionskontext ist mit 24\% (Österreicher) bzw. 26,2\% (Migranten) annähernd im gleichen Ausmaß ausgeprägt. Grundlegende Unterschiede sind jedoch hinsichtlich der beiden Gesprächskategorien, der kurzen zufälligen und der langen persönlichen, festzustellen. So bekunden nur $42 \%$ der Befragten ohne Migrationshintergrund, kurze Gespräche mit österreichischen Nachbarn zu führen. Unter den Migranten tun dies 
immerhin nahezu zwei Drittel (65,6\%). Dies kann demzufolge als ein wichtiger empirischer Beleg für die größere Bereitschaft vieler Migranten zu kommunikativen Kontakten gewertet werden. Etwas anders sieht es bei den intensiveren und auch die persönliche Sphäre touchierenden Gesprächen aus. Selbige werden von über einem Drittel $(34 \%)$ der Inländer mit anderen inländischen Nachbarn geführt, jedoch nur von $8,2 \%$ der Respondenten mit migratorischem Background. Äußerst krass unterschiedlich ist die Bereitschaft zu Erbringung von diversen kleineren oder größeren Gefälligkeiten ausgeprägt. Während nur ein Viertel der inländischen Befragten Österreichern gegenüber solche Gefälligkeiten nicht erweist, liegt unter den Migranten der diesbezügliche Prozentsatz bei $62,3 \%$ (!). Die Frage, ob dies mit einer grundsätzlichen diesbezüglichen Verweigerungshaltung zusammenhängt, im Kontext eines allgemein distanzierteren Nachbarschaftsverhältnisses zu Österreichern oder aber auch damit zusammenhängt, dass sich Inländer bezüglich Gefälligkeiten eher an inländische denn an immigrierte Nachbarn wenden, muss in diesem Zusammenhang unbeantwortet bleiben, da nach den Ursachen dieses Phänomens nicht gefragt wurde.

Auf jeden Fall werden sowohl kleinere (58\%) als auch größere Gefälligkeiten (16\%) von der Subgruppe ohne Migrationshintergrund den inländischen Nachbarn viel häufiger erwiesen, als dies Personen mit Migrationshintergrund tun (kleinere Gefälligkeiten: 32,8\%; größere: 4,9\%). Die eine erhebliche Vertrauensbasis voraussetzende Hinterlegung des Wohnungsschlüssels lässt ebenfalls gravierende Divergenzen zu Tage treten. Mit 96,7\% artikulierten nahezu alle befragten Migranten, dass es zu keiner gegenseitigen Hinterlegung des Wohnungsschlüssels mit österreichischen Hausbewohnern kommt, unter den Österreichern ist die Reziprozität der Schlüsselhinterlegung bei $30 \%$ sehr wohl der Fall. Gegenseitige Besuche innerhalb der Wohnung von inländischen Nachbarn werden von jedem fünften Befragten ohne Migrationserfahrung, aber nur von 11,5\% der Migranten bekundet. Bezüglich gemeinsamer Unternehmungen außerhalb der Wohnung sind die Unterschiede aber bloß marginal ( $10 \%$ bei Nichtmigranten, $11,5 \%$ bei Migranten). Diese Kategorie der Kontakte erfordert kein „Einbrechen“ in die Privatsphäre der Wohnung des Nachbarn und ist daher als weniger prekär zu bewerten als etwa gegenseitige Besuche.

Wie gestalten sich nun die Kontakte zu den ausländischen Nachbarn? Bei der distanziertesten Kontaktvariante, die auf dem Kennen der Nachbarn bloß vom Sehen basiert, bestehen nur äußerst geringe Unterschiede zwischen den beiden Subgruppen mit/ohne Migrationshintergrund. Etwas stärker, wenngleich undramatisch, treten Unterschiede im Grußverhalten zu Tage. Die Anteile der Nichtgrüßer variieren bloß geringfügig. Die Bereitschaft, alle (in diesem Fall ausländischen) Hausbewohner zu grüßen, ist - wie gegenüber den inländischen Nachbarn - wiederum bei den Österreichern mit (82\%) deutlich stärker ausgeprägt als bei den Migranten (75,4\%). Letztere huldigen in höherem Ausmaß (19,7\%; 12\% bei Inländern) einer selektiven Praxis des Grußaustausches (vgl. Tab. 10).

Aus statistischer Perspektive geringfügige Unterschiede bestehen auch hinsichtlich nachbarschaftlicher Kommunikation. Keine Gespräche mit ausländischen Nach- 
barn führen 32\% der Respondenten ohne Migrationshintergrund und 36,1\% derjenigen mit Migrationserfahrung. Zu kurzen, zufälligen Gesprächskontakten ist in beiden Gruppen etwa die Hälfte der Respondenten bereit. Intensivere persönliche Kommunikation mit ausländischen Nachbarn wird etwas häufiger (18\%) von Österreichern als von Migranten $(14,8 \%)$ gepflegt.

Tabelle 10: Kontakte mit in- und ausländischen Nachbarn nach vorhandenem/nicht vorhandenem Migrationshintergrund

\begin{tabular}{|c|c|c|c|c|c|c|c|}
\hline \multirow{4}{*}{ Nur vom Sehen } & \multirow{3}{*}{ nein } & \multicolumn{3}{|c|}{ Kontakte m. inländ. Nachb. } & \multicolumn{3}{|c|}{ Kontakte m. ausländ. Nachb. } \\
\hline & & ohne MH & mit MH & insg. & ohne MH & mit MH & insg. \\
\hline & & 14,0 & 6,6 & 9,9 & 14,0 & 13,1 & 13,5 \\
\hline & ja alle & 46,0 & 44,3 & 45,0 & 42,0 & 45,9 & 44,1 \\
\hline \multirow{4}{*}{ Grüßen } & ja einige & 40,0 & 49,2 & 45,0 & 44,0 & 41,0 & 42,3 \\
\hline & nein & 2,0 & 1,6 & 1,8 & 6,0 & 4,9 & 5,4 \\
\hline & ja alle & 88,0 & 72,1 & 79,3 & 82,0 & 75,4 & 78,4 \\
\hline & ja einige & 10,0 & 26,2 & 18,9 & 12,0 & 19,7 & 16,2 \\
\hline \multirow[t]{3}{*}{ Gespräche } & nein & 24,0 & 26,2 & 25,2 & 32,0 & 36,1 & 34,2 \\
\hline & ja kurz zufällig & 42,0 & 65,6 & 55,0 & 50,0 & 49,2 & 49,5 \\
\hline & ja lange pers. & 34,0 & 8,2 & 19,8 & 18,0 & 14,8 & 16,2 \\
\hline \multirow[t]{3}{*}{ Gefälligkeiten } & nein & 26,0 & 62,3 & 45,9 & 46,0 & 59,0 & 53,2 \\
\hline & kleinere & 58,0 & 32,8 & 44,1 & 46,0 & 37,7 & 41,4 \\
\hline & größere & 16,0 & 4,9 & 9,9 & 8,0 & 3,3 & 5,4 \\
\hline \multirow[t]{2}{*}{ Schlüssel } & nein & 70,0 & 96,7 & 84,7 & 86,0 & 93,3 & 90,0 \\
\hline & ja & 30,0 & 3,3 & 15,3 & 14,0 & 6,7 & 10,0 \\
\hline \multirow[t]{2}{*}{ Besuche } & nein & 80,0 & 88,5 & 84,7 & 90,0 & 86,7 & 88,2 \\
\hline & $\mathrm{ja}$ & 20,0 & 11,5 & 15,3 & 10,0 & 13,3 & 11,8 \\
\hline \multirow[t]{2}{*}{ Unternehmungen } & nein & 90,0 & 88,5 & 89,2 & 94,0 & 82,0 & 87,4 \\
\hline & ja & 10,0 & 11,5 & 10,8 & 6,0 & 18,0 & 12,6 \\
\hline
\end{tabular}

Quelle: Befragung 2005; MH = Migrationshintergrund.

Eine weitere enge Kontaktvariante lässt ebenfalls deutliche Unterschiede je nach vorhandenem oder nicht vorhandenem Migrationshintergrund hervortreten: die Ebene der Gefälligkeiten. 59\% der Migranten sind hierbei durch eine generelle Verweigerungshaltung gekennzeichnet. In der Subkategorie ohne Migrationserfahrung sind es $46 \%$, die ihren Nachbarn niemals Gefälligkeiten erweisen und exakt derselbe Prozentsatz ist zu kleineren Hilfestellungen bereit. Der Austausch größerer Gefälligkeiten tritt im wohnnachbarschaftlichen Kontext nur selten auf, allerdings sind 8,8\% der Befragten ohne Migrationserfahrung, jedoch bloß 3,3\% der Migranten ihren ausländischen Nachbarn gegenüber dazu bereit.

Die Hinterlegung des Wohnungsschlüssels bedarf eines erheblichen Vertrauensverhältnisses. Sie wird im Austausch mit ausländischen Nachbarn unter den Respon- 
denten ohne Migrationshintergrund in einem rund zweimal höheren Ausmaß (14\%) praktiziert als von jenen, die selbst in einem migratorischen Kontext stehen $(6,7 \%)$. Bei den beiden ebenfalls sehr engen Interaktionsvarianten der Besuche und der gemeinsamen Aktivitäten zeigt sich allerdings eine Trendumkehr, die einer Interpretation schwer zugänglich ist. Hier sind es viel eher die Respondenten mit migratorischem Background, die solche nachbarschaftlichen Interaktionen betreiben, nämlich 13,3\% bei den gegenseitigen Besuchen und sogar 18\% bei den kollektiven Aktivitäten. Die Österreicher in der Stichprobe unterhalten nur zu 10\% Besuchskontakte und 6\% sind auch zu Gemeinschaftsaktivitäten bereit.

Wie sieht nun das Interaktionsgeschehen, differenziert nach Befragten mit und ohne Migrationsbiographie und bezogen auf die drei Baubestandskategorien aus? Zunächst die Resultate für die Subgruppe ohne Migrationshintergrund. Alle inländischen Nachbarn nur vom Sehen zu kennen charakterisiert augenscheinlich in erster Linie die Nachbarschaftsbeziehungen in Gründerzeithäusern. Deutlich weniger oft wird diese distanzierte Version des nachbarschaftlichen Umgangs im kommunalen Wohnbau $(43,8 \%)$ sowie im Segment Genossenschaft/Eigentum (28,6\%) praktiziert. Einige inländische Nachbarn nur vom Sehen zu kennen ist bei der Hälfte der Befragten in der letztgenannten Wohnbaukategorie der Fall, aber nur bei jeweils etwas mehr als einem Drittel der Mieter in Gründerzeit- und Gemeindewohnhäusern. Alle ausländischen Nachbarn nur vom Sehen zu kennen, geben jeweils exakt $50 \%$ der Respondenten in Gemeindebauten und Gründerzeithäusern an, aber bloß 21,4\% der Bewohner des Bestandssegments Genossenschaft/Eigentum. Dafür artikulieren fast zwei Drittel der Bewohner in der letztgenannten Baukategorie, dass sie einige ausländische Nachbarn nur vom Sehen kennen. In Gemeindebauten und im gründerzeitlichen Baubestand sind die Prozentanteile mit 31,3 bzw. 40\% erheblich geringer. Alle inländischen Nachbarn zu grüßen ist im gründerzeitlichen Baubestand mit $95 \%$ am stärksten ausgeprägt, seltener im kommunalen Wohnbau (87,5\%) und wird am wenigsten im Baubestand Genossenschaft/Eigentum $(78,6 \%)$ praktiziert. Eine analoge Hierarchie, allerdings mit etwas schwächeren prozentuellen Ausprägungen, tritt zu Tage, wenn es um das Grüßen der ausländischen Nachbarn geht: 90\% tun dies in Gründerzeithäusern, $81,3 \%$ im Gemeindebau und 71,4\% in Genossenschafts-/Eigentumswohnhäusern.

Kurze und zufällige Gesprächskontakte werden von der Subgruppe ohne Migrationshintergrund in allen drei Baubestandskategorien häufiger ausländischen als inländischen Nachbarn gegenüber praktiziert: im Gründerzeitmilieu zu 25\% gegenüber Inländern und zu 30\% gegenüber Migranten, im kommunalen Wohnbau zu 62,5\% gegenüber Österreichern und zu 68,8\% gegenüber Nichtösterreichern, im Wohnbausegment Genossenschaft/Eigentum zu 42,9\% mit Inländern und zu 57,1\% mit Zuwanderern. Als Kommunikationspartner für intensivere, persönliche Gespräche werden von den Befragten ohne Migrationsbackground eindeutig die inländischen Nachbarn bevorzugt - und dies in allen drei Wohnungsbestandsklassen. So führen $45 \%$ der Gründerzeitmieter persönliche Gespräche mit inländischen Nachbarn, aber nur 30\% mit Migranten im Haus. Unter den Gemeindewohnungsmietern betragen die prozen- 
tuellen Anteile 31,3\% gegenüber 12,5\% und in der Kategorie Genossenschaft/Eigentum $21,4 \%$ zu 7,1\%.

Im Bereich der kleinen und größeren Gefälligkeiten ist ein analoges Gefälle nachweisbar, welches wiederum in allen drei Wohnungsbestandskategorien aufritt. Ein Beispiel: Exakt drei Viertel der in Gemeindewohnungen lebenden Befragten erweisen inländischen Nachbarn gerne kleine Gefälligkeiten, ausländischen Nachbarn gegenüber sinkt der entsprechende Anteil auf 56,3\% ab. Noch krasser tritt die Distanzierung gegenüber zugewanderten Nachbarn bei den engeren Kontaktvarianten in Erscheinung. So würden 30\% der Gründerzeitmieter ohne Migrationshintergrund ihren Wohnungsschlüssel bei einem österreichischen Nachbarn hinterlegen, aber nur jeder zehnte würde selbiges bei einem immigrierten Nachbarn tun. Für den kommunalen Wohnbau belaufen sich die Relationen auf 43,8\% zu 25\% und in Genossenschaftsbauten auf 14,3\% zu 7,1\%. Die Tendenz zur stärkeren Distanzierung der Befragten ohne Migrationshintergrund gegenüber nichtösterreichischen Nachbarn findet in der Kontaktkategorie der gegenseitigen Besuche ihre Fortsetzung. Jeder vierte Gründerzeitwohnungsmieter besucht inländische Nachbarn in deren Wohnung, jedoch tun dies nur 15\% bei ausländischen Mitbewohnern. Ganz ähnlich verhalten sich die Relationen unter den Gemeindewohnungsmietern. Wohnungseigentümer sind ohnehin nur zu 7,1\% bereit, inländische Nachbarn zu besuchen. Besuchskontakte zu Nachbarn mit Migrationshintergrund unterhält kein einziger im Sample.

Die Subgruppe der Respondenten mit Migrationshintergrund verhält sich differenzierter nach Baubestands- und Interaktionskategorien. Dies manifestiert sich bereits auf der Ebene der Grußkontakte. In Gründerzeithäusern sind es fast $90 \%$, die alle inländischen Nachbarn grüßen, aber nur $84,2 \%$, die auch allen ausländischen Hausbewohnern einen Gruß entbieten. Im Gegensatz dazu sind 70,8\% der in Gemeindebauten lebenden Migranten bereit, alle ausländischen Nachbarn zu grüßen, während nur 58,3\% diese Bereitschaft auch allen österreichischen Hausbewohnern gegenüber an den Tag legen. Im Baubestand von Genossenschaft/Eigentum besteht diesbezüglich kein Unterschied. 72,2\% bekunden, sowohl alle in- als auch alle ausländischen Nachbarn zu grüßen.

Auch Gespräche werden je nach Wohnungsbestandsklasse in unterschiedlichem Ausmaß eingegangen. In allen drei Kategorien sind kurze, unverbindliche Gespräche mit inländischen Nachbarn häufiger als mit Zuwanderern. Die prozentuellen Relationen betragen für die Gründerzeithäuser $84,2 \% \mathrm{zu} 57,9 \%$, für die Gemeindebauten $50 \%$ zu 41,7\% und für die Eigentumswohnungen 66,7\% zu 50\%. Längere Gespräche werden von Migranten in Gründerzeit- und Gemeindewohnhäusern deutlich öfter mit Ausländern geführt, nämlich zu 15,8\% (zu 0\% mit Inländern) und zu 20,8\% (16,7\% mit Inländern). In Genossenschafts- und Eigentumshäusern zeigt sich in diesem Punkt kein Unterschied (jeweils 5,6\%).

In Bezug auf kleinere und größere Gefälligkeiten sind die Resultate überaus heterogen. Die Gründerzeitmieter mit Migrationshintergrund erweisen ihren zugewanderten Nachbarn gegenüber viel häufiger (47,4\%) Gefälligkeiten, als sie dies Inländern 
gegenüber (31,6\%) tun. Bei den größeren Gefälligkeiten besteht mit jeweils 5,3\% kein Unterschied. Auch im kommunalen Wohnbau werden größere Gefälligkeiten zu $4,2 \%$ in- und ausländischen Nachbarn gegenüber gleich gerne erbracht, bei kleineren Gefälligkeiten zeigen die befragten Migranten eine leichte Präferenz (33,3\% gegenüber 29,2\%) für ihre Nachbarn mit Migrationshintergrund. Im Baubestand von Genossenschaften und Eigentümern werden von den Migranten kleine Gefälligkeiten sogar etwas öfter (38,9\%) den Inländern als den Zuwanderern (33,3\%) gegenüber erbracht. Auch bei den größeren Hilfeleistungen ist eine Präferenz für die inländischen Nachbarn zu konstatieren. Die Schlüsselhinterlegung ist insgesamt unter den befragten Migranten sehr selten, die diesbezüglichen Resultate sind daher wenig aussagekräftig. Gegenseitige Besuche finden in etwas größerer Häufigkeit statt. In Gründerzeithäusern und in Gemeindewohnbauten werden diese Kontaktvarianten von Migranten untereinander häufiger gepflegt als gegenüber inländischen Nachbarn. Beispielsweise liegen die Relationen im Gründerzeithaus bei 22,2 zu 10,5\%, im kommunalen Wohnbau bei 16,7 zu 12,5\%. In Genossenschafts-/Eigentumsbauten ist genau das Gegenteil der Fall. Besuche von Migranten untereinander finden hier gar nicht statt. Besuche von Zuwanderern bei inländischen Nachbarn zu 11,1\%. Eine analoge Tendenz manifestiert sich bezüglich der Treffen außerhalb der Wohnung.

Resümierend ist festzustellen, dass seitens der Befragten ohne Migrationshintergrund in allen drei Baubestandskategorien, jedoch in variierenden Ausprägungen, eine Präferenz für die inländischen Nachbarn besteht. Diese werden sowohl als Kommunikationspartner für intensivere, persönliche Gespräche bevorzugt, auch Gefälligkeiten werden ihnen gegenüber häufiger erwiesen und sehr enge Kontaktformen, die ein hohes Ausmaß an Vertrauen erfordern, wie die Hinterlegung des Schlüssels, erfolgen vor allem bei inländischen Nachbarn.

Diese etwas größere soziale Distanz ist aber nicht automatisch gleichzusetzen mit einem höheren Konfliktpotential, wie die nachfolgenden Auswertungen zur KonfliktPerformance belegen werden. Die Unterschiede nach Baubestandskategorien sind vorhanden, allerdings nicht sehr aussagekräftig. Seitens der Befragten mit Migrationshintergrund sind die baubestandsspezifischen Divergenzen pointierter. Die Führung längerer Gespräche erfolgt in Gründerzeit- und Gemeindewohnhäusern eher zwischen Migranten. Diese erbringen kleine Gefälligkeiten auch öfter anderen $\mathrm{Zu}$ wanderern gegenüber als Inländern - dasselbe gilt für gegenseitige Besuche.

\subsubsection{Ethnisch strukturierte Konflikte im Interaktionsfeld der Wohnnachbarschaft - Frequenzen, Kausalfaktoren und Sanktionen}

Aus dem Nebeneinanderwohnen in ethnisch gemischter Nachbarschaft resultieren nicht nur Kontakte, sondern naturgemäß auch Konflikte. In welchem Ausmaß dies bei unseren Befragten der Fall ist, aus welchen Ursachen interethnische Nachbarschaftskonflikte vor allem entstehen und welches Konfliktmanagement zum Einsatz kommt, waren die primären Forschungsfragen. Mit anderen Worten: Das Interesse galt der 
„Performance“ des interethnischen Konfliktgeschehens. Es sollte der Frage nachgegangen werden, wie schwerwiegend das Konfliktpotential in ethnisch ,gemischter“ Nachbarschaft, welches sich in unserem Sample widerspiegelt, tatsächlich ist.

Welche Ursachen haben Nachbarschaftskonflikte vor allem? Ausgehend von den Resultaten deutscher Vergleichsstudien (Hemmer \& Leminsky 1974; Gleichmann 1976; Korte 1979; Hübschle 1980; Eichener 1988) war von „migrantenspezifischen“ Konfliktursachen, die im Zusammenhang mit einem anderen Wohnverhalten (z.B. infolge eines höheren Ausmaßes an Außenorientierung) stehen, auszugehen. Zu Vergleichszwecken wurden daher sowohl die Konfliktgründe mit österreichischen als auch die mit ausländischen Wohnungsnachbarn erhoben.

Auch in deutschen Vergleichsstudien (z.B. Eichener 1988: 126) wurden in erster Linie „Lärm“ (durch hohe Kinderzahl, häufigeren Besuch, intensiveres Sozialverhalten) und „Schmutz“ (Hemmer \& Leminsky 1974: 46 f.; Hübschle 1980: 162; Eichener 1988: 132) als die wichtigsten direkten Störungen interethnischen Zusammenlebens genannt. Die von Eichener (1988: 125 f.) in den RAG-Befragungen angesprochenen Merkmale des Wohnverhaltens vieler Zuwanderer (höheres Niveau der Affektivität, ausgeprägtere Orientierung an Outdoor-Freizeitgestaltung und an Kommunikation außerhalb der Wohnung, Erfahrungsdefizite im Umgang mit Haustechnik und mit Bereichen gemeinsamer Nutzung, eher extrinsische Orientierung des Wohnverhaltens und geringere Anpassung an rechtlich-abstrakte Regeln u. a.) spiegeln sich in den Befragungsergebnissen ebenfalls wider. Diese weniger rigoros disziplinierten Verhaltensstandards treffen auf inländertypische Verhaltensnormen im Wohnbereich, die als , hochgradig diszipliniert" (Gleichmann 1976; Korte 1979) bezeichnet werden können. Aus der Kollision dieser divergierenden Normen und der Verletzung ungeschriebener Verhaltenscodes resultieren Störungen und Konflikten, es kommt aber auch zur Stigmatisierung und Zuschreibung eines Außenseiterstatus. Die vielfach stärkere Orientierung auf den Außenbereich in Bezug auf Freizeit und Kommunikation macht die zugewanderten Nachbarn nach außen hin sichtbarer - bereits ihre bloße Anwesenheit kann als massive Störung der Ordnungsvorstellungen inländischer Hausbewohner aufgefasst werden.

Im Rahmen der Konflikthäufigkeit mit österreichischen und ausländischen Nachbarn wurde in etlichen Fragen, wenngleich nicht in allen, nicht nur nach den persönlichen Konflikten der Respondenten gefragt, sondern auch nach deren Einschätzung der entsprechenden Verhältnisse im Haus insgesamt. Die Befragten traten also nicht nur als persönlich Betroffene, sondern quasi zugleich auch als „Experten“ in der Beurteilung des Nachbarschaftsmilieus im Haus auf. ${ }^{26}$ Dieser Zugang wurde gewählt, da erstens auf Basis einer Zufallsstichprobe nicht mit Sicherheit angenommen werden

26 Eine analoge Fragenkomposition in Bezug auf die Erhebung des Nachbarschaftsverhältnisses wählte das Bundesamt für Bauwesen und Raumordnung (BBR) im Rahmen seiner Befragungen von 1993, 1995 und 1996 (vgl. Böltken 1999). 
konnte, eine nennenswerte Zahl von Respondenten mit sehr häufigen/häufigen Nachbarschaftskonflikten (vor allem mit Migranten) abzudecken, ${ }^{27}$ und zweitens, da die Annahme nahelag, dass sich aus der „Distanz des Experten“ auch existente persönliche Konflikte der Befragung leichter erschlossen. So konnten persönliche Konflikte „undramatisch“ angegeben werden und somit der aus der „,sozialen Erwünschtheit“ eines reibungslosen Nachbarschaftsverhältnisses resultierende Verfälschungseffekt minimiert werden.

Ein bemerkenswertes Faktum stellt der hohe Anteil an völlig konfliktfreien Nachbarschaftsverhältnissen dar. 39,6\% der Interviewten stufen das Verhältnis zu ihren inländischen Mitbewohnern in „Mischhäusern“ als völlig konfliktfrei ein, nahezu die Hälfte $(49,5 \%)$ hat sehr oder eher selten Konflikte mit österreichischen Nachbarn und nur $10,8 \%$ geben an, dass sich Konflikte mit Österreichern oft oder sehr oft ereignen. ${ }^{28}$ Hier zeigen sich allerdings einmal mehr Unterschiede bezüglich der drei untersuchten Respondentengruppen. Während nur 5,7\% der ausländischen Staatsbürger sehr oft/oft Friktionen mit österreichischen Nachbarn austragen und mit $8 \%$ auch nur relativ wenige Inländer häufige Konflikte mit anderen Inländern angeben, sind es $23 \%$ der Neoösterreicher, die oft oder sehr oft in Konflikte mit inländischen Wohnungsnachbarn geraten. Sie sind es auch, die im geringsten Ausmaß (34,6\%) angeben, nie in diesbezügliche Konflikte verwickelt zu sein, während 40\% der Ausländer und $42 \%$ der österreichischen Respondenten ein völlig konfliktfreies Verhältnis zu ihren österreichischen Nachbarn pflegen. Von eher/sehr seltenen Konflikten mit im Haus wohnenden Österreichern berichten 54,2\% der ausländischen und 50\% der inländischen Befragten, aber nur 42,3\% der Eingebürgerten.

Konflikte mit Migranten als Nachbarn treten in summa noch seltener auf als solche mit Österreichern. Mehr als die Hälfte unserer Respondenten $(52,3 \%)$ hatte zum Erhebungszeitpunkt noch niemals Konflikte mit zugewanderten Mitbewohnern im Haus, bei 39,6\% war dies eher/sehr selten der Fall und nur 8,1\% sprachen davon, dass solche Friktionen sich sehr oft/oft ereignen würden. Auch hierbei lassen sich empirisch gruppenspezifische Variationen nachweisen. Am häufigsten sind es wiederum die Neoösterreicher, die in Konflikt mit ihren ausländischen Nachbarn geraten. $15,3 \%$ von ihnen hatte bereits oft/sehr oft solche Auseinandersetzungen, gegenüber bloß $8 \%$ der Österreicher und nur 2,9\% der befragten Ausländer. Sehr hoch sind in allen drei Gruppen die Anteile jener, die noch nie Konflikte mit Migranten im Wohnumfeld ausgetragen haben: am höchsten bei den Österreichern (54\%), immerhin $51,4 \%$ bei den ausländischen Respondenten und exakt die Hälfte bei den Eingebür-

27 Für Deutschland (alte und neue Bundesländer) bestätigte beispielsweise Böltken (1999) auf der Grundlage der BBR- und MARPLAN-Erhebungen, dass manifeste interethnische Konflikte in Nachbarschaft und Wohngebietsalltag relativ selten sind.

28 Die diesbezügliche Frage lautete: „Hatten Sie oder Ihre Familie schon Konflikte mit österreichischen oder ausländischen Nachbarn und wenn ja wie häufig?" 
gerten. Von eher oder sehr seltenen Friktionen berichten 45,7\% der Ausländer, 38\% der Inländer und 34,6\% der Neoösterreicher.

Dies bedeutet also, dass die Konfliktfrequenz der Österreicher in unserem Sample mit zugewanderten Nachbarn deutlich geringer ist als die Konflikthäufigkeit mit anderen Österreichern im unmittelbaren Wohnumfeld. Das höchste Konfliktpotential sowohl mit in- als auch mit ausländischen Nachbarn geben die Neoösterreicher an.

\subsubsection{Nachbarschaftliche Konfliktfrequenz nach Wohnungsbestandskategorien}

In einer unserer Arbeitshypothesen sind wir von der bislang unbestätigten Annahme ausgegangen, dass die Konfliktfrequenz in unterschiedlichen Baubestandskategorien unterschiedlich sein könnte. Die Kausalfakatoren dieser Annahme bildete in erster Linie die Berichterstattung in den Printmedien, welche immer wieder auf ein erhebliches interethnisches Konfliktpotential vor allem in den Wiener Gemeindebauten hinweist (z.B. Lohmeyer \& Wetz 2005: 15). Wie steht es also tatsächlich mit der Qualität des Nachbarschaftsverhältnisses im Gemeindebau, in gründerzeitlichen Zinshäusern sowie in Genossenschafts- und Eigentumswohnhäusern rezenteren Errichtungsdatums? Lässt sich empirisch nachweisen, dass ethnisch strukturierte Nachbarschaftskonflikte in unterschiedlichen Wohnbaukategorien in unterschiedlichem Ausmaß auftreten und wenn ja, welche Kausalfaktoren sind dafür primär verantwortlich zu machen?

Faktum ist, dass in unserem Sample die Konfliktfrequenz mit ausländischen Nachbarn in gründerzeitlichen Mietshäusern sowie in Gemeindebauten am geringsten ist (vgl. Abb. 2). Die Mittelwerte der Konflikthäufigkeit belaufen sich in diesen beiden Baubestandskategorien auf Werte von 3,23 bzw. 3,22. 10,3\% der Befragten, die in einem Gründerzeithaus wohnhaft sind, berichten von oft stattfindenden Konflikten mit ausländischen Wohnungsnachbarn. Dem steht allerdings der Befund gegenüber, dass mit 56,4\% hier auch der höchste Anteilswert jener Respondenten zu Hause ist, gemäß deren Angaben Konflikte mit ausländischen Nachbarn niemals stattfinden. Wie sieht es nun damit im oftmals geschmähten Gemeindebau aus? Mit 55\% ist der Anteil jener, die von niemals auftretenden Konflikten berichten nahezu analog hoch wie im gründerzeitlichen Wohnsektor. Mit 7,5\% der Gemeindebaubewohner, die sehr oft/oft stattfindende Auseinandersetzungen angeben, ist die Kategorie der häufigen Konfliktfrequenz im kommunalen Wohnbau etwas schwächer besetzt als in gründerzeitlichen Mietshäusern, andererseits aber etwas stärker als in den Genossenschafts- bzw. Eigentumsanlagen $(6,3 \%)$. In letzteren treten Spannungen mit ausländischen Hausbewohnern mit einem arithmetischen Mittel von 3,03 am häufigsten auf. Bloß 43,8\% der Befragten im Genossenschaftssektor geben an, dass sich interethnische Konflikte niemals ereignen. Es sind also vor allem die Häufigkeitsklassen „eher selten“ und „sehr selten", in denen sich die Unterschiede zwischen den Wohnungsbestandskategorien manifestieren. Exakt 50\% der Befragten aus Genossenschafts-/Eigentumswohnungen geben eher oder sehr selten stattfindende Konflikte mit Migranten im Haus an. Von den Gemeindewohnungsmietern artikulieren 37,5\% eine analoge Einschätzung, gegenüber exakt einem Drittel der Mieter in Gründerzeithäusern. 
Abbildung 2: Häufigkeit von Konflikten mit ausländischen Nachbarn nach Baubestandskategorien

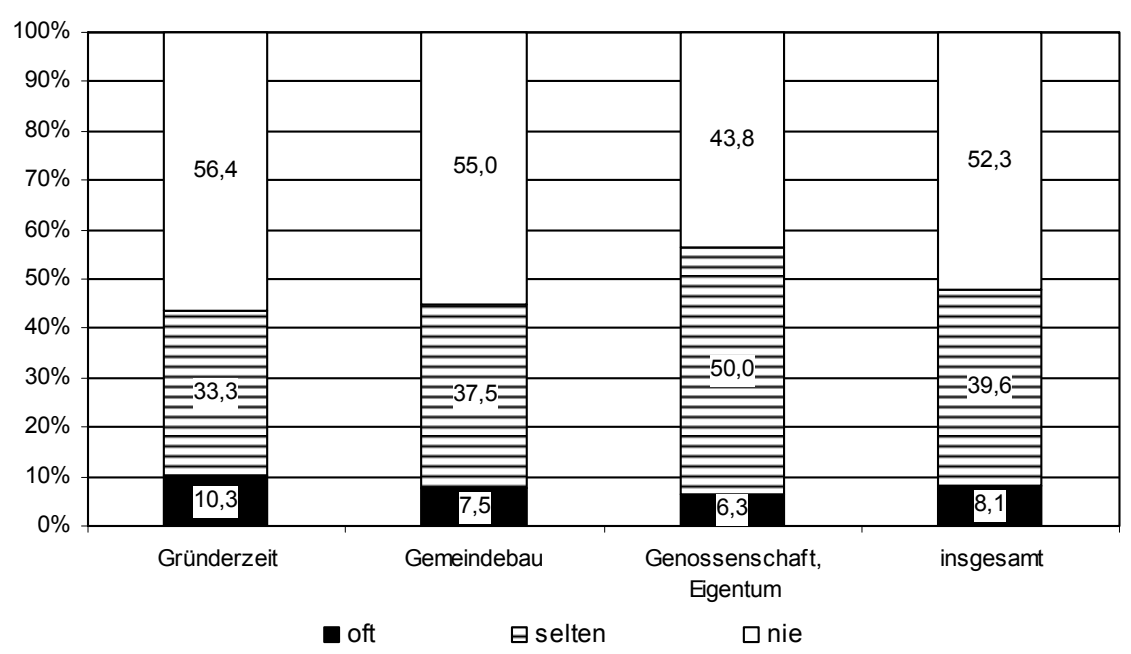

Quelle: Befragung 2005.

Abbildung 3: Häufigkeit von Konflikten mit österreichischen Nachbarn nach Baubestandskategorien

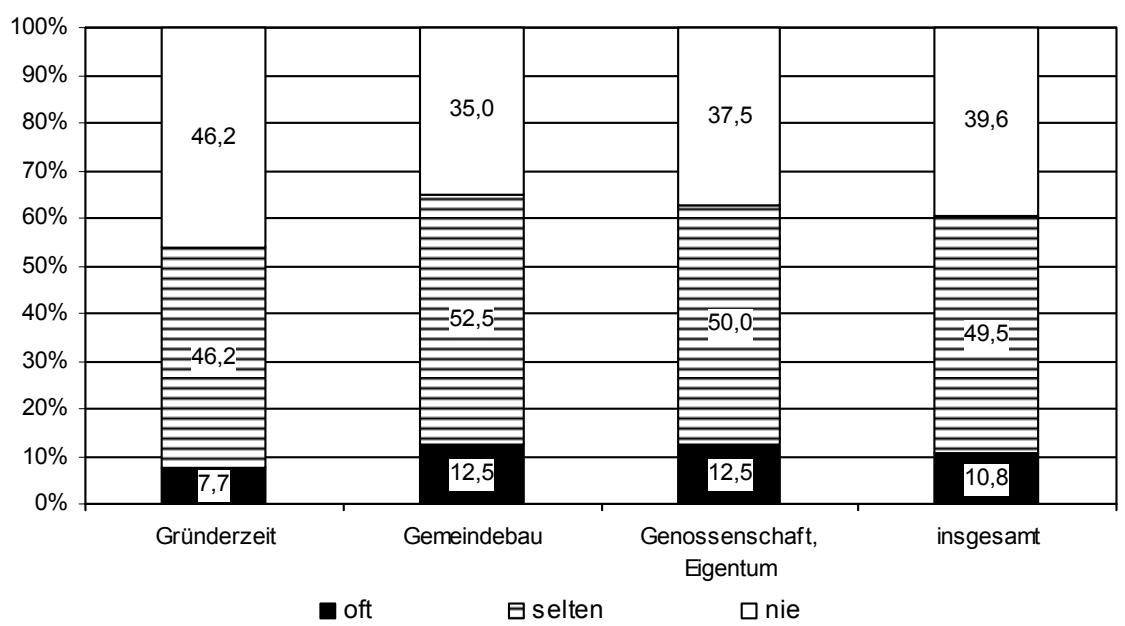

Quelle: Befragung 2005.

Wie steht es nun im Vergleich dazu mit den Konflikten mit österreichischen Nachbarn (vgl. Abb. 3)? Zum Zwecke des wohnungsbestandsbezogenen Vergleichs ist 
auch hier eine Mittelwertanalyse aufschlussreich. Hierbei zeigt sich, dass die höchste Konfliktfrequenz im kommunalen Wohnsektor $(\bar{x}=2,78)$ sowie im Wohnbautyp Genossenschaft/Eigentum $(\bar{x}=2,88)$ vorzufinden ist. Jeweils $12,5 \%$ der in diesen beiden Wohnbaukategorien wohnhaften Respondenten gaben an, dass Friktionen mit inländischen Nachbarn oft/sehr oft stattfinden. In gründerzeitlichen Mietshäusern $(\bar{x}$ $=3,12$ ) waren es bloß 7,7\%, die eine analoge Einschätzung abgaben. Hier ist auch der höchste Anteil jener Befragten angesiedelt, die angaben, dass sich hausinterne Konflikte mit Österreichern niemals ereignen würden, nämlich 46,2\%. Im rezenteren Wohnbausegment von Eigentum und Genossenschaft waren nur 37,5\% dieser Meinung, von den Mietern kommunaler Wohnungen 35\%. Bezüglich der Kategorien ,eher selten“ und „sehr selten“ zeigen sich spezifische Variationen. Ein Schwergewicht in der Klasse „sehr selten“ (mit 30,8\%) im Gründerzeitwohnbau (eher selten 15,4\%) sowie eine nahezu analoge Verteilung in den beiden anderen Wohnungsbestandskategorien. Im Bestandssegment Eigentum/ Genossenschaft tendiert jeweils ein Viertel der Befragten zu den Konfliktfrequenzklassen „eher selten“ sowie „sehr selten“, im Gemeindebau ebenfalls ein Viertel zu ,sehr selten“ und 27,5\% zu ,eher selten“.

Wie eine Gegenüberstellung der beiden Abbildungen 2 und 3 dokumentiert, sind die Unterschiede hinsichtlich der Konflikthäufigkeit mit in- und ausländischen Nachbarn zwar vorhanden, weisen allerdings in eine andere Richtung, als durch die Berichterstattung in den Massenmedien eigentlich erwartbar wäre. Bezogen auf das gesamte Sample geben 10,8\% häufige Konflikte mit im Haus wohnhaften Inländern an (bei ausländischen Nachbarn nur 8,1\%), 49,5\% berichten von seltenen und 39,6\% von keinerlei Friktionen. Mit Anteilen von 39,6\% (seltene Konflikte) und 52,3\% (keine Konflikte) schneiden Nachbarn mit Migrationshintergrund in Bezug auf die Konflikthäufigkeit deutlich besser ab. Gerade im oftmals geschmähten Gemeindebau treten Spannungen mit inländischen Hausparteien deutlich öfter auf als solche mit Mietern mit Migrationshintergrund. 55\% der befragten Kommunalwohnungsmieter gaben an, dass Konflikte mit immigrierten Nachbarn niemals stattfinden, nur 7,5\% sprachen von solchen Konflikten als einem oft/sehr oft stattfindenden Ereignis. Gegenüber österreichischen Mitbewohnern sind Friktionen in 12,5\% der Fälle häufig/sehr häufig und treten nur zu 35\% niemals auf. Deutlich, wenngleich in eine andere Richtung weisend, auch die diesbezüglichen Unterschiede im gründerzeitlichen Wohnungsbestand, dem im Kontext des ethnisch gemischten Wohnens mitunter ein besonders hohes Ausma $\beta$ an Integrationspotential zugeschrieben wird: Hier treten Friktionen mit Migranten zwar zu 10,3\% oft/sehr oft auf (gegenüber 7,7\% mit inländischen Nachbarn), andererseits sind 56,4\% (bei inländischen Nachbarn nur 46,2\%) der Gründerzeithäuser auch völlig konfliktfrei in Bezug auf Spannungen mit im Haus lebenden Zuwanderern. Im Wohnsegment Genossenschaft/Eigentum sind vor allem österreichische Hausbewohner in Konflikte involviert. 12,5\% der Respondenten geben sehr häufige/häufige Spannungen mit inländischen Nachbarn an, nur 6,3\% berichten von gleichermaßen häufigen Konflikten mit Mitbewohnern mit migratorischem Background. 
Keinerlei Konflikte mit zugewanderten Hausparteien geben 43,8\% der Respondenten an, nur 37,5\% berichten von keinen Friktionen bezogen auf inländische Nachbarn.

\subsubsection{Die nachbarschaftliche Konflikthäufigkeit nach Baubestandskategorien sowie differenziert nach vorhandenem/nicht vorhandenem Migrationshintergrund}

Die folgenden Auswertungen entsprechen angesichts der relativ geringen Fallzahlen nicht den strengen Anforderungen der deskriptiven Statistik, es zeigen sich aber Tendenzen, die durchaus interessant sind. Im gründerzeitlichen Baubestand, den 39 unserer Respondenten (20 Österreicher, 7 Neoösterreicher, 12 ausländische Staatsbürger) bewohnen, ist zwar die Kategorie häufiger Konflikte mit 10,3\% für die Migranten etwas stärker besetzt als für die Inländer (7,7\%), andererseits ist die völlige Absenz von durch Zuwanderer verursachten Konflikten mit 56,4\% erheblich höher als im Fall der inländischen Nachbarn (46,2\%). Es sind die Eingebürgerten, die die höchsten nachbarschaftlichen Konfliktfrequenzen sowohl mit in- als auch mit ausländischen Nachbarn angeben. 42,9\% der Neoösterreicher haben oft Konflikte mit Migranten. Bei den befragten Österreichern beträgt der entsprechende Anteilswert bloß 5\% (!) und fast zwei Drittel (65\%) der inländischen Bewohner von Gründerzeitmietwohnungen haben sogar niemals Konflikte mit ihren zugewanderten Mitbewohnern.

\section{Abbildung 4: Gründerzeitliche Mietshäuser: Konflikte mit österreichischen und ausländischen Nachbarn nach vorhandenem/nicht vorhandenem Migrationshintergrund}

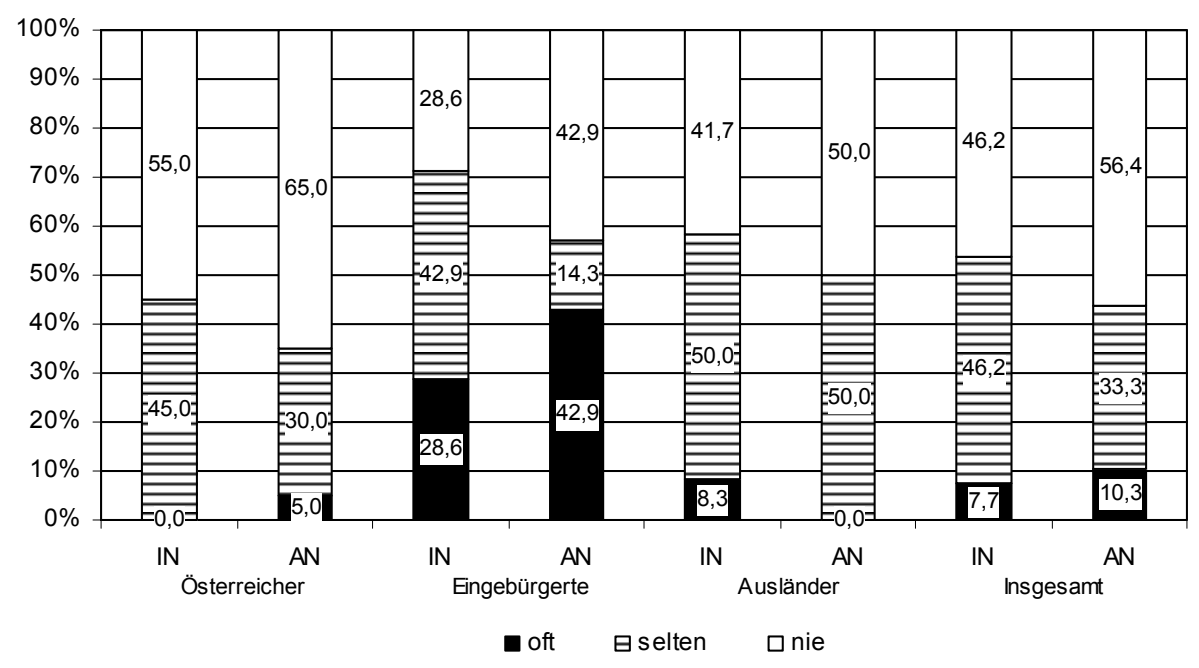

Quelle: Befragung 2005; IN = inländische Nachbarn, AN = ausländische Nachbarn. 
In diesem Baubestandssegment wohnhafte Ausländer haben zu jeweils der Hälfte keine bzw. seltene Konflikte mit immigrierten Nachbarn. Auch im Umgang mit inländischen Nachbarn sind es wiederum die Eingebürgerten, die die höchste Konflikthäufigkeit aufweisen: $28,6 \%$ von ihnen geben oftmalige Friktionen mit österreichischen Hausparteien an, gegenüber nur $8,3 \%$ bei den befragten Ausländern im Gründerzeitmilieu und keinem einzigen Österreicher, der mit anderen Inländern im nachbarlichen „Dauerclinch“ läge. Nur 28,6\% der Neoösterreicher geraten niemals in Konflikte mit österreichischen Nachbarn. Dagegen pflegen 41,7\% der Ausländer und $55 \%$ der Inländer ein friktionsfreies nachbarschaftliches Nebeneinander mit den im Haus wohnhaften Österreichern (vgl. Abb. 4).

\section{Abbildung 5: Gemeindebau: Konflikte mit österreichischen und ausländischen Nachbarn nach vorhandenem/nicht vorhandenem Migrationshintergrund}

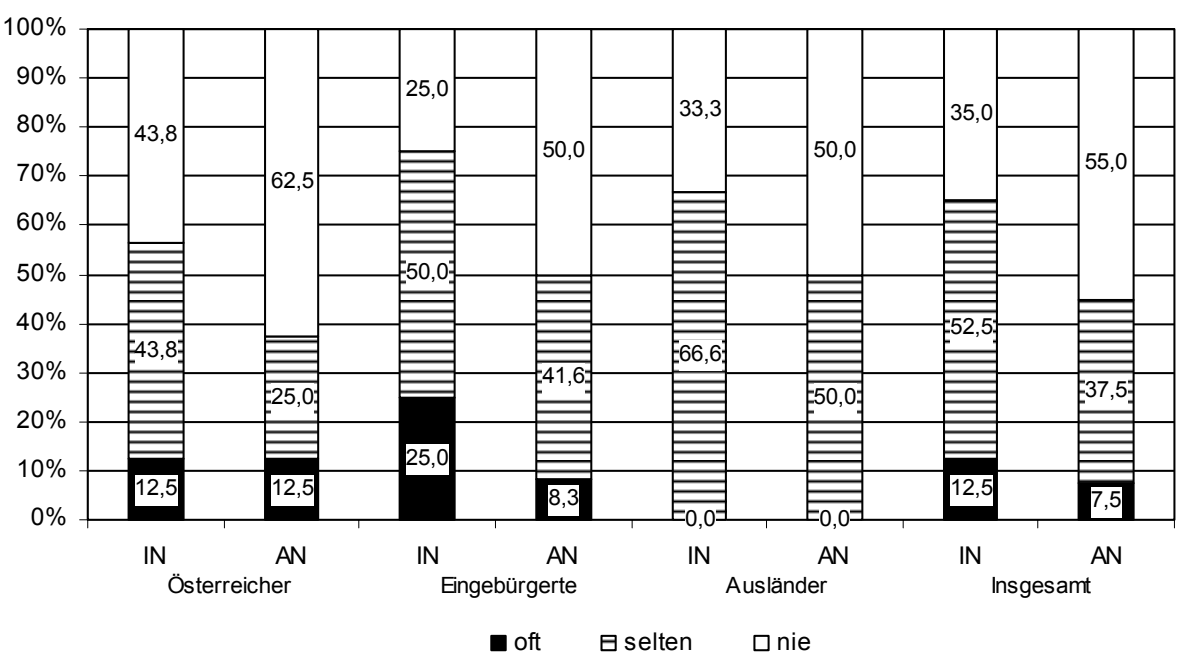

Quelle: Befragung 2005; IN = inländische Nachbarn, AN = ausländische Nachbarn.

Im Gemeindebau, wo 40 unserer Respondenten (16 Österreicher, 12 Eingebürgerte und 12 Ausländer, letztere als Familienangehörige oder Partner/-innen bereits eingebürgerter Hauptmieter oder als Bewohner so genannter „Notfallwohnungen“) ihren Wohnsitz haben, geben zwar 55\% keinerlei Konflikte mit ausländischen Wohnungsnachbarn, aber nur 35\% selbiges für die inländischen Nachbarn an. Auch im kommunalen Wohnbau treten die Neoösterreicher als die Subgruppe mit der höchsten nachbarschaftlichen Konfliktfrequenz hervor, allerdings im Vergleich weniger krass als in den gründerzeitlichen Mietwohnungen. Jeder vierte Neoösterreicher, aber kein einziger in einer Gemeindewohnung wohnhafter Ausländer ist oft in Streitigkeiten mit seinen österrreichischen Nachbarn verwickelt (vgl. Abb. 5). Nur ein Viertel der Eingebürgerten, aber ein Drittel der Ausländer hatten bis zum Erhebungszeitpunkt noch nie 
Konflikte mit Inländern im Haus. Zwei Drittel der ausländischen Respondenten geben aber seltene Konflikte an. Das Nachbarschaftsverhältnis der Österreicher untereinander ist durch eine große Bandbreite der Konflikthäufigkeit charakterisiert: 12,5\% der inländischen Befragten sprechen von oftmaligen Friktionen und jeweils 43,8\% von seltenen bzw. niemals stattfindenden Auseinandersetzungen mit anderen Österreichern im Wohnbereich.

Die Konflikte mit Nachbarn mit Migrationshintergrund werden im Gemeindebau am häufigsten von inländischen Mietern ausgetragen, wobei sich auch eine deutliche Polarisierung konstatieren lässt (vgl. Abb. 5). Während 12,5\% der inländischen Mieter von Kommunalwohnungen oftmalige Auseinandersetzungen mit Ausländern im Haus angeben, sind es umgekehrt beachtliche $62,5 \%$, die von keinerlei interethnischen Nachbarschaftskonflikten berichten. Die Neoösterreicher im Gemeindebau haben zu immerhin 8,3\% oft nachbarschaftliche Verdrießlichkeiten mit ausländischen Nachbarn, während die Hälfte von ihnen nie diesbezügliche Konflikte austrägt. Unter den ausländischen Kommunalwohnungsbewohnern haben jeweils die Hälfte keine bzw. seltene Konflikte mit anderen Ausländern im Haus.

\section{Abbildung 6: Eigentums-/Genossenschaftswohnungen: Konflikte mit österreichischen und ausländischen Nachbarn nach vorhandenem/nicht vorhandenem Migrationshintergrund}

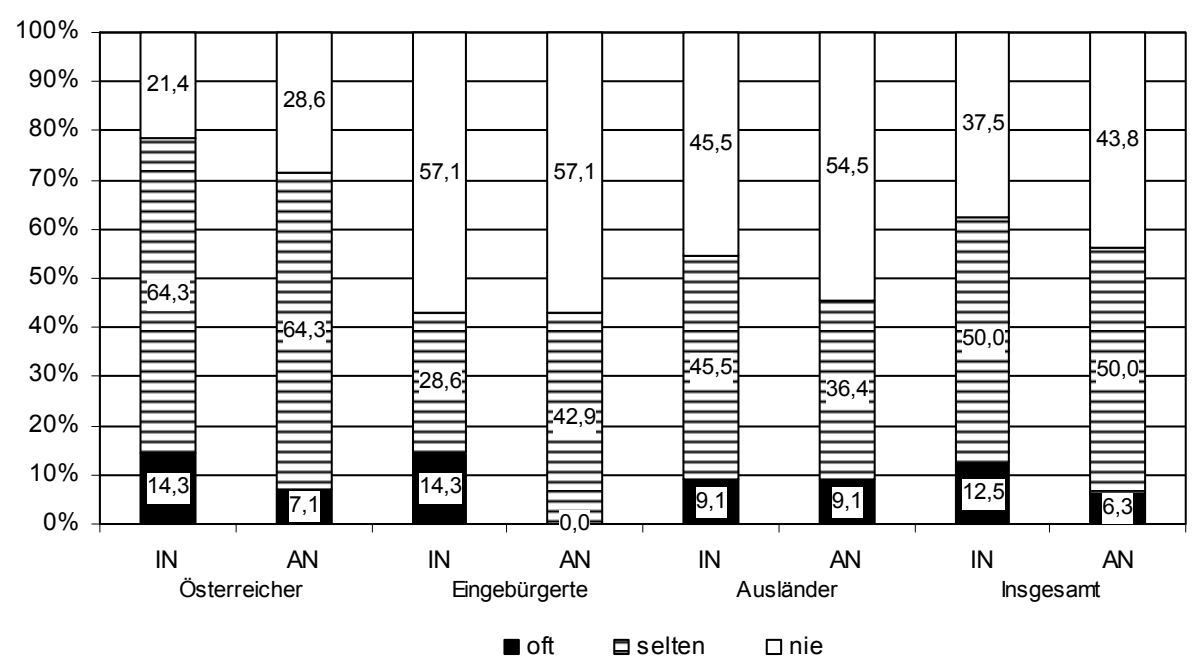

Quelle: Befragung 2005; IN = inländische Nachbarn, AN = ausländische Nachbarn.

In der Wohnungsbestandskategorie Genossenschaft/Eigentum präsentiert sich bezüglich der nachbarschaftlichen Konfliktfrequenz ein anderes Bild. Oftmalige Konflikte mit zugewanderten Hausbewohnern werden in erster Linie von ausländischen $(9,1 \%)$ sowie österreichischen $(7,1 \%)$ Respondenten ausgetragen - kein einziger Ein- 
gebürgerter gibt häufige Konflikte an (vgl. Abb. 6). Im Gegenteil, mit 57,1\% sind es vor allem die Neoösterreicher, die völlig konfliktfrei mit ihren immigrierten Nachbarn zusammenleben. Nahezu zwei Drittel $(64,3 \%)$ der in diesem Wohnungsbestandssegment ansässigen Inländer sowie mehr als ein Drittel $(36,4 \%)$ der Ausländer geben immerhin seltene Konflikte an. Gänzlich konfliktfrei gestaltet sich das Verhältnis zu den zugewanderten Nachbarn bei mehr als der Hälfte (54,5\%) der Ausländer, allerdings nur für 28,6\% der Inländer.

Friktionen mit österreichischen Nachbarn (12,5\% ,oft“) sind in Eigentums- und Genossenschaftswohnungen häufiger anzutreffen als solche mit Nachbarn mit Migrationsbackground $\left(6,3 \%, \mathrm{oft}^{\text {“ }}\right)$, wobei selbstverständlich davon auszugehen ist, dass die im Durchschnitt geringere Zahl von in diesem Wohnbausegment ansässigen Migranten als Determinante dieser niedrigeren Konflikthäufigkeit eine nicht zu unterschätzende Rolle spielen dürfte (vgl. Abb. 6). Jeweils 14,3\% der österreichischen und der eingebürgerten Befragten geben oftmalige Friktionen mit österreichischen Hausparteien an. Unter den Ausländern liegt der entsprechende Anteilswert bei nur 9,1\%. Gänzliche Konfliktfreiheit mit Inländern wird von $57,1 \%$ der Neoösterreicher und 45,5\% der Ausländer, aber bloß von 21,4\% der Österreicher angegeben. Bei letzteren liegt das Schwergewicht auf seltenen Konflikten (64,3\%). Ebenfalls seltene Spannungen mit österreichischen Mitbewohnern werden von $45,5 \%$ der ausländischen und $28,6 \%$ der eingebürgerten Bewohner von Genossenschafts- oder Eigentumswohnungen artikuliert.

\subsubsection{Die Einschätzung des nachbarschaftlichen Konfliktmilieus im Wohnhaus aus der Perspektive der Befragten}

Im Rahmen unserer Erhebung interessierte uns nicht nur das Ausmaß an persönlich erlebten und ausgetragenen Konflikten unserer Respondenten mit ihren Nachbarn, sondern auch das allgemeine Konfliktmilieu im Haus. Es wurde also nicht nur nach den persönlichen Konflikten der Respondenten gefragt, sondern nach deren Einschätzung der entsprechenden Verhältnisse im Haus insgesamt. Die Befragten traten also quasi als „Experten“ in der Beurteilung des Nachbarschaftsmilieus im Haus auf. Dieser Zugang, der sich bereits in anderen Befragungen ${ }^{29}$ bewährt hatte, wurde erstens gewählt, da auf Basis einer Zufallsstichprobe nicht mit zwingender Notwendigkeit angenommen werden konnte, eine nennenswerte Zahl von Respondenten mit häufigen Nachbarschaftskonflikten aufzufinden, und zweitens, da die Annahme nahelag, dass sich aus der „Distanz des Experten“ auch existente persönliche Konflikte der Befragung leichter erschlossen. So konnten persönliche Konflikte „undramatisch“ angegeben werden und somit der aus der „,sozialen Erwünschtheit“ eines reibungslosen Nachbarschaftsverhältnisses resultierende Verfälschungseffekt minimiert werden.

29 Vgl. die Befragung der Autoren im Rahmen des Forschungsschwerpunktes „Fremdenfeindlichkeit" des bm:bwk. 
Konkret wurde allerdings nicht nur nach Österreicher-Migranten-Friktionen gefragt, sondern das Konfliktmilieu als solches sollte, basierend auf den persönlichen Einschätzungen der Respondenten, abgebildet werden, wobei Auseinandersetzungen zwischen österreichischen Hausparteien ebenso wie solche zwischen immigrierten Nachbarn erhoben wurden. Faktum ist, dass sich hierbei nach Wohnungsbestandskategorien divergierende Konfliktmilieus nachweisen ließen (vgl. dazu die Abb. 7-9).

Das interethnische Konfliktmilieu unterteilt sich je nach Interaktionspartnern in drei Subkategorien:

1) Konflikte zwischen Österreichern und zugewanderten Nachbarn aus einem bestimmten Herkunftsland,

2) Konflikte zwischen Österreichern und zugewanderten Nachbarn aus unterschiedlichen Herkunftsländern sowie

3) Konflikte zwischen Nachbarn ausländischer Herkunft.

\section{Abbildung 7: Einschätzung der Konflikthäufigkeit zwischen unterschiedlichen Gruppen von Nachbarn: Gründerzeithäuser}

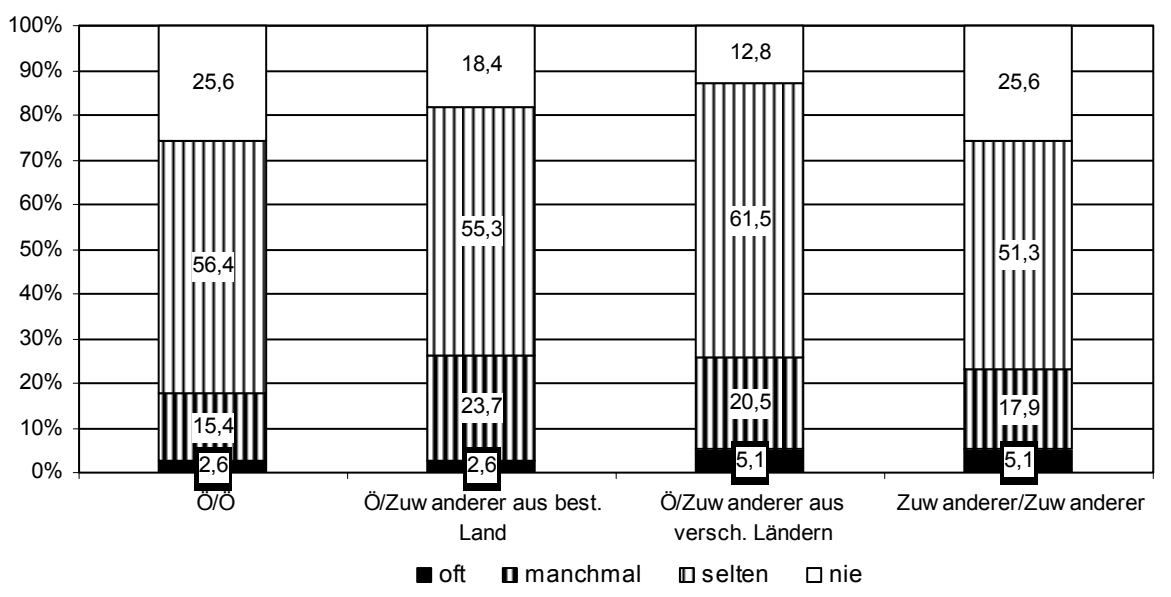

Quelle: Befragung 2005.

Ergänzend wurden auch die Konflikte zwischen im jeweiligen Haus wohnhaften Inländern erhoben. Was diese anbelangt so zeigt sich, dass gemäß der Einschätzung unserer Befragten vor allem in den Gemeindebauten, aber auch im Genossenschaftsund Eigentumswohnungssektor solche Konflikte deutlich öfter stattfinden als im gründerzeitlichen Baubestand. Im Wohnungsbestand der Stadt Wien finden ÖsterrreicherÖsterreicher-Konflikte zu 7,5\% oft und zu 17,5\% manchmal statt. Im Wohnsegment Genossenschaft/Eigentum zu 3,1\% oft und zu 28,1\% manchmal, hingegen in Gründerzeithäusern bloß zu 2,6\% oft und zu 15,4\% manchmal. Die völlige Absenz solcher Auseinandersetzungen wird von jeweils einem Viertel der Gründerzeitmieter und der 
Wohnungseigentümer sowie von 22,5\% der Gemeindebaumieter angegeben (vgl. Abb. 7-9). Rein österreichische Nachbarschaftskonflikte sind also am häufigsten im kommunalen Wohnbau $(\bar{x}=1,90)$ sowie in Genossenschafts-/Eigentumswohnhäusern $(\bar{x}=$ 1,91). Am seltensten treten sie in Gründerzeitbauten auf $(\bar{x}=2,05)$.

\section{Abbildung 8: Einschätzung der Konflikthäufigkeit zwischen unterschiedlichen Gruppen von Nachbarn: kommunaler Wohnbau}

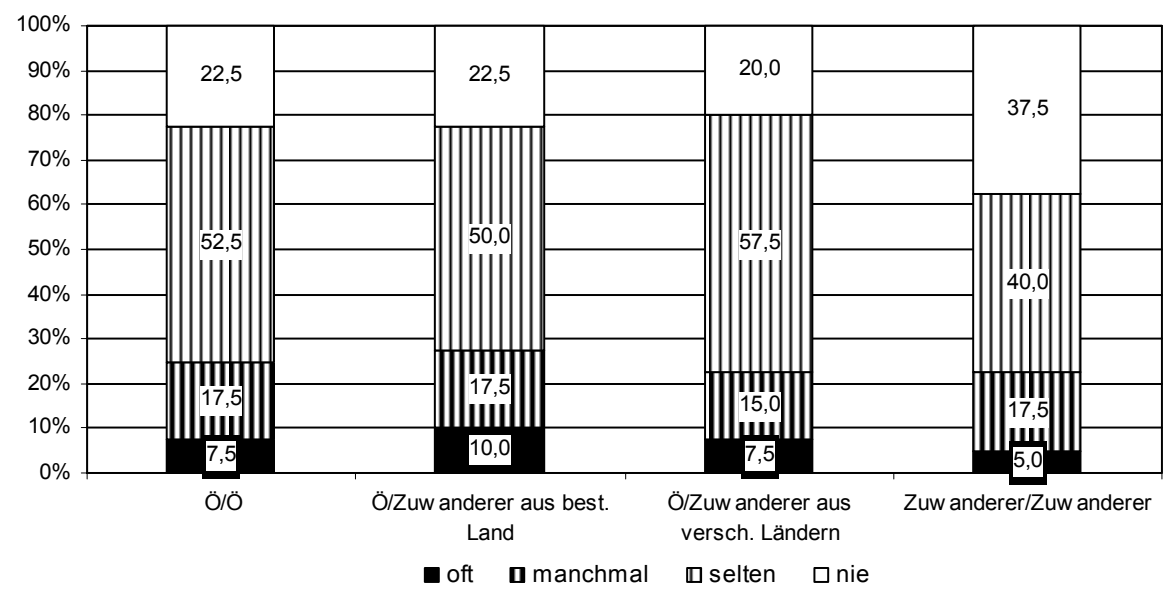

Quelle: Befragung 2005.

Wie sieht es nun mit den Nachbarschaftskonflikten zwischen Österreichern und ihren immigrierten Nachbarn aus einem bestimmten Herkunftsland aus? Aus Gründen der geringen Samplegröße wurde bei dieser Frage auf eine nähere Spezifikation des Herkunftslandes verzichtet, um den Zellenbesatz nicht zu sehr zu verringern und empirische Analysen damit zu verunmöglichen. Die daraus abzuleitenden Resultate repräsentieren dadurch zwar eine simplifiziertes Abbild der sozialen Realität, lassen aber - insbesondere durch den Vergleich mit den Resultaten betreffend Nachbarn aus unterschiedlichen Herkunftsländern - Schlussfolgerungen über die Strukturierung von Konfliktmilieus zu. Im Gemeindebau treten gemäß unserer Erhebung Konflikte zwischen Inländern und ausländischen Nachbarn aus einem jeweils bestimmten Land zu $10 \%$ oft auf. In Gründerzeithäusern $(2,6 \%)$ und in der Kategorie Genossenschaft/Eigentum $(3,1 \%)$ ist diese Häufigkeitsklasse weit schwächer besetzt. Niemals treten solche Konflikte vor allem im Bereich Genossenschaft/Eigentum (28,1\%) auf. 22,5\% der Gemeindebaumieter und 18,4\% der Bewohner privater Zinshäuser können sich auch an keinerlei derartige Auseinandersetzungen erinnern. Zieht man die beiden Kategorien „manchmal“ und „selten“ zu einer zusammen, so sind es in erster Linie die Gründerzeithäuser (79\%), in denen solche Konflikte in dieser Häufigkeit auftreten. Die entsprechenden Anteile betragen im Bereich Genossenschaft/Eigentum 68,7\%, im kom- 
munalen Wohnbau 67,5\% (vgl. Abb. 7-9). Der Mittelwertvergleich dokumentiert, dass die Einschätzung der interethnischen Konfliktfrequenz für den Gemeindebau $(\bar{x}=$ $1,85)$ am höchsten ist, gefolgt vom Gründerzeitsegment $(\bar{x}=1,89)$. Am seltensten ist diese Kategorie von Friktionen im Genossenschafts-/Eigentumssektor $(\bar{x}=1,94)$.

Abbildung 9: Einschätzung der Konflikthäufigkeit zwischen unterschiedlichen Gruppen von Nachbarn: Genossenschafts- und Eigentumswohnbauten

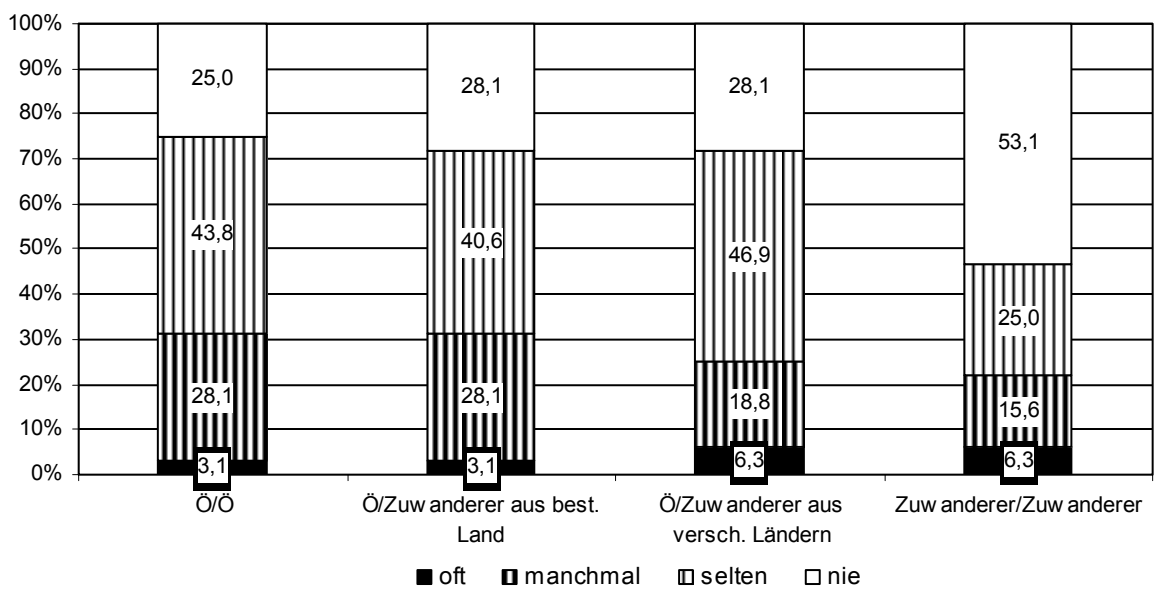

Quelle: Befragung 2005.

Das nachbarschaftliche Konfliktmilieu zwischen Inländern und immigrierten Nachbarn unterschiedlicher Provenienz ist folgendermaßen zu bewerten: Die Analyse der Mittelwerte belegt, dass solche Friktionen am öftesten im Gründerzeitmilieu $(\bar{x}$ $=1,82)$ auftreten, etwas seltener im kommunalen Wohnbau $(\bar{x}=1,90)$ und am seltensten in Genossenschafts-/Eigentumshäusern $(\bar{x}=1,97)$. Die Kategorie „oft“ ist im Gemeindebau mit 7,5\% besetzt, etwas schwächer im Baubestandssegment Genossenschaft/Eigentum (6,3\%) und noch schwächer im Gründerzeitbau (5,1\%). Wo sind solche Konflikte unseren Respondenten gemäß nie zu finden? Hier führt mit 28,1\% Genossenschaft/Eigentum, gefolgt von einem Fünftel der Bewohner von Gemeindebauten und $12,8 \%$ in gründerzeitlichen Wohnbauten. Führt man erneut eine Kontraktion der Kategorien „selten“ und „manchmal“ durch, so ist es primär das gründerzeitliche Zinshaus, in dem zu 82\% derartige Konflikte gelegentlich auftreten (im Gemeindebau zu 72,5\%, im Sektor Genossenschaft/Eigentum zu 65,7\%) (vgl. Abb. 7-9).

Im Kontext des interethnischen nachbarschaftlichen Konfliktmilieus spielen auch Konflikte zwischen ausländischen Nachbarn unterschiedlichster Herkunft eine Rolle. Diese Konflikte treten in Gründerzeitbauten am häufigsten $(\bar{x}=1,97)$, etwas seltener in Gemeindewohnhäusern $(\bar{x}=2,10)$ und am seltensten in Genossenschafts- 
/Eigentumswohnbauten ( $\bar{x}=2,25)$ auf. Bezogen auf das gesamte Sample ereignen sich Friktionen zwischen immigrierten Nachbarn zu 5,4\% oft. In den drei untersuchten Wohnbaukategorien bestehen hinsichtlich der Anteile oftmaliger Konflikte nur geringe Unterschiede. Insgesamt 37,8\% geben an, dass solche Friktionen niemals auftreten, wobei dies vor allem für die Kategorie Genossenschaft/Eigentum (53,1\%) gilt, etwas weniger für den Gemeindebau (37,5\%) und noch weniger für das Gründerzeithaus (25,6\%). Mit 40,6\% manchmal bzw. selten vorhanden sind solche Auseinandersetzungen im Bereich Genossenschaft/Eigentum. Auf 57,5\% beläuft sich der entsprechende Prozentanteil im kommunalen Wohnbau und auf 69,2\% in den Gründerzeithäusern (vgl. Abb. 7-9).

\subsubsection{Verursacher und Kausalfaktoren von nachbarschaftlichen Konflikten}

Wir haben unseren Respondenten im Rahmen einer Frage ${ }^{30}$ eine Liste mit den unterschiedlichsten, möglichen nachbarschaftlichen Konfliktursachen vorgelegt. Sie sollten angeben, ob die betreffenden Konfliktursachen in ihrem Wohnhaus eine Rolle im nachbarschaftlichen Konfliktgeschehen spiel(t)en und ob die Urheberschaft den im Haus wohnhaften Österreichern oder den Immigranten zuzuschreiben sei.

Eine allgemeine Analyse des nachbarschaftlichen Konfliktgeschehens, die zunächst eine Differenzierung der Konflikte nach deren Urheberschaft noch ausklammert, also In- und Ausländer betrifft, gelangt zu dem Resultat, dass Lärm $(23,4 \%)$ mit Abstand die dominierende Konfliktursache in Wiener Hausgemeinschaften darstellt (vgl. Abb. 10).

Daran schließt sich eine erhebliche Bandbreite an Ursachen, die für Unstimmigkeiten im Haus sorgen: Unsauberkeit/Unordentlichkeit (18\%), Konflikte um gemeinsam genutzte Bereiche $(16,2 \%)$, kulturelle Unterschiede ${ }^{31}(15,3 \%)$, Beschädigungen durch Kinder (13,5\%), Nichtgrüßen/Unfreundlichkeit (12,6\%), Geruchsbelästigung/Küchengerüche (12,6\%), Beschädigungen (11,7\%). Nur 27,9\% der Befragten geben an, dass die Harmonie ihrer Hausgemeinschaft noch nie durch Konflikte, die auf Lärmerregung zurückzuführen waren, gestört wurde. Keinerlei Generationenkonflikte traten bis zum Erhebungszeitpunkt in 46,8\% der durch unsere Respondenten repräsentierten Wiener Wohnhäuser auf.

Das mit Abstand am häufigsten genannte und damit augenscheinlich gravierendste unter den Problemen nachbarlichen Zusammenlebens mit österreichischen Nachbarn

30 „Wenn es in Ihrem Wohnhaus zu Konflikten zwischen Nachbarn kam: Wer hat diese verursacht und was waren die Ursachen?"

31 Diese Item-Formulierung wurde gewählt, da seitens der Respondenten beim Pretest vor allem in der Beantwortung der offenen Fragen oftmals die ,, andere Kultur " ihrer Nachbarn als Konfliktursache verbalisiert wurde. Der undifferenziert-simplifizierende Alltagssprachgebrauch und die exakten kulturwissenschaftlichen Definitionen von „Kultur“ und somit „kulturellen Unterschieden“ weichen selbstverständlich stark voneinander ab. 
stellen offensichtlich intergenerationale Konflikte (36,9\%) dar. Eine besonders große Bedeutung im nachbarschaftlichen Konfliktgeschehen kommt bei den von Inländern verursachten Konflikten mit 27\% auch der Kategorie „Nichtgrüßen, Unfreundlichkeit", d.h. einem Defizit an Höflichkeit in den nachbarschaftlichen Interaktionen, zu. Persönliche Feindschaften sowie Lärmemissionen rangieren mit jeweils 16,2\% genau gleichrangig. Weitere in nennenswerter Häufigkeit angeführte Konfliktursachen, die Österreichern zugeschrieben werden, sind Konflikte um gemeinsam genutzte Bereiche $(13,5 \%)$, Beschädigungen im Haus $(11,7 \%)$ sowie Unsauberkeit/Unordentlichkeit $(10,8 \%)$.

Abbildung 10: Verursacher und Ursachen nachbarschaftlicher Konflikte im Wohnhaus

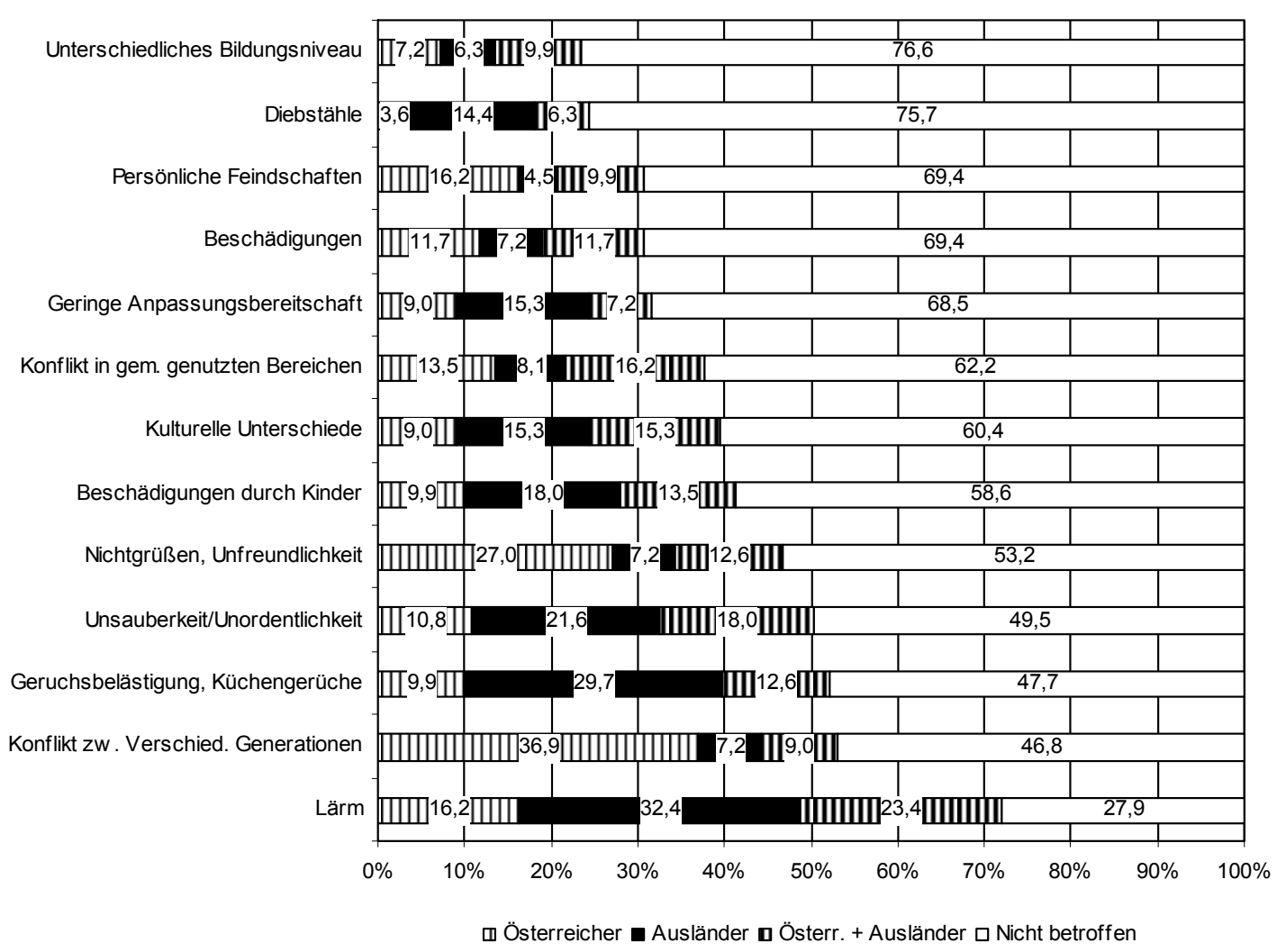

Quelle: Befragung 2005.

Bei den den zugewanderten Nachbarn zugeschriebenen Konfliktursachen führt übermäßige Lärmerregung mit 32,4\% mit deutlichem Abstand. Hinsichtlich ihrer Bedeutung an zweiter Stelle rangieren allerdings - zum Unterschied von den inländi- 
schen Nachbarn - Geruchsemissionen („Geruchsbelästigung, Küchengerüche“) mit 29,7\% sowie Unsauberkeit/Unordentlichkeit (21,6\%). Eine breite Palette an weiteren, Konfliktursachen folgt: Beschädigungen durch Kinder (18\%), kulturelle Unterschiede und geringe Anpassungsbereitschaft (jeweils 15,3\%), Diebstähle (14,4\%). Interessanterweise rangiert die bei den Österreichern dominierende Konfliktursache der Konflikte zwischen den Generationen mit nur 7,2\% sehr weit hinten.

Ein Vergleich der Hierarchie der am häufigsten angeführten Konfliktgründe lässt eine Reihe von Unterschieden zwischen den Konfliktursachen inländischer und ausländischer Urheberschaft hervortreten: Während sich Auseinandersetzungen mit österreichischen Nachbarn besonders häufig als intergenerationale Konflikte manifestieren und Inländern unfreundliche Umgangsformen und Beschädigungen vorgeworfen werden, scheinen Nachbarn mit Migrationshintergrund viel eher die Urheber von Lärm, (tatsächlicher oder vorurteilig zugeschriebener) Unsauberkeit und Geruchsemissionen zu sein. Auch wird ihnen viel häufiger der verschwommene Vorwurf eines allgemeinen Anpassungsdefizites (vgl. auch Bonacker \& Häufele 1986) gemacht. Persönliche Antipathien scheinen viel eher im Umgang mit Inländern als mit Migranten eine Rolle zu spielen. Inwieweit sich in dem bereits seit der Frühphase der Gastarbeiterzuwanderung gegenüber Migranten häufig artikulierten Vorwurf der Unsauberkeit Vorurteile oder nur eine andere Art des Umganges mit Hausinfrastruktur manifestiert, wurde nicht näher erhoben und muss daher an dieser Stelle dahingestellt bleiben. Die „Klassiker“ unter den ausländerspezifischen Konfliktursachen - große Kinderzahl, hohe Besuchsfrequenz - sind insgesamt weniger bedeutend, werden Nachbarn mit Migrationsbackground aber doch öfter zugeschrieben als Inländern. Größere Kinderzahl und rege Besuchsaktivitäten äußern sich auch in Form von Geräuschemissionen - in den Konfliktfaktor Lärm fließt zweifellos einiges davon ein.

\subsubsection{Konfliktursachen nach Wohnungsbestandskategorien}

Im gründerzeitlichen Baubestand (vgl. Tab. 11) sind die am häufigsten angeführten nachbarschaftlichen Konfliktursachen die folgenden: kulturelle Unterschiede $(15,4 \%)$, Konflikte um gemeinsam genutzte Bereiche (12,8\%), Beschädigungen (12,8\%), Lärm (10,3\%) sowie Geruchsbelästigung/Küchengerüche (10,3\%). In der Liste der den inländischen Hausbewohnern zugeschriebenen Konfliktgründe führen Generationenkonflikte (30,8\%), sodann folgen Lärm und Nichtgrüßen/Unfreundlichkeit ex aequo mit 25,6\%, gefolgt von persönlichen Feindschaften (23,1\%). Öfter genannt werden weiters Geruchsemissionen, Beschädigungen durch Kinder, Unsauberkeit sowie Friktionen um gemeinsam genutzte Bereiche. Migranten „sorgen“ in besonders hohem Ausmaß durch Lärm (30,8\%), Geruchsemissionen (28,2\%) sowie durch Unsauberkeit $(25,6 \%)$ und geringe Anpassungsbereitschaft $(25,6 \%)$ für Unstimmigkeiten in gründerzeitlichen Zinshäusern. Weitere Konfliktursachen sind in Beschädigungen durch Kinder, kulturellen Unterschieden, Beschädigungen allgemein, Diebstählen, aber auch in Generationenkonflikten, in Konflikten um gemeinsam genutzte Bereiche und in divergierenden Bildungsniveaus zu finden. 
Tabelle 11: Verursacher und Ursachen von Nachbarschaftskonflikten im Wohnhaus: gründerzeitlicher Wohnbaubestand

\begin{tabular}{lrrrrr}
\hline & Österreicher & $\begin{array}{r}\text { Auslän- } \\
\text { der }\end{array}$ & $\begin{array}{r}\text { Österr. } \\
\text { + Ausl. }\end{array}$ & $\begin{array}{r}\text { nicht be- } \\
\text { troffen }\end{array}$ & insg. \\
\hline Konflikt zw. verschiedenen Generat. & 30,8 & 10,3 & 5,1 & 53,8 & 100,0 \\
Lärm & 25,6 & 30,8 & 10,3 & 33,3 & 100,0 \\
Beschädigungen durch Kinder & 15,4 & 17,9 & 7,7 & 59,0 & 100,0 \\
Geruchsbelästigung, Küchengerüche & 15,4 & 28,2 & 10,3 & 46,2 & 100,0 \\
Unsauberkeit/ Unordentlichkeit & 15,4 & 25,6 & 5,1 & 53,8 & 100,0 \\
Konflikt in gem. genutzten Bereichen & 15,4 & 10,3 & 12,8 & 61,5 & 100,0 \\
Beschädigungen & 10,3 & 12,8 & 12,8 & 64,1 & 100,0 \\
Diebstähle & 5,1 & 12,8 & 7,7 & 74,4 & 100,0 \\
Persönliche Feindschaften & 23,1 & 5,1 & 7,7 & 64,1 & 100,0 \\
Nichtgrüßen, Unfreundlichkeit & 25,6 & 7,7 & 5,1 & 61,5 & 100,0 \\
Kulturelle Unterschiede & 2,6 & 17,9 & 15,4 & 64,1 & 100,0 \\
Geringe Anpassungsbereitschaft & 5,1 & 25,6 & 7,7 & 61,5 & 100,0 \\
Unterschiedliches Bildungsniveau & 5,1 & 10,3 & 7,7 & 76,9 & 100,0 \\
\hline
\end{tabular}

Quelle: Befragung 2005.

Tabelle 12: Verursacher und Ursachen von Nachbarschaftskonflikten im Wohnhaus: kommunaler Wohnbaubestand

\begin{tabular}{lrrrrr}
\hline & Österreicher & $\begin{array}{r}\text { Auslän- } \\
\text { der }\end{array}$ & $\begin{array}{r}\text { Österr. } \\
+ \text { Ausl. }\end{array}$ & $\begin{array}{r}\text { nicht be- } \\
\text { troffen }\end{array}$ & insg. \\
\hline Konflikt zw. verschiedenen Generat. & 45,0 & 2,5 & 15,0 & 37,5 & 100,0 \\
Lärm & 10,0 & 27,5 & 37,5 & 25,0 & 100,0 \\
Beschädigungen durch Kinder & 10,0 & 17,5 & 20,0 & 52,5 & 100,0 \\
Geruchsbelästigung, Küchengerüche & 7,5 & 27,5 & 10,0 & 55,0 & 100,0 \\
Unsauberkeit/ Unordentlichkeit & 10,0 & 22,5 & 25,0 & 42,5 & 100,0 \\
Konflikt in gem. genutzten Bereichen & 12,5 & 10,0 & 10,0 & 67,5 & 100,0 \\
Beschädigungen & 10,0 & 7,5 & 10,0 & 72,5 & 100,0 \\
Diebstähle & 5,0 & 12,5 & 5,0 & 77,5 & 100,0 \\
Persönliche Feindschaften & 10,0 & 2,5 & 12,5 & 75,0 & 100,0 \\
Nichtgrüßen, Unfreundlichkeit & 25,0 & 5,0 & 22,5 & 47,5 & 100,0 \\
Kulturelle Unterschiede & 12,5 & 7,5 & 20,0 & 60,0 & 100,0 \\
Geringe Anpassungsbereitschaft & 17,5 & 12,5 & 5,0 & 65,0 & 100,0 \\
Unterschiedliches Bildungsniveau & 12,5 & 5,0 & 15,0 & 67,5 & 100,0 \\
\hline
\end{tabular}

Quelle: Befragung 2005. 
Im Wohnungsbestand der Stadt Wien (vgl. Tab. 12) führt Lärm mit 37,5\% die Konfliktursachen mit deutlichem Abstand an. Auf den Plätzen zwei und drei folgen sodann Unsauberkeit/Unordentlichkeit (25\%) sowie Nichtgrüßen/Unfreundlichkeit (22,5\%). Öfter angeführt werden auch Beschädigungen durch Kinder (20\%) und kulturelle Divergenzen (20\%). In der Liste der den österreichischen Mietern zugeordneten Konfliktursachen dominieren deutlich die intergenerationalen Konflikte (45\%), mit klarem Abstand folgen mangelnde Umgangsformen (25\%), aber auch geringe Anpassungsbereitschaft (17,5\%). Letztere scheint also ganz offensichtlich keine ausschließlich Migranten zugeschriebene Eigenschaft zu sein. Eine ganze Reihe weiterer Konfliktursachen wurde ebenfalls, wenngleich in geringerer Häufigkeit, angeführt. Den in Wiener Gemeindebauten wohnhaften Nachbarn mit Migrationshintergrund werden in erster Linie Lärm und Geruchsbelästigungen/Küchengerüche (jeweils $27,5 \%$ ) vorgeworfen. Weitere Konfliktursachen von größerer Relevanz stellen Unsauberkeit/Unordentlichkeit (22,5\%), Beschädigungen durch Kinder (17,5\%) sowie geringe Anpassungsbereitschaft und Diebstähle (jeweils 12,5\%) dar.

Tabelle 13: Verursacher und Ursachen von Nachbarschaftskonflikten im Wohnhaus: Genossenschafts- und Eigentumswohnbauten

\begin{tabular}{lrrrrr}
\hline & Österreicher & $\begin{array}{r}\text { Auslän- } \\
\text { der }\end{array}$ & $\begin{array}{r}\text { Österr. } \\
+ \text { Ausl. }\end{array}$ & $\begin{array}{r}\text { nicht be- } \\
\text { troffen }\end{array}$ & insg. \\
\hline Konflikt zw. verschiedenen Generat. & 34,4 & 9,4 & 6,3 & 50,0 & 100,0 \\
Lärm & 12,5 & 40,6 & 21,9 & 25,0 & 100,0 \\
Beschädigungen durch Kinder & 3,1 & 18,8 & 12,5 & 65,6 & 100,0 \\
Geruchsbelästigung, Küchengerüche & 6,3 & 34,4 & 18,8 & 40,6 & 100,0 \\
Unsauberkeit/ Unordentlichkeit & 6,3 & 15,6 & 25,0 & 53,1 & 100,0 \\
Konflikt in gem. genutzten Bereichen & 12,5 & 3,1 & 28,1 & 56,3 & 100,0 \\
Beschädigungen & 15,6 & 12,5 & 0,0 & 71,9 & 100,0 \\
Diebstähle & 0,0 & 18,8 & 6,3 & 75,0 & 100,0 \\
Persönliche Feindschaften & 15,6 & 6,3 & 9,4 & 68,8 & 100,0 \\
Nichtgrüßen, Unfreundlichkeit & 31,3 & 9,4 & 9,4 & 50,0 & 100,0 \\
Kulturelle Unterschiede & 12,5 & 21,9 & 9,4 & 56,3 & 100,0 \\
Geringe Anpassungsbereitschaft & 3,1 & 6,3 & 9,4 & 81,3 & 100,0 \\
Unterschiedliches Bildungsniveau & 3,1 & 3,1 & 6,3 & 87,5 & 100,0 \\
\hline
\end{tabular}

Quelle: Befragung 2005.

Im Genossenschafts- und Eigentumsbauten (vgl. Tab. 13) führen Auseinandersetzungen um gemeinsam genutzte Bereiche mit 28,1\% den Reigen der nachbarschaftlichen Konfliktursachen an. Es handelt sich hierbei um eine sehr spezifische Konstellation, die auch damit zusammenhängen könnte, dass in solchen Wohnanlagen zumeist rezenteren Errichtungsdatums eine größere Zahl an Gemeinschaftseinrichtungen vor- 
handen ist als etwa im gründerzeitlichen Altmietwohnungsbereich. Die weiteren wichtigen Konfliktursachen sind nur zu bekannt: Unsauberkeit (25\%), Lärm (21,9\%) und Gerüche (18,8\%). Die den österreichischen Hausbewohnern einerseits und den Migranten andererseits zugeordneten Konfiktursachen divergieren auch in dieser Wohnungsbestandskategorie erheblich. Österreicher bewirken in erster Linie durch Generationenkonflikte $(34,4 \%)$ und unfreundliche Umgangsformen $(31,3 \%)$ ein erhebliches Reservoir an nachbarschaftlichen Auseinandersetzungen. Mit klarem Abstand folgen weitere Konfliktursachen: Beschädigungen und persönliche Feindschaften ex aequo mit 15,6\%, Lärm, Friktionen um gemeinsam genutzte Bereiche sowie kulturelle Differenzen mit jeweils $12,5 \%$. Immigranten verursachen Nachbarschaftskonflikte infolge von Lärm (40,6\%) und Geruchsemissionen (34,4\%), weiters spielen kulturelle Unterschiede $(21,9 \%)$ eine Rolle. Öfter angeführt werden weiters Beschädigungen durch Kinder sowie Diebstähle (jeweils 18,8\%).

Bezüglich der Konflikte wurden zwei unterschiedliche Ebenen der Involvierung der/des Befragten unterschieden: Erstens persönlich erlebte und zweitens im Haus bestehende Konflikte. Bei den Konflikten der zweiten Kategorie übernahmen die Respondenten die Rolle des Experten bzw. Informanten - eine unmittelbare persönliche Involvierung in das Konfliktgeschehen musste jedoch nicht bestehen. Je nach Konfliktursache und Baubestandskategorie zeigen sich hierbei teils deutliche Unterschiede.

Auf der Ebene der persönlichen Betroffenheit wird das Nichtgrüßen seitens österreichische Nachbarn in besonders hohem Ausmaß (15,6\% „häufig“) von Bewohnern von Eigentums- oder Genossenschaftswohnungen angeführt. Am seltensten berichten davon Mieter in Gründerzeithäusern (64,1\% ,nie“). Persönliche Betroffenheit und die allgemeine Einschätzung des Konfliktklimas im Haus weichen hierbei nur geringfügig voneinander ab. Das Nichtgrüßen seitens ausländischer Nachbarn betrifft persönlich vor allem Bewohner in Gründerzeitbauten (zu 17,9\% ,häufig“), weiters Befragte aus Genossenschafts-/Eigentumswohnanlagen (12,5\% „häufig“) und am wenigsten den Gemeindebau. Die Einschätzung des diesbezüglichen Klimas im Haus ist allerdings etwas positiver: auf Hausebene wird von den Respondenten für die Kategorien „Gründerzeit“ und „Genossenschaft/Eigentum“ eine geringere Frequenz häufiger Grußverweigerung durch ausländische Nachbarn angegeben, für den Gemeindebau eine etwas höhere.

Von der Nichtbeantwortung von Fragen seitens österreichischer Nachbarn zeigen sich vor allem Mieter im Gründerzeitsegment sowie im kommunalen Wohnbau (jeweils zu 10\%) häufig betroffen. Am seltensten tritt diese Konfliktursache in Genossenschafts-/Eigentumshäusern auf. Bezüglich der Situation im Haus insgesamt, ist die Einschätzung in allen drei Baubestandskategorien günstiger, die höchste Frequenz (7,7\% „häufig“) wird für den kommunalen Wohnbau angegeben. Die Antwortverweigerung durch ausländische Nachbarn ist in allen drei Baubestandskategorien weit seltener. Dies zeigt sich sowohl auf der Ebene der unmittelbaren persönlichen Involvierung als auch auf jener der Einschätzung der Situation im Haus allgemein. Am ehesten 
tritt diese Konfliktvariante noch im Gründerzeitbausegment auf. 5,1\% der Befragten ordnen ihr im Rahmen der Einschätzung des Klimas im Haus die Frequenzkategorie „häufig“ zu, auf der Ebene persönlicher Betroffenheit ist diese Verhaltensweise viel seltener.

Die individuelle Betroffenheit durch abfällige oder unwahre Behauptungen seitens inländischer Nachbarn ist in kommunalen Wohnhäusern $(7,5 \%$,häufig“) am größten; auch die Einschätzung der Häufigkeit solcher Vorkommnisse im Haus fällt für dieses Baubestandssegment am negativsten aus (5,1\% ,häufig“ und bloß 59\% „nie“). Von abfälligen/unwahren Behauptungen seitens ausländischer Nachbarn sind am öftesten Gründerzeitwohnungsmieter (5,1\%,,häufig“) betroffen. Die Einschätzung bezüglich des Hauses fällt hier für Gründerzeithäuser und Gemeindebauten gleichermaßen schlechter aus als in Genossenschafts-/Eigentumswohnanlagen.

Die Verweigerung kleiner Gefälligkeiten durch österreichische Nachbarn ist sowohl im Kontext persönlicher Betroffenheit als auch im Rahmen der Schätzung der Häufigkeit im Haus in allen drei Wohnungsbestandskategorien relativ schwach ausgeprägt. Die Gefälligkeitsverweigerung durch ausländische Nachbarn wird persönlich am öftesten in Gründerzeithäusern erlebt (5,1\% ,häufig“), am seltensten in Genossenschafts-/Eigentumswohnbauten. Die Unterschiede zwischen persönlicher Involvierung und geschätzter Häufigkeit im Haus sind unerheblich.

Die Gesprächsverweigerung durch inländische Nachbarn wird ebenfalls in Gründerzeithäusern am häufigsten persönlich erlebt (7,7\% ,häufig“), etwas seltener im Bestandssegment „Genossenschaft/Eigentum“ (3,1\% ,häufig“) und am seltensten in Wohnhäusern der Gemeinde Wien. Kurioserweise wird im Rahmen der allgemeinen Einschätzung der Häufigkeit dieser Verhaltensweise, bezogen auf das gesamte Haus, dem Gemeindebau die höchste Frequenz zugeschrieben (5,1\% „häufig“, 35,9\% ,selten“). Kommunikationsverweigerung seitens nichtösterreichischer Nachbarn tritt insgesamt sehr selten, aber am öftesten noch in Gründerzeitzinshäusern auf.

Von fremdenfeindlichen Äußerungen durch österreichische Nachbarn persönlich betroffen sind vor allem Mieter von Gründerzeitwohnungen (10,3\% „häufig“, 17,9\% „selten“). In den beiden anderen Baubestandskategorien ist das Ausmaß persönlicher Betroffenheit weitaus geringer. Das allgemeine Klima im Haus wird hinsichtlich dieser nachbarschaftlichen Konfliktursache für Gründerzeit- und Gemeindewohnhäuser in etwa gleichermaßen eingeschätzt $(7,7 \%$ und $10,5 \%$,häufig“"). Xenophobe Äußerungen durch ausländische Nachbarn sind ein in summa seltenes Phänomen und treten am wenigsten in Genossenschafts-/Eigentumswohnbauten auf. Im Rahmen der Einschätzung im Haus wird diese Konfliktvariante am ehesten den Gründerzeithäusern zugeschrieben.

Beschimpfungen oder Drohungen sowohl seitens österreichischer als auch durch ausländische Nachbarn treten im nachbarschaftlichen Interaktionskontext insgesamt eher selten auf. Interessanterweise werden beide Kategorien im Rahmen der Beurteilung der Verhältnisse im Haus weit öfter genannt als im Kontext der persönlichen Betroffenheit. Sowohl Beschimpfungen/Drohungen seitens inländischer als auch solche 
durch ausländische Nachbarn werden am häufigsten für Gemeindewohnhäuser angeführt (7,5 bzw. 7.7\% ,häufig“). Beschimpfungen seitens österreichischer Nachbarn werden auch für Gründerzeitbauten (5,1\% ,häufig"), solche durch ausländische Hausbewohner für das Wohnungssegment „Genossenschaft/Eigentum“ (6,3\% „häufig“) in nennenswerter Frequenz angegeben.

Tätlichkeiten stellen offensichtlich ein im wohnnachbarschaftlichen Umgang extrem seltenes Phänomen dar. Auf der Ebene persönlicher Involvierung werden Tätlichkeiten sowohl seitens österreichischer als auch seitens ausländischer Nachbarn am ehesten für den gründerzeitlichen Altbaubestand angeführt. Bei der Beurteilung der Verhältnisse im Haus ist es der Genossenschafts-/Eigentumswohnungsbestand, wo für 6,3\% der Hausgemeinschaften Übergriffe durch ausländische Nachbarn als „häufig" klassifiziert werden. Bosheitsakte und die Beschädigung von Eigentum treten in weitgehend analoger Seltenheit auf wie tätliche Auseinandersetzungen. Die Befragten sind davon weit weniger selbst betroffen, für die Situation im Haus werden derlei Konflikte aber in etwas höherer Frequenz angegeben.

Bosheitsakte und die Beschädigung fremden Eigentums durch österreichische Nachbarn werden, bezogen auf das Haus, vor allem für Gemeindewohnhäuser angegeben (5,1\% „häufig“). Durch ausländische Nachbarn verursachte Beschädigungen werden für das Wohnhaus deutlich öfter genannt. Zu 6,3\% „häufig“ in der Wohnbestandsklasse „Genossenschaft/Eigentum“ und zu jeweils 5,1\% „häufig“ für Altmiethäuser und Gemeindebauten. Die Eskalation nachbarschaftlicher Konflikte in Form von Strafanzeigen und die Involvierung der Exekutive durch österreichische wie ausländische Nachbarn betraf nur sehr wenige Respondenten. Anzeigen durch österreichische Mitbewohner wurden am ehesten von Altbauwohnungsmieter $(5,1 \%$,häufig") verbalisiert. Anzeigen seitens ausländischer Nachbarn treten in höherer Frequenz vor allem losgelöst von der eigenen Person und bezogen auf das Konfliktgeschehen im Haus auf. Zu 7,7\% „,häufig“ in Gründerzeithäusern und zu 6,3\% in genossenschaftlichen bzw. Eigentumswohnhäusern.

Beschwerden bei der Hausverwaltung und/oder dem/der Hausbesorger/-in sind in der nachbarschaftlichen Alltagsrealität ganz offensichtlich etwas häufiger. Von Beschwerden seitens österreichischer Nachbarn häufig betroffen waren bereits 10,3\% der Mieter von Gründerzeitwohnungen. $\mathrm{Zu}$ jeweils $7,7 \%$ als häufig wurden Beschwerden durch österreichische bzw. auch durch ausländische Nachbarn ebenfalls für Gründerzeithäuser und im Rahmen der Charakterisierung des Konfliktgeschehens auf Hausebene angegeben. Von Beschwerden bei anderen Nachbarn waren unsere Befragten in summa seltener betroffen. Für das ganze Haus wurden solche Beschwerden durch ausländische Nachbarn relativ am häufigsten angeführt. $\mathrm{Zu} 9,4 \%$ traten also diese Beschwerden häufig in Genossenschafts-/Eigentumswohnbauten, zu 7,7\% in Altmiethäusern und zu 7,5\% in Gemeindebauten auf. Auf der individuellen Ebene zeigte sich eine sehr seltene Betroffenheit durch Beschwerden bei anderen Nachbarn. 


\subsubsection{Die Performance nachbarschaftlicher Konflikte}

Neben der Konfliktfrequenz und den Konfliktursachen ist eine Analyse der „Konfliktperformance" besonders aufschlussreich, denn valide empirische Daten über tatsächlich stattfindende Nachbarschaftskonflikte, deren Ablauf sowie die Bewältigungsstrategien sind bis dato Mangelware geblieben. Wie also äußern sich Nachbarschaftskonflikte in Wiener Wohnhäusern und in welcher Häufigkeit finden diese statt? ${ }^{32}$ Lassen sich Unterschiede zwischen den einzelnen Baubestandskategorien nachweisen und wenn ja, wie sind diese zu interpretieren?

In der Fragenformulierung wurde auf zwei Ebenen rekurriert: 1) auf jene Konflikte, welche den/die Respondenten/-in persönlich betreffen, d.h. bei welchen der Faktor der persönlichen Involvierung eine Rolle spielt, und 2) auf sich im Haus allgemein ereignende Konflikte (Konfliktmilieu im Haus, losgelöst von der individuellen Erfahrungsebene), von denen der/die Befragte gehört hat, die er/sie als Augenzeuge/-in miterlebte oder von deren Existenz er/sie auf irgendeine andere Weise erfahren hat. Analog zu den Kontakten wurde eine Art von „Konfliktkontinuum“ erstellt, welches von der bloßen Grußverweigerung, die einen Affront darstellt, aber keine zwingende Handlungsrelevanz besitzt, über die Gesprächsverweigerung und verbale Angriffe bis zur Ebene der Tätlichkeiten, Sachbeschädigungen und der Involvierung der Exekutive reicht.

Wie gestaltet sich also das konkrete Konfliktgeschehen in den drei Bebauungstypen auf der Ebene der persönlichen Betroffenheit? Die Grußverweigerung zählt hierbei zu den am häufigsten auftretenden Ursachen für nachbarschaftliche Friktionen. Die Grußverweigerung seitens österreichischer Nachbarn ist ein Phänomen, das in der Wohnbaukategorie „Genossenschaft/Eigentum“ am öftesten auftritt (zu 15,6\% „häufig“) und im Gemeindebau am seltensten (nur 10\% „häufig“). Die Gründerzeithäuser liegen hinsichtlich der Häufigkeit $(12,8 \%)$ dazwischen. Das Nichtgrüßen seitens mancher Immigranten ist eine Konfliktvariante, die überproportional häufig (17,9\% ,häufig“) im gründerzeitlichen Wohnkontext sowie auch im Segment Genossenschaft/Eigentum (12,5\%) festzustellen ist. Gemäß unserem Sample ist diese Verhaltensweise in Wohnhäusern der Gemeinde Wien bei weitem seltener nachzuweisen ( $0 \%$,häufig“" und 27,5\%,,selten“).

Die Verweigerung der Beantwortung von Fragen durch österreichische Nachbarn tritt in Gemeinde- und Gründerzeithäusern zu jeweils rund 10\% häufig auf, im Segment Genossenschaft/Eigentum zu 6,3\%. Viel seltener ist in allen drei Wohnbautypen die Antwortverweigerung durch Nachbarn mit Migrationshintergrund: im Gründerzeitmilieu zu 2,6\% häufig, in Gemeinde- und Genossenschaftshäusern ist die Kategorie „häufig“ überhaupt nicht vertreten. Abfällige Behauptungen seitens österreichi-

32 Die Auswertungen dieses Kapitels beziehen sich auf die Frage: ,, Wenn sie bereits Konflikte mit österreichischen Nachbarn/mit Nachbarn ausländischer Herkunft hatten oder davon im Haus gehört haben: Wie äußerten sich diese und wie häufig?" 
scher Nachbarn treten am ehesten im kommunalen Wohnbau (7,5\% „häufig“, 17,5\% „selten“), seltener in Gründerzeithäusern und am spärlichsten im Sektor Genossenschaft/Eigentum auf. Eine persönliche Betroffenheit durch abfällige Behauptungen seitens zugewanderter Nachbarn lässt sich in erster Linie für Gründerzeithäuser (5,1\% „häufig“, $15,4 \%$,selten“) nachweisen, seltener im Gemeindebau und am seltensten bei Bewohnern von Genossenschafts-/Eigentumswohnanlagen.

Neben der Ebene der persönlichen Betroffenheit interessierte uns auch die Häufigkeit, mit welcher die angeführte Palette an Konfliktursachen im Haus insgesamt auftritt, also das generelle Konfliktklima. Hierbei manifestieren sich bezüglich etlicher Konfliktursachen erhebliche Abweichungen im Vergleich zur Ebene der persönlichen Involvierung. Diese Abweichungen lassen allerdings keine einheitlichen Trends erkennen, weshalb sie im Folgenden nur deskriptiv abgehandelt werden sollen.

Das Nichtgrüßen durch österreichische Nachbarn tritt in allen drei Bebauungsformen mit Werten von 12,5 bis 12,8\% in der Kategorie ,häufig“ auf. Ein wesentlicher Unterschied besteht jedoch darin, dass $77 \%$ der Befragten aus Gründerzeithäusern angeben, dass diese Form der Grußverweigerung in ihrem Haus niemals auftritt. In den beiden anderen Wohnungsbestandskategorien geben nur 50\% (Genossenschaft/Eigentum) bzw. 51,3\% (Gemeindebau) der Befragten diese Einschätzung ab. Das Nichtgrüßen seitens ausländischer Nachbarn ist ein selteneres Phänomen als die Grußverweigerung seitens inländischer Hausbewohner. Einerseits ist die Kategorie „häufig“ in Gründerzeithäusern am stärksten $(7,7 \%)$ besetzt (Gemeindebau: 5\%; Genossenschaft/Eigentum: 6,3\%), andererseits sind aber 79,5\% der Gründerzeitwohnungsmieter (Gemeindebau: 67,5\%; Genossenschaft/Eigentum: 62,5\%) der Meinung, dass diese Variante der Grußverweigerung in ihrem Haus niemals auftritt.

Die Nichtbeantwortung von Fragen wird vor allem von österreichischen Nachbarn praktiziert. Diese diskriminierende Verhaltensweise tritt zu 7,7\% häufig in Gemeindewohnhäusern auf, zu 3,1\% im Bausegment Genossenschaft/Eigentum und zu 2,6\% in Gründerzeithäusern. Mit 84,2\% und 81,3\% der Befragten, die hier „nie“ angaben, ist dieses Verhalten vor allem in der Gründerzeitbebauung und in Genossenschaftshäusern selten anzutreffen. Ausländische Nachbarn verweigern nur äußerst selten die Antwort auf Fragen. Die Kategorie „häufig“ ist hier nur für die Gründerzeithäuser mit $5,1 \%$ besetzt. Ansonsten sind in allen drei Baubestandskategorien weit über $80 \%$ der Befragten der Meinung, dass dieses Verhalten in ihrem Haus nie auftreten würde.

Die (insgesamt seltenere) Gesprächsverweigerung wird etwas häufiger von inländischen Hausbewohnern an den Tag gelegt. 5,1\% der Respondenten aus Gemeindebauten gaben hier „häufig“ an. 87,2\% der Gründerzeitmieter, $75 \%$ der Bewohner von Eigentums-/Genossenschaftsanlagen sowie 59\% der Gemeindebaumieter bekundeten, dass solches Verhalten in ihrem Haus niemals auftreten würde. Gesprächsverweigerung durch ausländische Nachbarn ist im Gemeindewohnungssektor am häufigsten. Sie tritt im Gründerzeitmilieu zu 94,9\% niemals, im Bausegment Genossenschaft/Eigentum zu 90,6\% nie und in kommunalen Wohnbauten zu fast exakt drei Vierteln nie auf.

Fremdenfeindliche Äußerungen durch österreichische Nachbarn werden am öftesten in Gemeindebauten (10,5\% ,häufig\%) verbalisiert, seltener in Gründerzeithäusern 
(7,7\%) und am seltensten im Segment Genossenschaft/Eigentum (6,3\%). Völlig frei von xenophoben Bemerkungen sind in erster Linie Genossenschafts-/Eigentumshäuser (zu 78,1\% „nie“). In den Gemeindebauten ist die Kategorie „nie“ mit 63,2\% am schwächsten besetzt. Xenophobe Bemerkungen durch ausländische Nachbarn sind am öftesten für die Gründerzeithäuser nachweisbar ( $5,1 \%$ „häufig“), am seltensten treten diese in Genossenschaftsbauten auf.

Beschimpfungen und Drohungen sowohl seitens in- als auch ausländischer Nachbarn werden für das Wohnhaus erheblich häufiger angegeben als auf der Ebene persönlicher Betroffenheit. Beschimpfungen und Drohungen seitens österreichischer Nachbarn manifestieren sich am häufigsten im kommunalen Wohnsektor (zu 7,7\% „häufig“) sowie in Gründerzeithäusern (5,1\% „häufig“). Beschimpfungen und Drohungen seitens ausländischer Nachbarn sind ein in Gemeindebauten am ehesten auftretendes Phänomen (7,5\% ,häufig“).

Tätliche Auseinandersetzungen sind in summa selten. Die Kategorie „häufig“ ist hier in allen drei Baubestandsklassen unbesetzt. Tätlichkeiten seitens österreichischer Nachbarn können auf Basis unseres Samples noch am öftesten für Gemeindehäuser nachgewiesen werden. Sie treten hier zu 13,2\% ,selten“ auf. Tätlichkeiten seitens ausländischer Hausbewohner sind ebenfalls für den Gemeindebau am ehesten nachweisbar. Zwar ist die Klasse „häufig“ mit 6,3\% für das Segment Genossenschaft/Eigentum am stärksten besetzt, allerdings ist hier zugleich auch Kategorie ,nie“ mit fast 94\% am meisten präsent.

Beschädigungen von fremdem Eigentum durch österreichische Nachbarn erfolgen im kommunalen Wohnsektor zu 5,1\% häufig und sind am seltensten in Gründerzeithäusern. Beschädigungen seitens ausländischer Nachbarn werden in deutlich höherer Frequenz angegeben als Vandalenakte durch Inländer. Häufige Beschädigungen werden von $6,3 \%$ der Bewohner von Genossenschafts-/Eigentumswohnungen verbalisiert, weiters von jeweils 5,1\% der Befragten aus den beiden anderen Wohnbestandskategorien.

Anzeigen bzw. die Einschaltung der Exekutive sind Reaktionen, die inländischen Nachbarn gegenüber seltener an den Tag gelegt werden als gegenüber im Haus lebenden Migranten. Anzeigen ausländischer Hausbewohner sind am häufigsten in Gründerzeithäusern (7,7\% ,häufig“) und in Genossenschafts-/Eigentumswohnanlagen (6,3\%).

Offizielle Beschwerden bei Hausverwaltung und/oder Hausbesorger sind in Gründerzeithäusern sowohl bezüglich in- als auch ausländischer Nachbarn analog häufig. In den beiden anderen Baubestandsgruppen weisen die Resultate in eine gegensätzliche Richtung. Beschwerden bei anderen Nachbarn über Migranten treten häufiger auf als Klagen über inländische Hausbewohner. Die Antwortkategorie „häufig“ ist mit 9,4\% der Befragten aus dem Wohnbereich Genossenschaft/Eigentum, mit 7,7\% bei den Gründerzeitmietern und mit 7,5\% im Gemeindebau besetzt.

Ein interessantes Bild ergibt sich, wenn das Ausmaß der persönlichen Betroffenheit bzw. Nichtbetroffenheit der Befragten durch die aufgezählten Konflikte nach dem Kriterium des vorhandenen/nicht vorhandenen Migrationshintergrundes analysiert wird. In nahezu allen angegebenen Konfliktkategorien ist das Ausmaß persönlicher 
Betroffenheit seitens der Befragten mit Migrationshintergrund um einiges höher als jenes der österreichischen Respondenten. Bereits auf der Ebene der Grußverweigerung sind es bei den Migranten 55,7\%, die angeben, von einem solchen Verhalten im nachbarschaftlichen Interaktionskontext betroffen (gewesen) zu sein. Bei den Befragten ohne Migrationshintergrund liegt das Ausmaß der persönlichen Betroffenheit bei bloß 38\%. Krass ist der Unterschied auch bezüglich der Antwortverweigerung: Nur 8,2\% unserer österreichischen Befragten, jedoch 37,7\% der Respondenten mit Migrationshintergrund geben hier persönliche Betroffenheit an. Bei abfälligen Behauptungen liegen die prozentuellen Relationen bei $14 \%$ zu 26,2\%, bei Gesprächsverweigerung bei $14 \%$ zu $25 \%$ und bei fremdenfeindlichen Äußerungen bei $18 \%$ zu 27,9\%.

Keine Unterschiede lassen sich allerdings in der Kategorie „Auslachen, Beschimpfung, Drohung“ (jeweils 10\%) und nur geringe bei der Verweigerung von Gefälligkeiten $(10 \%$ zu 13,1\%) konstatieren. Gegen sie persönlich gerichtete nachbarliche Tätlichkeiten erlebten die Migranten im Sample nahezu dreimal häufiger (11,7\%) als Nichtmigranten (4\%). Bosheitsakten und Beschädigungen sind sie in einem rund doppelt so hohen Ausmaß (19,7\%) ausgesetzt wie Nichtmigranten (10\%) und die Verständigung der Polizei erfolgt Zuwanderern gegenüber ebenfalls weit häufiger $(14,8 \%)$ als bei österreichischen Respondenten (4\%). Krass auch die Unterschiede hinsichtlich der Beschwerden bei der Hausverwaltung, wovon bereits 29,5\% der Migranten, aber nur 14\% der Nichtmigranten betroffen waren.

Das Ausmaß persönlicher Betroffenheit durch Konflikte mit österreichischen Nachbarn divergiert in den drei untersuchten Wohnmilieus zum Teil erheblich. Auf der Ebene der Grußverweigerung durch österreichische Nachbarn manifestieren sich die gravierendsten Unterschiede im gründerzeitlichen Wohnbaubestand. Nur 20\% der inländischen Befragten, jedoch 52,6\% der Respondenten mit Migrationshintergrund waren davon bereits betroffen. Im Wohnungsbestandssegment Genossenschaft/Eigentum liegen die Unterschiede bei $50 \%$ zu $61,1 \%$, im Gemeindebau bei $50 \%$ zu $54,2 \%$.

Die Nichtbeantwortung von seitens Migranten gestellter Fragen betrifft besonders in Gründerzeithäusern und in Gemeindebauten lebende Respondenten mit Migrationshintergrund: in ersteren 47,4\% (Inländer: 5,3\%), in zweiteren 41,7\% (Inländer: $12,5 \%)$.

Abfällige Behauptungen durch österreichische Nachbarn bekundeten ebenfalls die im Gründerzeitmilieu lebenden Migranten am häufigsten (36,8\% gegenüber 10\% der Inländer), etwas seltener die Gemeindemieter ( $29,2 \%$ zu 18,8\%). Seitens der Respondenten mit Migrationshintergrund, die in Genossenschafts-/Eigentumswohnungen leben, werden abfällige Behauptungen durch österreichische Nachbarn sogar seltener angegeben $(11,1 \%)$ als seitens österreichischer Befragter $(14,3 \%)$ in diesem Wohnbausegment.

Von der Verweigerung von Gefälligkeiten seitens österreichischer Nachbarn sind vor allem im kommunalen Wohnbau lebende Migranten (25\%) betroffen. In Gründerzeit- und Genossenschaftshäusern geben mehr Personen ohne Migrationsbackground 
als Migranten an, damit bereits konfrontiert gewesen zu sein. Gesprächsverweigerung von österreichischer Seite ist in den drei Wohnmilieus vor allem ein Problem der Zuwanderer. In Gründerzeit- und Gemeindewohnhäusern sind davon jeweils über 26\% der Immigranten betroffen, in Genossenschafts-/Eigentumsbauten 22,2\%. Mit nur $7,1 \%$ Inländern, die in diesem Punkt eigene Betroffenheit artikulieren, ist der Unterschied zwischen Befragten mit und ohne Migrationshintergrund in Genossenschaftshäusern am krassesten.

Xenophobe Äußerungen durch Inländer erleben Migranten im Gründerzeithäusern sowie in Genossenschafts-/Eigentumswohnanlagen am häufigsten (36,8\% gegenüber einem Fünftel der Inländer).

Auch hinsichtlich der Beschimpfungen tritt das Gründerzeitwohnmilieu als besonderer Nährboden hervor. 21,2\% der Respondenten mit migratorischem Background, jedoch kein einziger Inländer erklären sich davon betroffen. Im kommunalen Wohnbau sind Inländer mit $25 \%$ von Beschimpfungen sogar weit stärker betroffen als Migranten (8,7\%).

Tätlichkeiten seitens österreichischer Nachbarn sind ebenfalls im Gründerzeitmilieu besonders häufig. 22,2\% der befragten Migranten, jedoch kein einziger Inländer artikulieren eigene Betroffenheit. Im kommunalen Wohnbau erklären sich Migranten davon zu 8,3\% und damit seltener betroffen als österreichische Respondenten (12,5\%).

Auch Bosheitsakte/Beschädigungen, Anzeigen/Verständigung der Exekutive sowie Beschwerden bei Nachbarn und der Hausverwaltung werden von im Gründerzeitbaubestand wohnhaften Immigranten am häufigsten bekundet. Während nur zwischen 5 und 10\% der inländischen Gründerzeitwohnungsmieter davon betroffen sind, rangieren die entsprechenden Prozentwerte bei den Migranten in einem Bereich von $32 \%$ bis $42 \%$. Ähnliche Diskrepanzen sind für das Wohnungsbestandssegment Genossenschaft/Eigentum hinsichtlich der Beschwerden bei Nachbarn $(33,3 \%$ zu $14,3 \%)$ und der Hausverwaltung $(27,8 \%$ zu 7,1\%) zu konstatieren.

Im Gemeindebau betreffen Bosheitsakte sowie Beschwerden bei der Hausverwaltung durch Österreicher in höherem Ausmaß die inländischen Befragten.

Untersucht man nun die persönliche Betroffenheit unserer Respondenten durch die unterschiedlichsten Konfliktszenarien, wenn Zuwanderer als deren Verursacher angegeben werden, so zeigt sich, dass in vielen (aber nicht allen) Konfliktkategorien die Respondenten mit Migrationshintergrund auch von Konflikten mit zugewanderten Nachbarn stärker betroffen sind. Konflikte zwischen Migranten scheinen also, zumindest bezogen auf den Kanon der angegebenen Konfliktursachen, häufiger zu sein als Konflikte zwischen Migranten und Inländern.

Während bei der Grußverweigerung seitens zugewanderter Nachbarn die Unterschiede relativ moderat ausfallen (Migranten: 36,1\%, Nichtmigranten: 30\%), treten deutlichere Diskrepanzen bei der Nichtbeantwortung von Fragen $(19,7 \%$ gegenüber $8 \%$ ), bei abfälligen Behauptungen (21,3\% gegenüber 14\%), bei Gesprächsverweigerung (13,3\% gegen $8 \%$ ) und bei Tätlichkeiten (16,4\% gegen $6 \%$ ) hervor. Auch polizeiliche Anzeigen (21,3\% gegenüber 10\%), Beschwerden bei der Verwaltung (21,3\% 
zu 12\%) und Beschwerden bei Nachbarn (29,5\% zu 10\%) sind Probleme, mit denen Befragte mit Migrationshintergrund bei weitem öfter konfrontiert werden als Inländer. Nur hinsichtlich der Verweigerung von Gefälligkeiten und Beschimpfungen/Drohungen artikulieren die Inländer in unserem Sample eine etwas stärkere Betroffenheit als die befragten Migranten.

Wiederum zeigen sich in den unterschiedlichen Wohnungsbestandskategorien divergierende Konfliktkonstellationen. Das Nichtgrüßen durch zugewanderte Nachbarn betrifft 52,6\% der Gründerzeitmieter mit Migrationshintergrund, aber nur $15 \%$ der in diesem Baubestandssegment wohnhaften Österreicher. Im Gemeindebau $(37,5 \% \mathrm{zu}$ $20,8 \%)$ sowie in Genossenschaftshäusern $(42,9 \%$ zu $38,9 \%)$ sind die Inländer in einem höherem Ausmaß als die Migranten mit ausländischen Nichtgrüßern konfrontiert. In Gründerzeithäusern sind auch die Nichtbeantwortung von Fragen, fremdenfeindliche Äußerungen (15,8\% zu 5\%), Tätlichkeiten (31,6\% zu 5\%) und Beschädigungen durch ausländische Mitbewohner im Haus Probleme, die häufiger die Migranten als die Inländer betreffen. Deutlich manifestieren sich im Gründerzeitmilieu auch die Unterschiede hinsichtlich Anzeigen bei der Polizei (36,8\% zu 10\%), Beschwerden beim Hausverwalter (31,6\% zu 10\%) und Beschwerden bei Nachbarn (36,8\% zu 5\%). Einzig die Verweigerung von Gefälligkeiten seitens immigrierter Nachbarn wird von Inländern mit 15\% häufiger angegeben als von den befragten Migranten (10,5\%).

Wie sieht es nun im kommunalen Wohnbau aus? Die Grußverweigerung seitens ausländischer Nachbarn betrifft hier viel stärker die inländischen Befragten (37,5\%) als jene mit Migrationshintergrund (20,8\%). Häufigere Betroffenheit artikulieren die befragten Österreicher auch bei Antwortverweigerung (18,8\% zu 16,7\%), Verweigerung von Gefälligkeiten (18,8\% zu 12,5\%), fremdenfeindlichen Äußerungen ( $25 \% \mathrm{zu}$ $12,5 \%)$, Beschimpfungen (18,8\% zu 12,5\%), Beschädigungen (12,5\% zu 4,2\%) und Beschwerden bei der Hausverwaltung (25\% zu 16,7\%). Ein höheres Ausmaß an Betroffenheit seitens der Migranten lässt sich bezüglich folgender Konfliktkategorien nachweisen: abfällige Behauptungen ( $25 \% \mathrm{zu} 18,8 \%)$, Kommunikationsverweigerung (20,8\% zu 12,5\%), Tätlichkeiten (16,7\% zu 12,5\%), polizeiliche Anzeigen (20,8\% zu $12,5 \%)$ und Beschwerden bei Nachbarn (29,2\% zu 25\%).

Für die Genossenschafts- und Eigentumswohnungen lässt sich aus den vorliegenden Daten ein spezifisches nachbarschaftliches Klima deduzieren. Mit Beschimpfungen und Tätlichkeiten seitens ausländischer Wohnungsnachbarn war noch keiner unserer Befragten Wohnungseigentümer bis zum Zeitpunkt der Befragung konfrontiert. Dies gilt für Inländer ebenso wie für Migranten. Einzig die Grußverweigerung durch ausländische Nachbarn tritt recht häufig auf. Betroffen sind $42,9 \%$ der inländischen Befragten und 38,9\% der Migranten. Von den folgenden Konfliktursachen sind nur Befragte mit Migrationshintergrund, jedoch kein einziger österreichischer Respondent betroffen: Antwortverweigerung und abfällige Behauptungen (jeweils 16,7\%), Verweigerung von Gefälligkeiten und Gesprächen sowie fremdenfeindliche Äußerungen mit jeweils über 5\%, Beschwerden bei der Verwaltung (16,7\%) und Beschwerden bei Nachbarn (22,2\%). Beschädigungen und Anzeigen durch ausländische Nachbarn 
betreffen österreichische Bewohner von Genossenschafts-/Eigentumswohnungen mit jeweils 7,1\% öfter als ihre Nachbarn mit Migrationshintergrund (jeweils 5,6\%).

\subsubsection{Soziale Distanz - Die Einstellungen gegenüber potentiellen Nachbarn unterschiedlicher ethnonationaler Herkunft}

Zum Zwecke des Vergleichs mit den Resultaten einer 1996 vom bm:bwk finanzierten Studie im Rahmen des Forschungsschwerpunktes „Fremdenfeindlichkeit“ haben wir aus dem deutschen ALLBUS (Allgemeine Bevölkerungsumfrage der Sozialwissenschaften) eine Frage in modifizierter Form übernommen und in unseren Fragebogen eingebaut. ${ }^{33}$ Diese zielte auf die Analyse der Einstellungen zu potentiellen Nachbarn ab, wobei die soziale Distanz gegenüber unterschiedlichen ethnonationalen Gruppen ermittelt werden sollte. Auf diese Weise konnte ein „Distanzkontinuum“ ermittelt werden, welches ablehnende Attitüden gegenüber unterschiedlichen Gruppen in Form einer 6-stufigen Skala (von „wäre mir sehr unangenehm“ bis zu „wäre mir sehr angenehm") widerspiegelt.

Sehr interessante Ergebnisse zeitigt die Analyse nach dem Kriterium eines vorhandenen/nicht vorhandenen Migrationshintergrunds der Befragten. So gingen wir von der Arbeitshypothese aus, dass die Distanz gegenüber neuen Nachbarn mit einem hohen Grad an „visibility“ unter den Respondenten ohne Migrationshintergrund besonders groß wäre, während Personen mit Migrationshintergrund aufgrund ihrer eigenen Migrationserfahrung ein höheres Ausmaß an Toleranz aufweisen. Gerade das Gegenteil ist aber der Fall!

Zwar zeigt sich in beiden Subgruppen (mit/ohne Migrationshintergrund), dass Menschen unterschiedlicher ethnonationaler Herkunft auch in divergierendem Ausmaß als Nachbarn willkommen sind, allerdings variiert das Ausmaß der sozialen Distanz beträchtlich. Die etlichen der angegebenen potentiellen Nachbarn entgegengebrachte Distanz ist seitens der Befragten ohne Migrationshintergrund vielfach moderater. Die befragten Personen ohne Migrationshintergrund tendieren den zur Auswahl stehenden Nachbarn gegenüber in einem viel höheren Ausmaß zu einer neutralen Mittelposition, während auf Seiten der Respondenten mit Migrationshintergrund eine stärker ausgeprägte Polarisierung in die beiden Gegenpole ,eher angenehm“ versus „eher unangenehm" zu konstatieren ist, wobei die soziale Distanz gegenüber Nachbarn bestimmter Herkunft (besonders Nigerianer und Türke) am größten ist.

Nun zunächst zu den Einstellungen der Subgruppe ohne Migrationshintergrund (vgl. Abb. 11): Von diesen wird einem potentiellen Nachbarn aus Österreich das größte Ausmaß an Sympathie ( $\bar{x}=0,96,40,7 \%$,eher angenehm“) entgegengebracht,

33 Die Frage lautete: „Stellen Sie sich vor, in die Wohnung neben Ihnen würde ein neuer Nachbar einziehen. Wie angenehm oder unangenehm wären Ihnen Angehörige der unten aufgezählten Gruppen als Nachbarn?" 
wenngleich einige Befragte $(6,1 \%)$ einen österreichischen Nachbarn als „eher unangenehm" empfänden. Ein Deutscher $(\bar{x}=0,47)$ oder ein Italiener $(\bar{x}=0,39)$ würde von den meisten als künftiger Wohnnachbar gleichermaßen akzeptiert werden. Vom Ausmaß der Ablehnung her weitgehend gleichrangig (16,3\%) positionieren sich Polen $(\bar{x}=0,20)$ und Chinesen $(\bar{x}=0,16)$, wobei erstere mit $22,5 \%$ in der Kategorie „eher angenehm“ etwas besser punkten können als die Ostasiaten $(18,4 \%$,eher angenehm"). In Bezug auf die Ablehnungsratings etwas höher rangieren der Kroate und der Serbe, wobei letzterer etwas stärker abgelehnt $(24,5 \% ; \bar{x}=0,0)$ wird als ein potentieller Nachbar aus der Islamischen Republik Ägypten $(22,5 \%, \bar{x}=-0,02)$. Gleichrangig mit den Serben positionieren sich die Russen $(\bar{x}=0,0)$, denen somit ein höheres Ausmaß an sozialer Distanz als den Ägyptern entgegengebracht wird. Die größte Distanz besteht gegenüber dem Nigerianer sowie dem Türken. Die Mittelwerte für die am meisten akzeptierten Gruppen liegen bei 0,96 (Österreicher), 0,47 (Deutsche) und 0,39 (Italiener). Sie betragen für die am stärksten abgelehnten Herkunftsgruppen $-0,02$ für die Ägypter, $-0,12$ für Nigerianer und $-0,14$ für Türken.

Abbildung 11: Einstellung zu potentiellen Nachbarn unterschiedlicher Herkunft: Respondenten ohne Migrationshintergrund

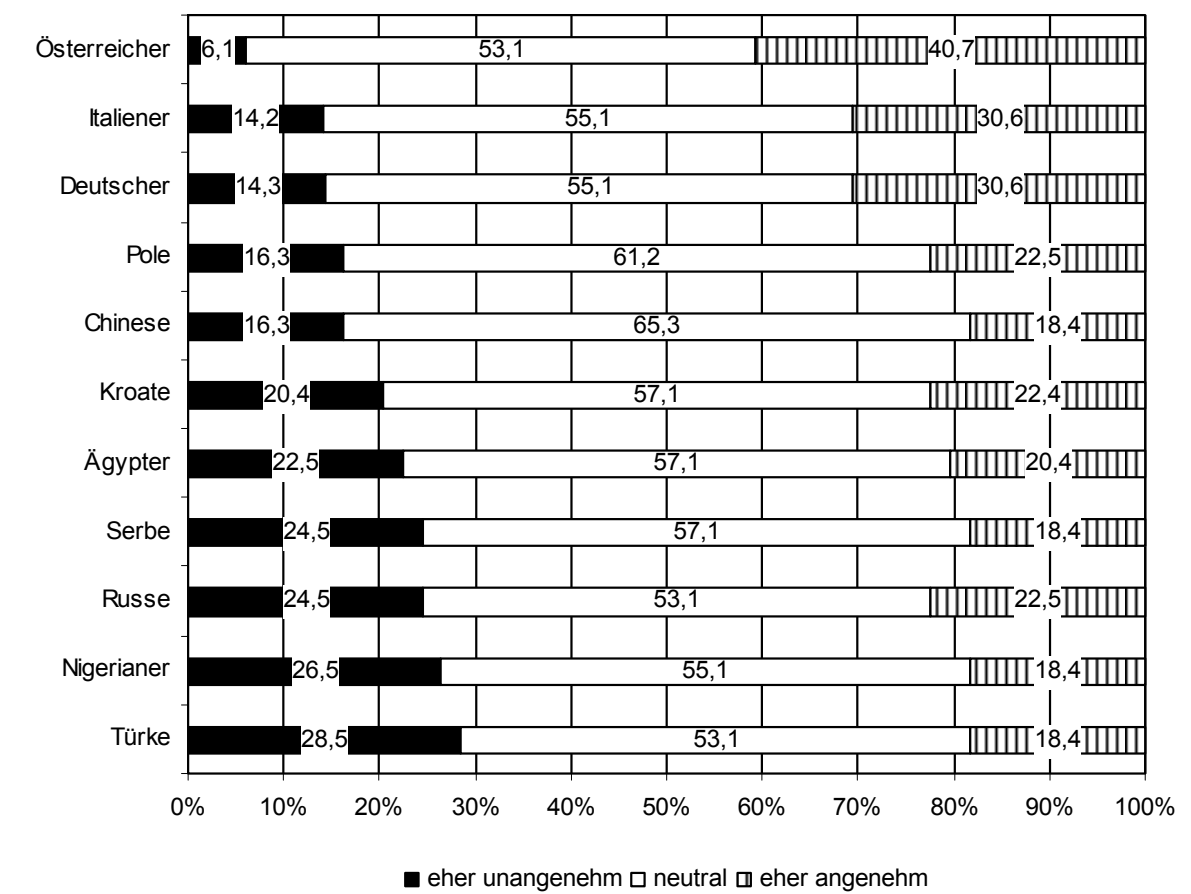

Quelle: Befragung 2005. 
Abbildung 12: Einstellung zu potentiellen Nachbarn unterschiedlicher Herkunft: Respondenten mit Migrationshintergrund

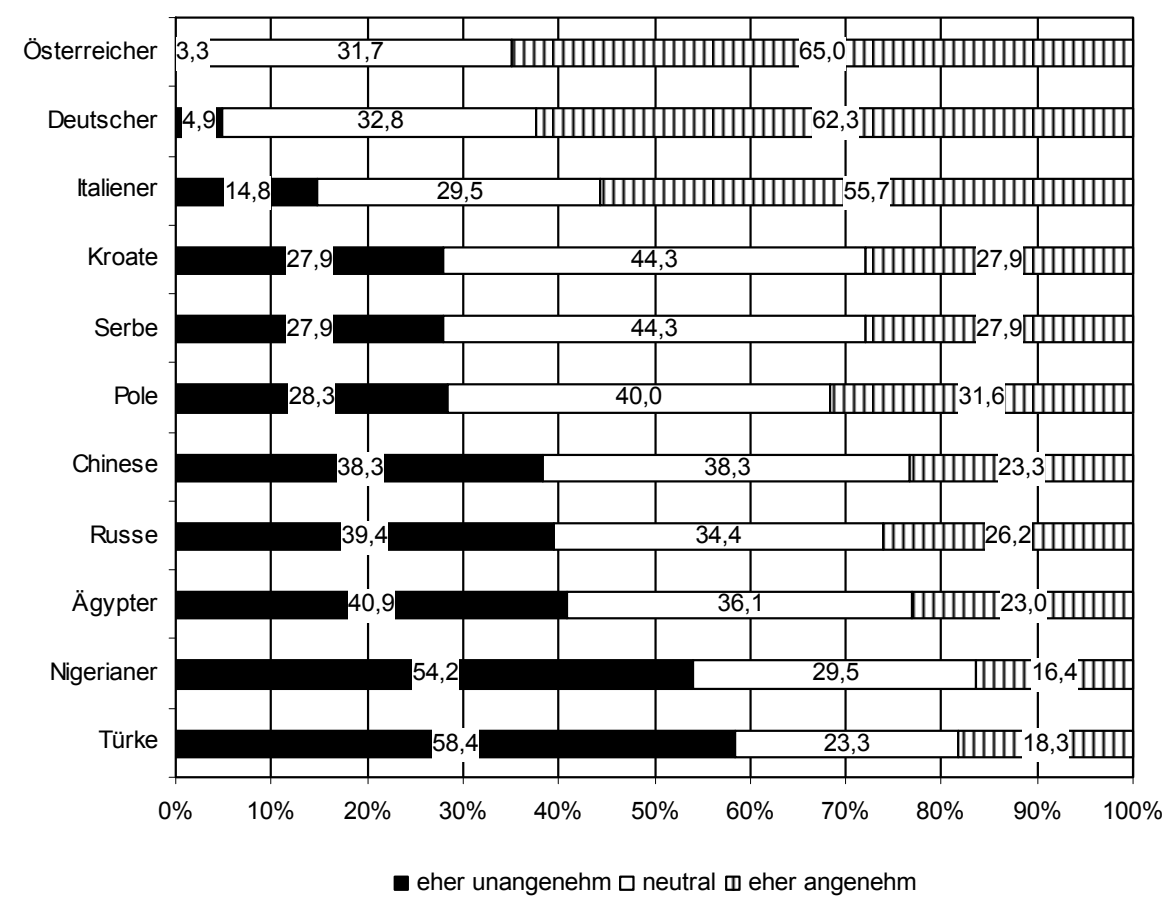

Quelle: Befragung 2005.

Deutliche Unterschiede zu obigen Resultaten bestehen hinsichtlich der Einstellungsanalyse der Befragten mit migratorischem Background (vgl. Abb. 12). Die geringste soziale Distanz besteht auch in dieser Subgruppe dem österreichischen und dem deutschen Nachbarn gegenüber. Der Italiener positioniert sich an der dritten Stelle. Die Mittelwerte (Österreicher: 1,38, Deutsche: 1,28, Italiener: 1,0) dokumentieren höhere Akzeptanzratings für diese „,beliebtesten“ Nachbarn als bei den Befragten ohne Migrationserfahrung, zugleich zeigt sich aber für die am stärksten abgelehnten Nachbarn auch eine beträchtlich größere soziale Distanz (Ägypter: $-0,18$, Türke: $-0,75$, Nigerianer: $-0,85)$. Von den Exjugoslawen wird der Serbe $(\bar{x}=0,11)$ stärker abgelehnt als der Kroate $(\bar{x}=0,26)$. Zu einem Chinesen $(\bar{x}=-0,03)$ und Russen $(\bar{x}=$ $-0,15)$ besteht ein ungleich höheres Ausmaß an Distanz als seitens der Respondenten ohne Migrationsbackground. Von den befragten Migranten würden 40,9\% einen ägyptischen Nachbarn $(\bar{x}=-0,18)$ als unangenehm empfinden. Die Hierarchie der sozialen Distanz wird vom Nigerianer $(54,2 \%, \bar{x}=-0,85)$ und dem Türken $(58,4 \%$, $\bar{x}=-0,75)$ angeführt, wobei das Ausmaß der Ablehnung unter den Immigranten beträchtlich höher ist als bei den Befragten ohne Migrationshintergrund. 
Abbildung 13: Einstellung zu potentiellen Nachbarn unterschiedlicher Herkunft in der Wohnungsbestandskategorie Genossenschaft/Eigentum

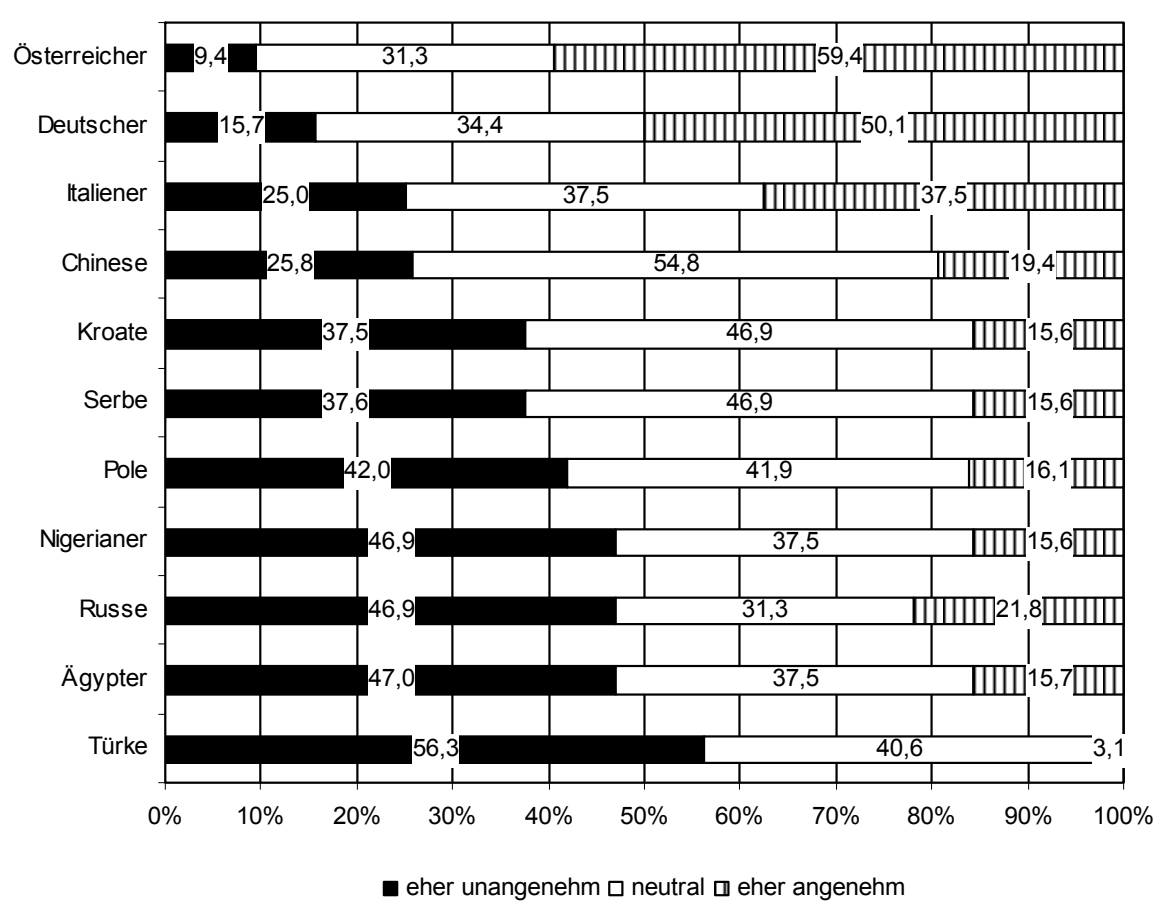

Quelle: Befragung 2005.

Es wurden auch Analysen nach Wohnungsbestandskategorien durchgeführt. Hierbei zeigte sich, dass die soziale Distanz gegenüber den meisten angeführten Nachbarn unter den Bewohnern von Genossenschafts- und Eigentumswohnungen (vgl. Abb. 13) am größten ist, wobei explizit anzumerken ist, dass in dieser Wohnungsbestandskategorie 14 Österreicher, 7 Neoösterreicher und 11 Ausländer in unser Sample Eingang gefunden haben. Jeweils $47 \%$ der Wohnungseigentümer würden es als eher unangenehm empfinden, neben einem russischen, nigerianischen oder ägyptischen Nachbarn leben zu müssen. Am stärksten abgelehnt wird der Türke mit 56,3\%. Mehr als 37\% würden aber auch nicht Tür an Tür mit einem Serben $(\bar{x}=-0,19)$ oder Kroaten $(\bar{x}$ $=-0,06)$ wohnen wollen und jeweils ein rundes Viertel würde einen Chinesen $(\bar{x}=$ $0,03)$ oder Italiener $(\bar{x}=0,44)$ in der Nachbarwohnung als unangenehm empfinden. Die arithmetischen Mittel unterstreichen das Ausmaß sozialer Distanz: Sie betragen 1,00 für einen Nachbarn aus der Türkei, $-0,69$ im Fall eines Nigerianers, $-0,56$ bei einem Russen und $-0,53$ bei einem Ägypter. Die höchsten Sympathiewerte erreichen Deutsche $(50,1 \%$ für ,,eher angenehm“; $\bar{x}=0,88)$ sowie Österreicher $(59,4 \%$,eher angenehm“; $\bar{x}=1,22$ ). 
Abbildung 14: Einstellung zu potentiellen Nachbarn unterschiedlicher Herkunft in den Wiener Gemeindebauten

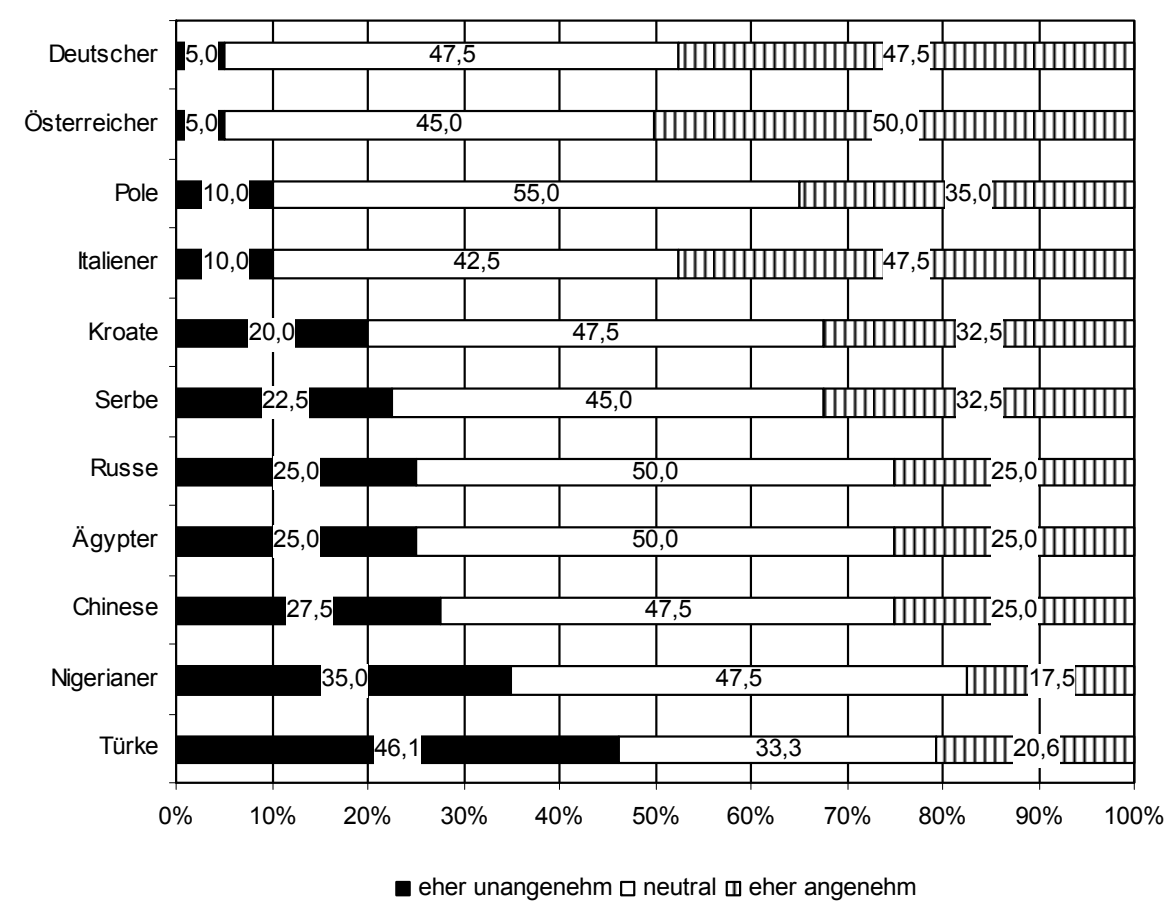

Quelle: Befragung 2005.

Auch im Gemeindebau (vgl. Abb. 14) liegt gegenüber Türken (46,1\% „eher unangenehm“) und Nigerianern (35\% „,eher unangenehm“) die größte soziale Distanz vor, allerdings in im Vergleich zum Segment Genossenschaft/Eigentum geringerem Ausmaß. Dies dokumentieren auch die Mittelwerte, die im Gemeindebau für einen türkischen Nachbarn bei $-0,41$ und für einen Nigerianer bei $-0,30$ liegen. Distanzmittelwerte von einem Viertel und darüber betreffen den Serben $(\bar{x}=0,38)$, den Russen $(0,25)$ und den Ägypter $(0,32)$. Größerer Beliebtheit würden sich künftige Nachbarn aus Kroatien $(0,53)$ erfreuen. Nur jeweils ein Zehntel der Mieter von Gemeindewohnungen würden polnische $(\bar{x}=0,73)$ oder italienische Nachbarn als eher unangenehm empfinden und nur jeweils 5\% einen Deutschen oder Österreicher in der Nachbarwohnung. Den größten Zuspruch ernten österreichische (50\% „eher angenehm“) sowie deutsche und italienische Nachbarn (jeweils 47,5\% ,eher angenehm“), wobei die Mittelwerte für Deutsche $(1,10)$ und Italiener $(0,88)$ über, der für den österreichischen Nachbarn $(1,12)$ etwas unterhalb des entsprechenden Wertes im Segment Genossenschaft/Eigentum liegt. 


\section{Abbildung 15: Einstellung zu potentiellen Nachbarn unterschiedlicher Herkunft im} gründerzeitlichen Wohnungsbestand

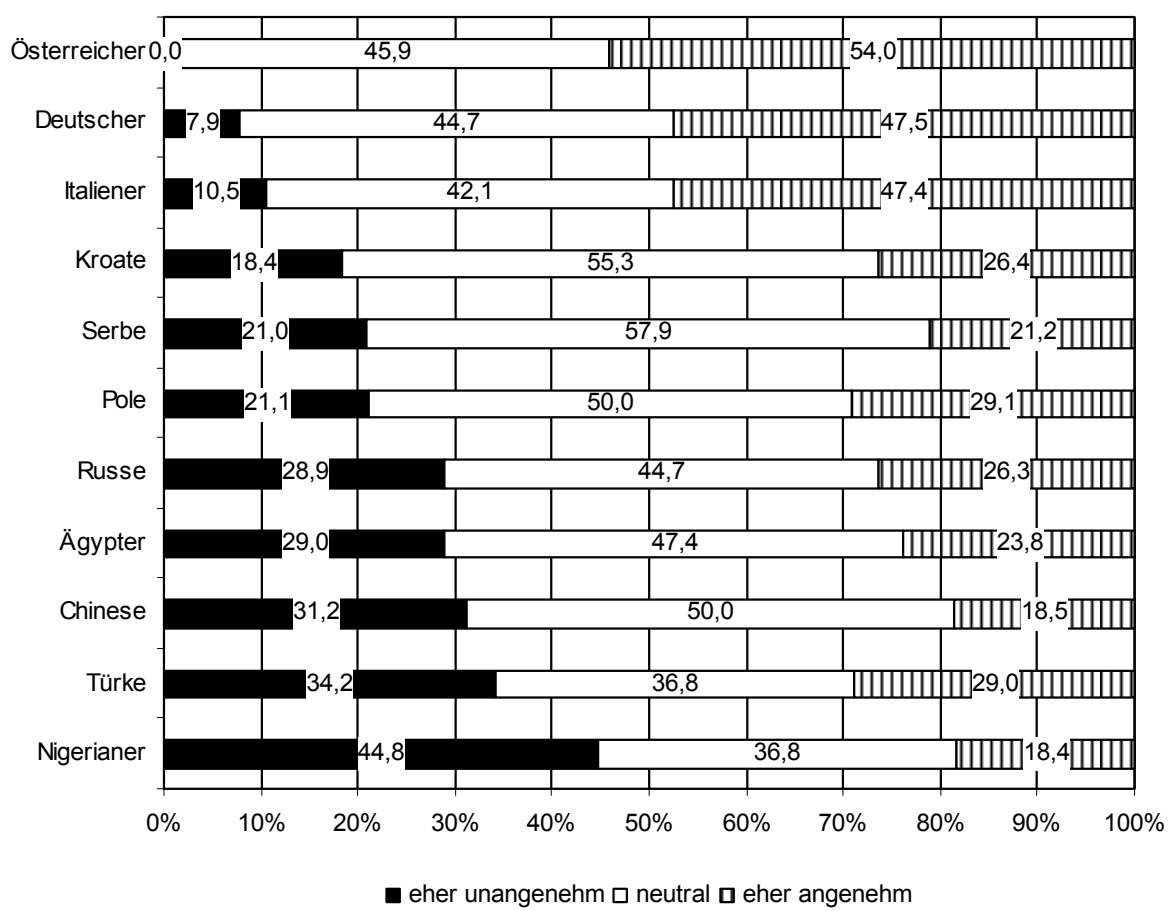

Quelle: Befragung 2005.

Auch unter den Bewohnern von Gründerzeitwohnungen (vgl. Abb. 15) besteht die geringste Distanz gegenüber einem österreichischen Nachbarn $(\bar{x}=1,24)$. Geringe Ablehnung erfahren auch Deutsche $(\bar{x}=0,76)$ und Italiener $(\bar{x}=0,82)$. Mit Mittelwerten von 0,18 für einen Polen, 0,16 für einen Kroaten und $-0,05$ für einen Serben sind diese als Wohnungsnachbarn etwas weniger beliebt. Ägypter $(\bar{x}=-0,21)$ werden mit $29 \%$ in der Kategorie ,,eher unangenehm“ in der unmittelbaren Nachbarschaft in geringerem Ausmaß präferiert. Ein Chinese $(\bar{x}=-0,05)$ würde von nahezu einem Drittel $(31,2 \%)$ der Mieter gründerzeitlicher Wohnungen als ein unangenehmer Nachbar empfunden werden. Türken $(\bar{x}=-0,11)$ werden mit $34,2 \%$ schwächer abgelehnt als in den beiden anderen Wohnungsbestandskategorien und von $29 \%$ als eher angenehme Mitbewohner klassifiziert. Mehr Ablehnung würde einem Ägypter ( $\bar{x}=-0,21)$ als Nachbarn entgegengebracht werden. Gegenüber einem Nigerianer besteht mit $44,8 \%$ Ablehnung ( $\bar{x}=-0,63$ ) die größte soziale Distanz. 